\title{
CHUNKY GRAPHITE IN FERRITIC SPHEROIDAL GRAPHITE CAST IRON: FORMATION, PREVENTION, CHARACTERIZATION, IMPACT ON PROPERTIES: AN OVERVIEW
}

\author{
Wolfram Baer (1) \\ Federal Institute for Materials Research and Testing (BAM), Unter den Eichen 87, 12205 Berlin, Germany
}

Copyright (C) 2019 The Author(s)

https://doi.org/10.1007/s40962-019-00363-8

\begin{abstract}
Ferritic spheroidal graphite cast iron (SGI) materials have a remarkable technical potential and economic impact in modern industry. These features are closely related to the question of how the cast materials can be produced without structural defects and graphite degenerations such as, for example, chunky graphite. Although the chunky graphite degeneration superficially seems to be well known, its metallurgical background is still controversially discussed, appropriate field-tested nondestructive tools for its quantification in castings are lacking, and the knowledge on its

measures are concisely summarized. Particular attention is paid to the morphology of chunky graphite and how it can be characterized by destructive and nondestructive techniques. Special emphasis was laid on providing a comprehensive overview on the impact of chunky graphite on strength, ductility, fatigue limit, fatigue crack growth rate as well as fracture toughness of ferritic SGI materials based on experimental data. Moreover, conclusions for the assessment of castings affected by chunky graphite are drawn.
\end{abstract} impact on material properties is fairly limited. Addressing this status, the article is providing a current overview on the subject. Existing theories on formation and growth mechanisms of chunky graphite are briefly reviewed. Furthermore, from a metallurgical point of view, causes for the appearance of chunky graphite as well as preventive
Keywords: ferritic spheroidal graphite cast iron, chunky graphite, properties, formation, prevention, characterization

\section{Introduction}

A combination of outstanding attributes makes ferritic spheroidal graphite cast iron (SGI) materials increasingly attractive to designers. Due to their remarkable mechanical properties, fracture toughness, design freedom, castability, energy efficiency due to low melting and pouring temperatures, machinability and cost-effectiveness, there is a continuously growing demand for complex, frequently heavy-sectioned SGI castings. ${ }^{1-5}$ Outstanding application fields are the wind energy, metal forming and nuclear industries, e.g., casks for storage and transport of nuclear materials. To assure the specified properties, the absence of structural defects and very high degrees of graphite nodularity are requested. Nevertheless, graphite degenerations-among which chunky graphite (CHG) is seen to be the most common and detrimental one-may occur in the castings under certain circumstances. The formation probability of such degenerations significantly increases with heavy sections above wall thicknesses of approximately 100-200 $\mathrm{mm}$ and solidification times longer than approximately $1 \mathrm{~h} .{ }^{6-8}$ However, chunky graphite has occasionally been observed even in 10-mm-thick castings. ${ }^{9}$ CHG has been reported to be a major problem with nickelcontaining austenitic ductile iron materials ${ }^{10}$ as well, but this is outside the scope of this article.

Up to now, nondestructive testing technologies to detect chunky graphite in castings have not been established successfully. ${ }^{6}$ A solitary report was identified which suggests the possibility to detect chunky graphite regions in SGI by changes in ultrasonic characteristics (sound velocity and bottom echo). ${ }^{11}$ Frequently, the presence of chunky graphite degeneration becomes obvious not before the mechanical machining of the component when dark areas are observed at the components surface (Figure 1). ${ }^{12}$ Occasionally, chunky graphite is ascertained as root cause not until the failure of a component ${ }^{8}$ (Figure 2). Since common quality control samples such as separately cast samples or cast-on samples are not capable of monitoring 
chunky graphite, ${ }^{2,3}$ the special importance of destructive investigation of test pieces cut from representative parts of a casting becomes obvious. Unfortunately, until now, fast technological access to information about the risk of chunky graphite formation in a melt, for instance, by melt sampling and performing thermo-analytical measurements or determination of oxygen activity has not yet been established successfully. ${ }^{6}$

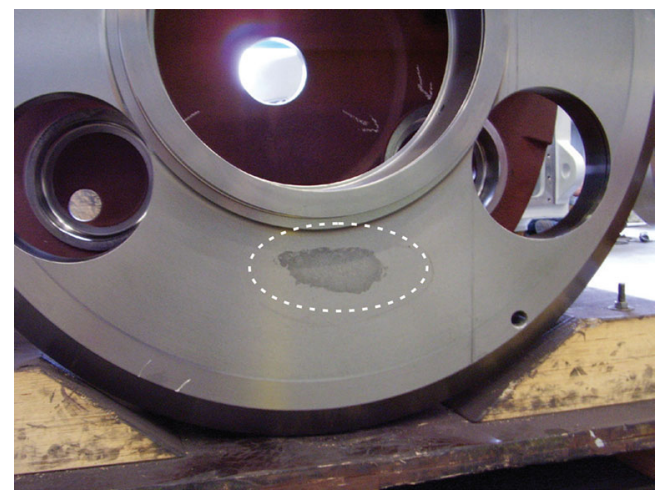

Figure 1. Example of a machined SGI casting with chunky graphite (dark gray area inside marking). Reprinted by permission from ASK Chemicals. ${ }^{12}$
Although a considerable amount of research on chunky graphite has been done over the last decades, the understanding of this graphite degeneration and its impact is still limited and a unanimous view on formation mechanism and technical avoidance of chunky graphite has not yet been acquired. While the specialists almost unanimously claim that avoidance of chunky graphite in heavy sections cannot yet be rated a hundred percent process safe, $2,6,7,13-20$ a single study has been identified testifying chunky graphite could be prevented by using state-of-the-art foundry procedures and appropriate charge materials. ${ }^{1}$

Nevertheless, due to the economic impact as well as high safety and quality requirements, the manufacturers must be aware of the origins of chunky graphite and how to avoid it. Contrary to the metallurgical aspects, the knowledge about the impact of chunky graphite on the materials/components properties is still surprisingly limited and an adequate summary is not available. Therefore, special emphasis of this paper is on the impact of chunky graphite degeneration on the properties of ferritic SGI. It is complemented by a current overview on metallurgical aspects as well as the morphology and structure of chunky graphite.
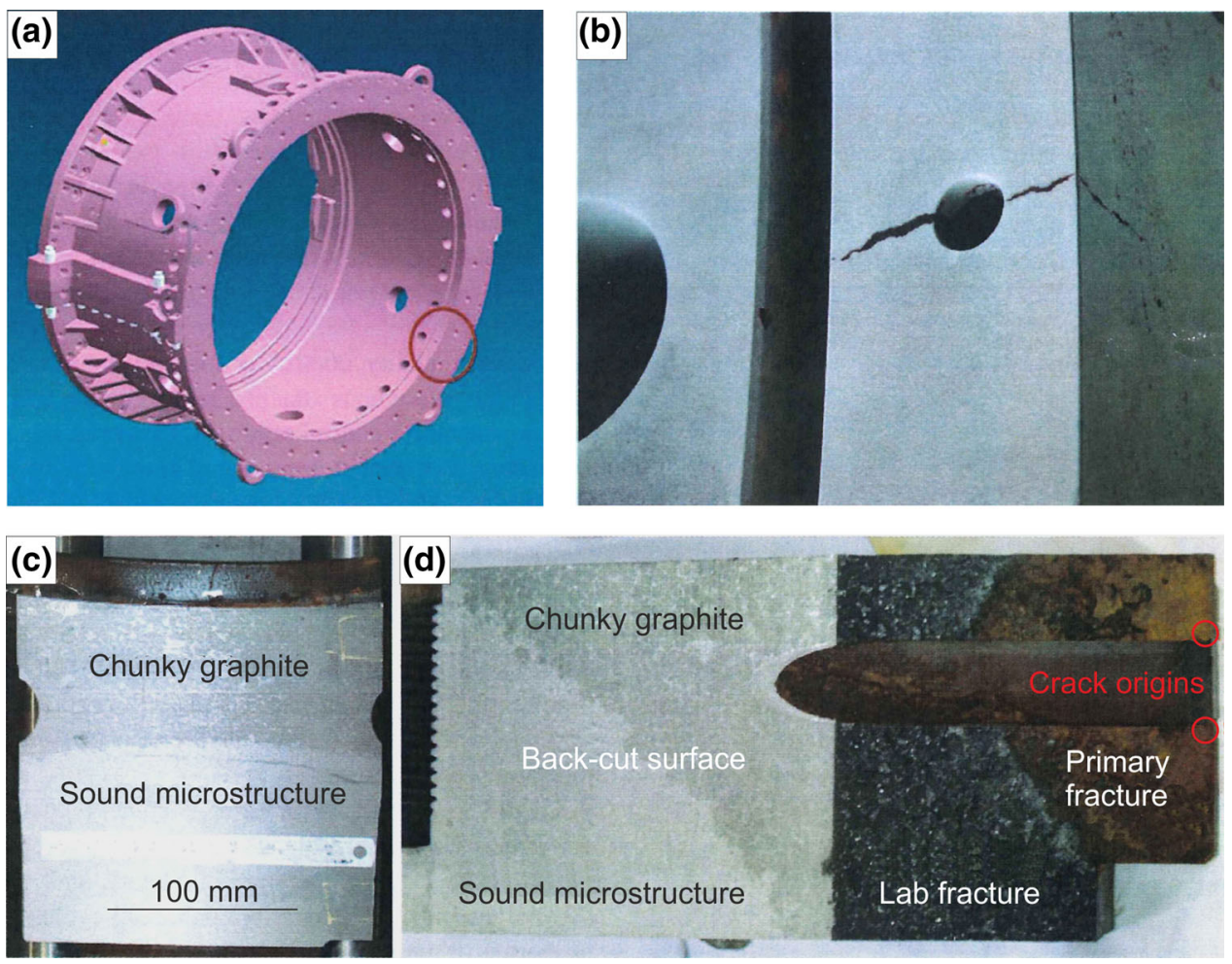

Figure 2. (a) Turbomachinery casing of nodular cast iron affected by cracking emanating from a technical hole, (b) result after application of dye penetrant, (c) cut surface showing dark area (chunky graphite) in the volume surrounding the crack and light area (sound microstructure), (d) fracture surface appearance after back cut and forced crack opening. Reprinted by permission from Springer Nature. ${ }^{8}$ 


\section{Formation and Growth of Chunky Graphite}

The room temperature graphite morphology in cast $\mathrm{Fe}-\mathrm{C}-$ $\mathrm{Si}$ alloys is basically the result of nucleation from the liquid melt and graphite crystal growth followed by solid-state carbon diffusion growth. The chemical complexity of the iron melts and the transitory nature of nucleation and local segregation produced by chemical alloy composition, melt treatment and casting conditions are the main governing factors. The interaction between these variables can produce a large variety of graphite shapes including lamellar/ flake (LG), compacted/vermicular (CG), spheroidal/nodular (SG) and temper graphite (TG), as well as some degenerated morphologies, such as spiky, exploded or chunky graphite (CHG). ${ }^{21}$ This illustrates the complexity of graphite crystallization and growth in iron melts. Considering the above-mentioned graphite formation steps, it is emphasized in Reference 22 that the growth step is most important for the final graphite shape. It is not the intention of this paper to present a detailed, wide-ranging overview on graphite formation from a more general point of view. This subject has recently thoroughly and comprehensively been reviewed, for instance, in References 21, 22 and 23.

In the present article, it is rather a question of treating and consolidating the subject focusing on chunky graphite. In particular, the studies ${ }^{6,9,13,19,21-26}$ especially contribute. Although several theories on the formation and growth of chunky graphite in SGI have been proposed, a universal, unanimously accepted explanation has not yet been established. While the growth of lamellar graphite is fairly well understood, that of compacted, chunky and spheroidal graphite is still in the focus of research. ${ }^{24}$ The growth mechanism of chunky graphite has recently even termed far from being understood. ${ }^{27}$ Known models for chunky graphite emphasize different aspects, partly complement each other, but simultaneously they are contradictory in parts. Källbom ${ }^{9}$ provided a valuable and detailed overview in which five approaches to the formation and growth of CHG are classified. These theories are cited here briefly in the following subsections (1) to (5) and occasionally complemented by further studies. The subsections (6) and (7) provide additional aspects contributing to a better understanding of $\mathrm{CHG}$ formation and growth. Moreover, very recent findings, mainly from, ${ }^{21,23,24}$ are incorporated in subsections (8) and (9). At the end of this chapter, preliminary conclusions on the formation and growth of chunky graphite are drawn.

1. Pursuant to an early proposal of Karsay et al.,28 chunky graphite emanates from small pieces broken off the ordinary graphite nodules. Due to thermal currents and growth stresses, the nodules can break into sectors (chunks) and be dispersed to interdendritic spaces. Carbon can diffuse from the melt and be deposited on the chunks changing their appearance and subsequently causing the characteristic graphite interconnections. Today, this theory has been ruled out by the later finding that chunky graphite grows interconnected. ${ }^{29}$

2. Liu et al. ${ }^{30}$ proposed a helical growth mechanism where chunky graphite is composed by a series of clustered, sector-shaped graphite segments. Branching is ascribed to microsegregation of certain elements like cerium and others. Chunky graphite is characterized as a deteriorated form of spheroidal graphite whereat there are intermediate forms between chunky graphite and spheroidal graphite possible which can be observed in chunky graphite zones of heavy-sectioned ductile iron castings (Figure 3). Common features are a central nucleus, and the main growth direction of the graphite is radial along its c-axis. ${ }^{30,31}$ For a better understanding, a schematic outline of the hexagonal graphite crystal structure is given in Figure 4. Within a single graphite layer (so-called graphene), planar $s p^{2}$-hybrid orbitals align themselves to a structure with strong binding, thus forming a regular hexagonal network of carbon atoms. Between the layers, side-to-side overlapping of unhybridized $p$-orbitals results in $\pi$-bonds which give rise to weak van der Waals forces. ${ }^{32}$

3. Itofuji et al. ${ }^{33,34}$ outlined that nodular graphite nucleates at the surface of magnesium bubbles and grows radial toward the center. A main reason for chunky graphite precipitation in the thermal center of heavy-sectioned castings is the possible lack of available magnesium in the form of gas bubbles with free surface for graphite

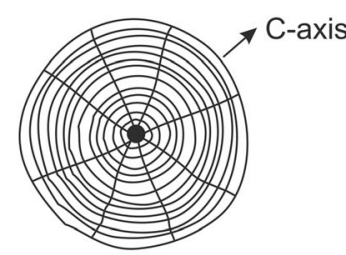

Spheroidal graphite

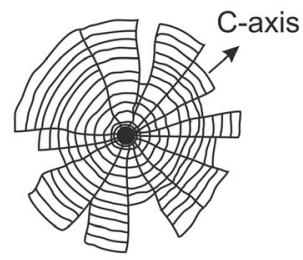

Intermediate graphite form

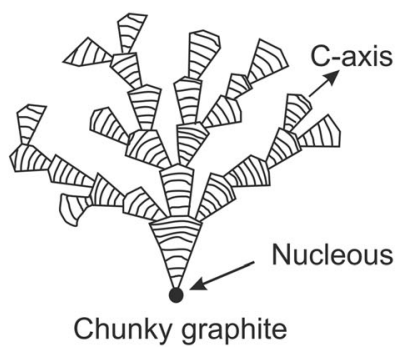

Figure 3. Growth of spheroidal, intermediate and chunky graphite forms, figure drawn after References 30, 31. 
formation. Further reasons for a lack of available magnesium may be a second oxidation during pouring, reaction with refractory ${ }^{35}$ or fading out by floating of gas bubbles and metallic magnesium segregation at the austenite-residual melt interface. $^{36}$

Each chunky graphite segment has a face of the basal plane and a section of the prism face of the hexagonal graphite crystal. As per Itofuji, ${ }^{34}$ chunky graphite dominantly grows along the a-axes of the hexagonal graphite crystal and helical growth does not exist. Carbon diffuses

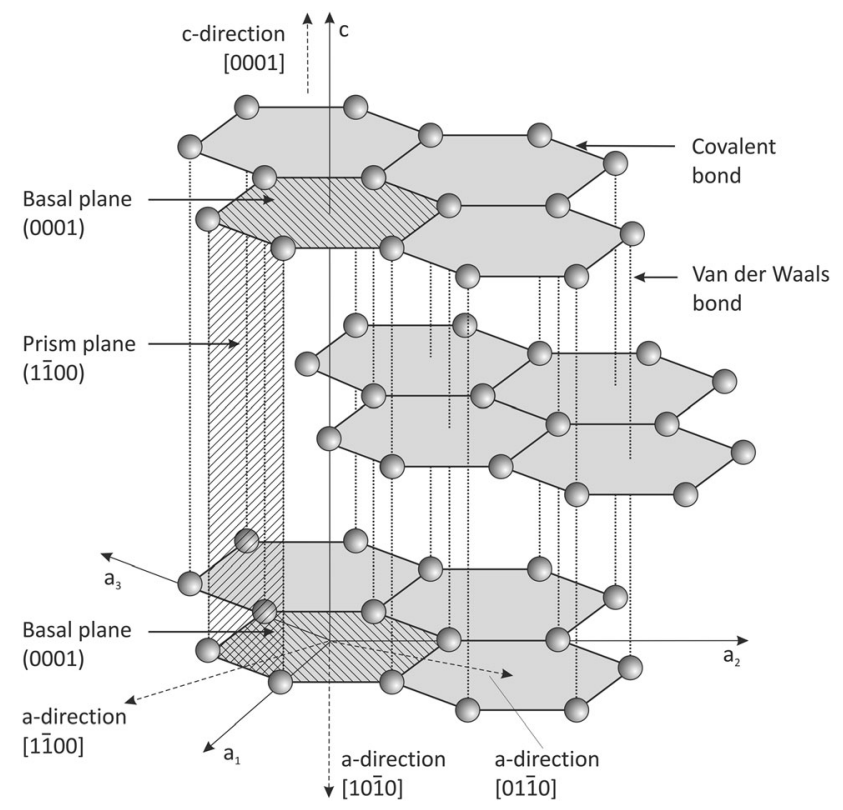

Figure 4. Graphite structure. through the austenite shell or thin melt channels and deposits on graphite by piling up of small chips. The substructure of vermicular, nodular and chunky graphite is basically the same (Figure 5). According to Itofuji, ${ }^{34}$ the chunky graphite formation mechanism consists of the following steps:

- Solidification in the thermal center is delayed compared to the subsurface of the casting.

- The thermal center may undergo the pressure of eutectic expansion from the subsurface, and therefore, magnesium gas bubbles may fade out before the solidification starts.

- Only small numbers of magnesium gas bubbles can exist in the melt under such circumstances, and graphite precipitates into them as nodular graphite at the early stages of the solidification.

- Liquid magnesium segregates at the austenite shell or dendrite-residual melt interface caused by the pressure of the eutectic expansion.

- After nodular graphite precipitates, chunky graphite starts to precipitate at interfaces among liquid magnesium, austenite shell and dendrite, inclusions, residual melt, etc., at the middle stages of the solidification.

- During growth, chunky graphite ends have contact with residual melt through the thin melt channels.

4. Zhou et al. ${ }^{37}$ presented a theory on chunky graphite formation which is based on heterogeneous nucleation of graphite and loose coupling between the eutectic phases. According to Reference 37, different graphite morphologies can be

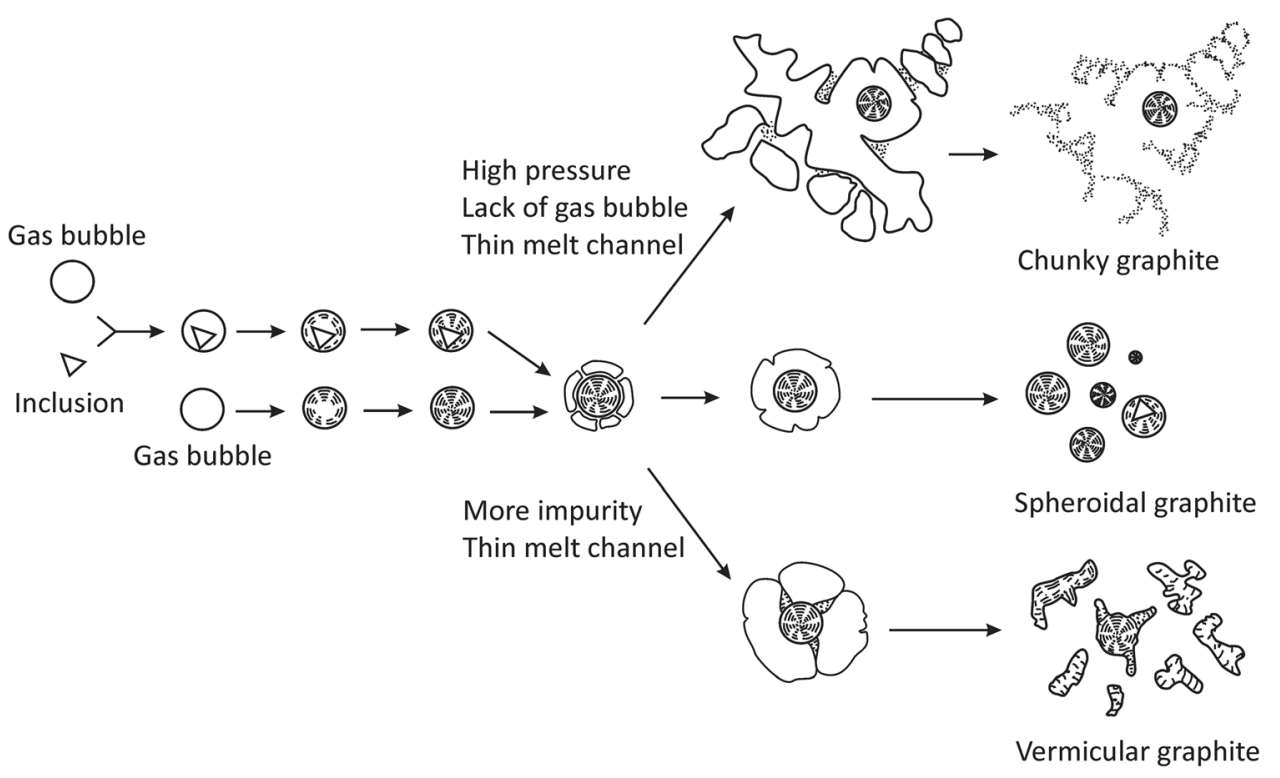

Figure 5. Graphite formation in molten iron treated with spheroidizer, figure drawn after Reference 34. 
attributed to the degree of coupling between the graphite and austenite phases during the eutectic solidification (Figure 6). Whereas flake graphite grows with tight coupling and nodular graphite without coupling, chunky graphite as well as vermicular graphite grows with loose coupling between the austenite and graphite phases. The graphite is free to twist, arch or branch due to the loose coupling with the crystallizing austenite. The formation procedure of chunky graphite in hypereutectic nodular cast iron according to Reference 37 is schematically outlined in four steps in Figure 7.

- At first, primary graphite nodules are formed shortly before reaching the eutectic temperature, (1) in Figure 7. Simultaneously and independently, small austenite dendrites are formed.

- Shortly after reaching the eutectic temperature, the crystallization of chunky graphite starts on the austenite dendrites, (2) in Figure 7. Subsequently, the precipitation of graphite and austenite simultaneously takes place with loose coupling between graphite and austenite.

- $\quad$ Eutectic chunky graphite cells continue to grow in the melt after nucleation, (3) in Figure 7. Meanwhile, the chunky graphite cells shed regular segregating elements (i.e., $\mathrm{Mg}, \mathrm{Mn}, \mathrm{Mo}, \mathrm{Cr}$, $\mathrm{V}, \mathrm{B}, \mathrm{Ti}$ ) into the melt. Additionally, new chunky graphite cells are continuously formed during the eutectic solidification. The growth of chunky graphite proceeds by precipitation of carbon directly from the melt.

- The growth of the eutectic terminates at a certain size, (4) in Figure 7. Elements being less soluble or insoluble in graphite as well as in austenite segregate in the residual melt and affect the solidification process there. For instance, the magnesium available in this area will promote the formation of nodular graphite. Furthermore, carbides can be precipitated at the grain boundaries.

5. As per the theory of Gagné et al., ${ }^{1,38}$ chunky graphite grows rapidly on the basal plane of graphite crystals in a helical manner along the c-axis. High driving forces are necessary to trigger instantaneous precipitation of carbon atoms from the melt on the basal plane of the graphite crystals, inhibiting the lateral growth on prism planes required for the crystallization of nodular graphite. It was concluded that the major driving forces for the accelerated spiral growth mechanism are carbon supersaturation, which is caused by a high carbon equivalent and low nucleation potential. The latter is due to a lack of oxygen in the last liquid to solidify reducing the number of suitable particles for graphite nucleation, ${ }^{9}$ or to an insufficient undercooling. ${ }^{10}$ As has been mentioned in Reference 38, the mechanism causing branching of chunky graphite remained obscure. However, the authors recalled that branching during growth on the basal plane has been reported to be due to the occurrence of crystal defects on the growing crystallographic planes that serve as nucleating sites for new graphite strings. Furthermore, the rapid growth of the chunky graphite filaments should favor the occurrence of such defects.

6. Original experimental investigations in Reference 9 provided some additional insight into the formation and growth of chunky graphite. As far as concerning the solidification sequence, it was clarified that chunky graphite starts to grow as eutectic cell. When approaching the outer

Graphite morphologies

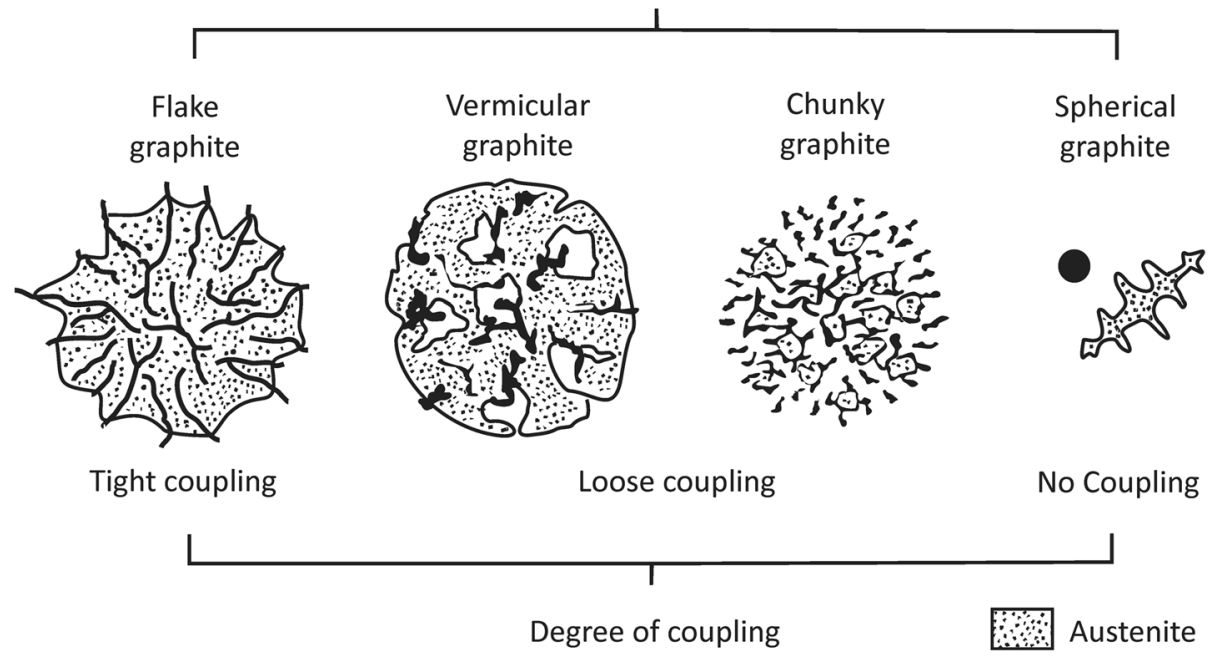

Figure 6. Influence of coupling between graphite and austenite growth on the graphite morphology, figure drawn after References 25, 37. 

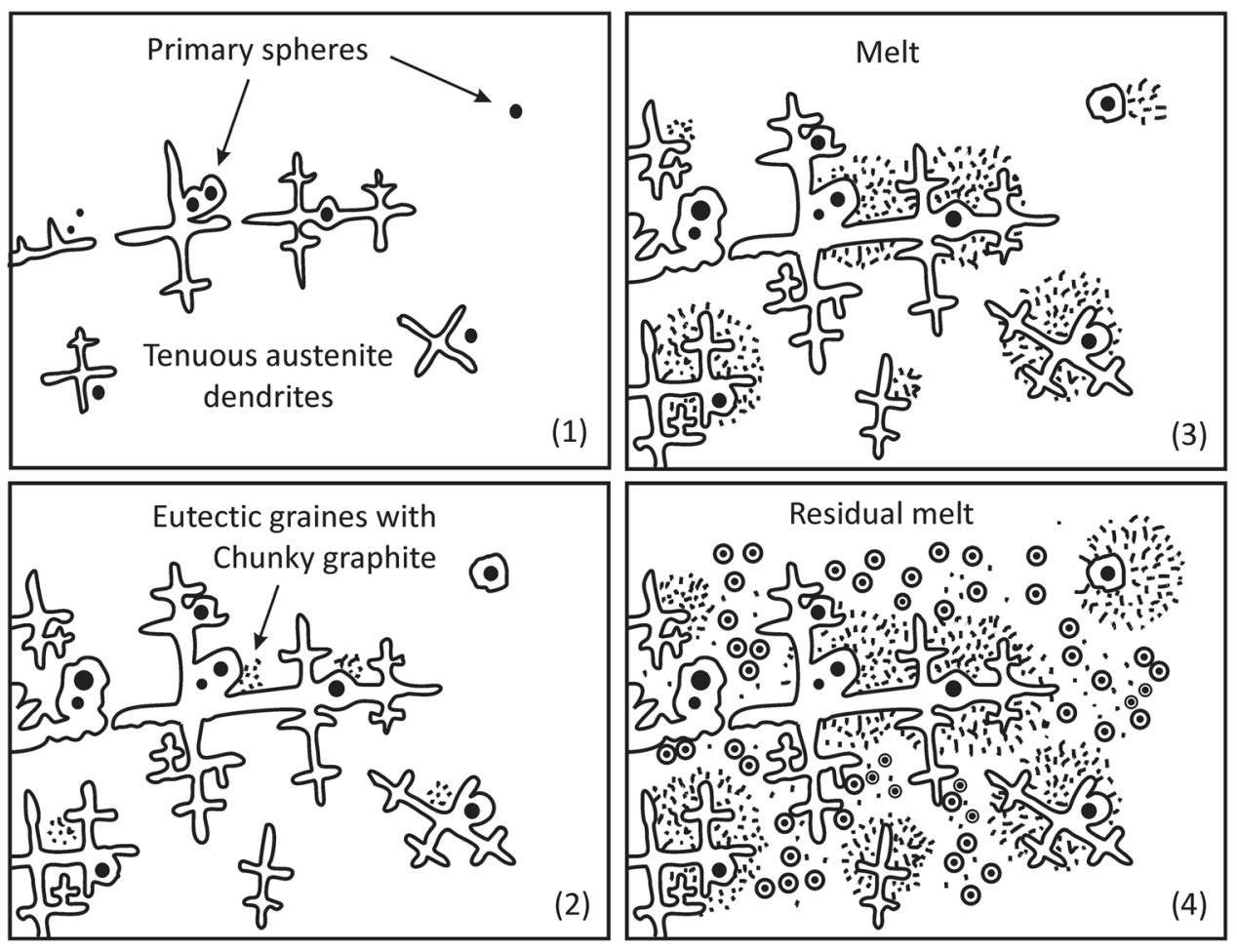

Figure 7. Formation of chunky graphite in hypereutectic nodular cast iron, figure drawn after Reference 37.

regions of the cells, the graphite becomes significantly coarser, before a complete transition takes place into ordinary graphite nodules. It is suggested that chunky graphite forms early during eutectic solidification and before the formation of nodular graphite. The growth rate of the eutectic cells was of the same order of magnitude as in gray cast iron with lamellar graphite but slower compared to supercooled D-graphite cells. Crystallographic studies confirmed the c-direction as main growth direction of chunky graphite what is basically the same as for nodular graphite. The author of Reference 9 concludes that the morphological differences between chunky graphite and nodular graphite will be due to differences in the local conditions near the graphite-liquid interface. Since macrosegregations had not been identified, further investigations on microsegregations as well as on the oxygen and sulfur contents are proposed.

7. A close relationship between the formation of two forms of degenerated graphite, chunky graphite and exploded spheroidal graphite has been confirmed in Reference 39. The authors observed chunky graphite strings developing from the outer surface of an exploded spheroid. According to Reference 29, it is well established that chunky graphite results from coupled eutectic growth of austenite and graphite. Corresponding to this mechanism, it is concluded in
Reference 39 that the development of an exploded nodule can be replaced by coupled growth with chunky graphite when austenite appears.

8. The focus of experimental investigations in References 21 and 24 was directed to documenting the graphite morphology in the early stages of solidification, analyzing graphite growth in chunky and compacted graphite, and probing the effect of nucleous crystallography on the final graphite shape. Using interrupted solidification experiments, deep etching as well as electron microscope techniques, it has been confirmed that both the helical (macro-spiral) and the foliated crystal growth mechanisms participate in the growth of chunky graphite (Figure 8). The general shaping mechanism for the overall graphite aggregate appears to be helical growth which is also called on in Reference 30. Helical growth leads to large c-directional stacked chunky graphite segments having a foliated crystal substructure (Figure 8a). The foliated dendrite growth mechanism basically produces tiled roof configurations of hexagonally faceted graphite platelets (Figure 8b). At higher constitutional undercooling (higher Mg content), the platelets which are mainly a-directionally grown increasingly stack and may form dendritic aggregates (Figure 8c). At sufficiently high undercooling and/or supersaturation preferably in c-direction, 

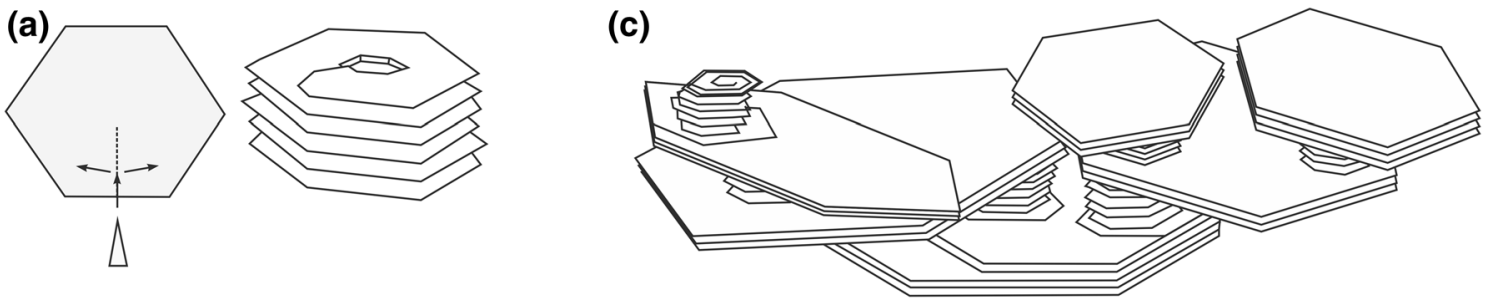

(b)

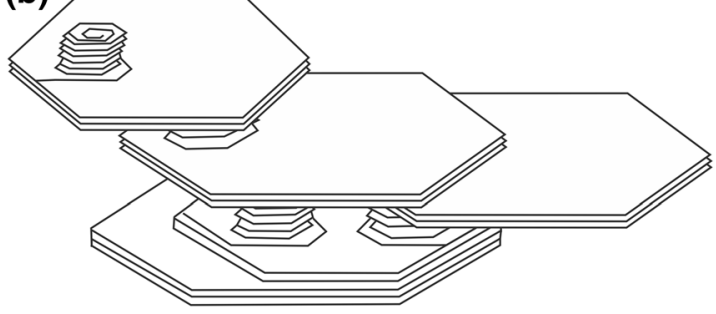

(d)

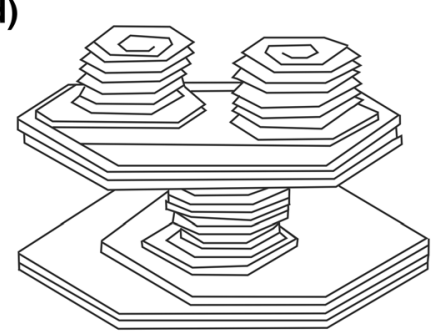

Figure 8. Growth models for chunky graphite aggregates: (a) helical (macro-spiral) growth, (b) tiled roof arrangement, (c) foliated dendrites, (d) columnar foliated crystals, figure drawn after Reference 21.

stacked columns as well as highly curved graphite aggregates branching in various directions are formed (Figure 8d). It is not the graphite crystal that grows in the c-direction, but the graphite aggregate. These findings on the growth directions of the graphite crystal/platelet and the overall aggregate are in line with the conclusions in Reference 22 for conical substructures of spheroidal graphite.

9. Interesting new insights into the formation and growth of graphite have recently been gained in Reference 23 first time using synchrotron X-ray tomography for four-dimensional (3d plus time) in situ solidification studies. Although the author did not especially investigate chunky graphite, a special focus was on the development of irregular graphite forms. Very limited graphite particle movement was observed during the solidification what entailed the conclusion that the particles must be anchored in austenite and most likely also encapsulated while they grow. Simultaneously, spherical graphite particles undergo significant morphological changes and, in many cases, develop irregular features. Furthermore, the particles which are the most irregular after solidification grow significantly faster than their regular counterparts and it seems that fast growth is associated with the development of irregular features. The author of Reference 23 comments that these observations were slightly surprising and highly interesting as it is usually assumed that irregular graphite shapes develop when the graphite is in contact with the liquid melt. The investigations have shown that it may be relevant to include the graphite-austenite interface in that discussion and that growth at this interface might not behave fundamentally different. These results have important implications for how degeneracy of spheroidal graphite should be understood and theoretically described in the future. ${ }^{23}$

\section{Preliminary Conclusion on Formation and Growth of Chunky Graphite}

Considering the present state of knowledge, the following condensed baseline concerning formation and growth of chunky graphite in heavy-sectioned SGI castings might be drawn:

- Result of coupled eutectic growth of austenite and graphite (diffusion coupling).

- Mostly in eutectic cells.

- Graphite platelets with hexagonal, but mostly irregular hexagonal shape.

- Growth of graphite aggregates by stacking of graphite platelets along the c-direction (while the platelets mainly grow along the a-direction).

- Both the helical (macro-spiral) and the foliated crystal growth mechanisms participate in the growth.

- Formation of interconnected, filigree strings with high level of branching.

\section{Causes and Prevention of Chunky Graphite}

The metallurgical causes of chunky graphite are obviously of a complex nature. Numerous interacting influence factors have been discussed, and a remarkable number of studies have been performed. As major influences, the chemical composition, solidification rate and nucleation have been identified. All attempts to relate chunky graphite to macrosegregations have failed as it was revealed, e.g., in 
References 1, 7, 9, 29 and 40. Noteworthy insight into causes and prevention of chunky graphite is provided, for example, in References 6, 13, 25, 27, 29, 41 and 42. Nevertheless, the published data are partly contradictory, its variation is broadly based, and the particularly discussed influence parameters are often interrelated. Thus, deducing strict rules for causes and prevention of $\mathrm{CHG}$ is complicated.

\section{Effect of Chemical Elements}

The solidification of SGI, which is the main driver of casting properties, ${ }^{43}$ follows the eutectic system $\mathrm{Fe}-\mathrm{C}-\mathrm{Si}$. With respect to the microstructure required for a particular SGI grade, a ferritic matrix is basically achieved by limiting pearlite stabilizing elements. An empirical estimation tool to control the pearlite stabilizing effect of chemical elements was reported in Reference 44. According to Reference $44 P_{x}$ is the so-called pearlite number and calculated by Eqn. 1 .

$$
\begin{aligned}
P_{x}= & 3.00 w_{\mathrm{Mn}}-2.65\left(w_{\mathrm{Si}}-2.00\right)+7.75 w_{\mathrm{Cu}}+90.00 w_{\mathrm{Sn}} \\
& +357.00 w_{\mathrm{Pb}}+333.00 w_{\mathrm{Bi}}+20.10 w_{\mathrm{As}}+9.60 w_{\mathrm{Cr}} \\
& +71.70 w_{\mathrm{Sb}}
\end{aligned}
$$

Eqn. 1

where $w_{i}$ stands for the content of the element " $i$ " in $\mathrm{wt} \%$. The ferrite share $F$ of the SGI matrix is then given by Eqn. 2:

$F=961 \cdot \mathrm{e}^{-P_{x}}$

Eqn. 2

As follows from Eqns. 1 and 2, Mn, Cu, Sn, Pb, Bi, As, Cr and $\mathrm{Sb}$ promote pearlite, thus preventing ferrite which is in fact the basis of the SGI key properties ductility and toughness. It is worth noting at this place that the positive influence of ferrite on ductility and toughness is mainly controlled by the $\mathrm{Si}$ solution strengthening level and the ferrite grain size. On the other hand, going back to, ${ }^{38,45}$ it is concluded in Reference 3 that despite that the controlled addition of $\mathrm{Sb}, \mathrm{Sn}, \mathrm{Mn}$ and $\mathrm{Cu}$ will promote the formation of pearlite, it simultaneously suppresses the formation of chunky graphite. According to Reference 38, the underlying mechanism is seen in the diffusion of carbon to the graphite particles which is decelerated, and thus, the carbon supersaturation level on the basal plane of the graphite is effectively lowered.

Basically, there is qualitative agreement about the importance of the carbon equivalent parameter (CE) for the appearance of chunky graphite in SGI. CE conflates the major SGI alloying elements silicon and carbon as well as some other elements depending on the CE definition. Since there are different $\mathrm{CE}$ definitions in use and publications may show a lack of specifying information, care should be taken assessing concrete CE values. Moreover, it may be noted that the $\mathrm{CE}$ values should differ for non-inoculated and inoculated castings from the same melt. ${ }^{46}$ Although, in principle, the CE parameter should be set slightly hypoeutectic to prevent formation of primary graphite and graphite flotation, the recommendations to avoid chunky graphite in heavy sections cover a CE range of 4.0-4.5\% as established by References 3, 6, 9, 30, 33, 42 and 47, but the finding of non-sensitivity ${ }^{16}$ as well. Special importance of the CE parameter has been pronounced in Reference 48 stating that effort should be made to modify CE or heat exchange parameters before $\mathrm{Sb}$ is used as a remedy for chunky graphite.

Published studies reveal different quantitative results on a maximum tolerable Si content (1.8-2.4\%) depending on the solidification time (wall thickness) and the contents of trace elements (also called tramp or accompanying elements). ${ }^{6,9,13,25,33,37,41,42,49}$

With the recently standardized grades of solid solutionstrengthened ferritic SGI, the Si content is a matter of special interest. ${ }^{50-52}$ With these SGI grades, Si is limited to approximately $4.2 \%{ }^{50}$ since above this limit $\mathrm{Fe}-\mathrm{Si}$ superstructures gain detrimental influence on the mechanical properties $^{53-55}$ and chunky graphite appears. Consequently, a chunky graphite-free microstructure is closely related to the acting combination of $\mathrm{Si}$ and trace elements and the solidification time which itself corresponds to the wall thickness. Therefore, the structural application potential of solid solution-strengthened SGI grades has been limited up to now with respect to the producible maximum wall thickness. $^{2,6,53}$ However, recent systematic investigations $^{51,52}$ considering two large series of SGI melts featuring high $\mathrm{Si}$ contents (altogether 50 alloys within $3.88 \% \leq \mathrm{Si} \leq 6.14 \%$ as well as one alloy with $2.29 \%$ and $9.12 \%$, respectively) revealed that the amount of chunky graphite can significantly be reduced by the addition of $\mathrm{Sb}$. That means the critical Si level can be increased when $\mathrm{Sb}$ is added. In a number of alloys, Sb additions were effective for decreasing the formation of chunky graphite even at $\mathrm{Si}$ contents higher than $6 \%$. Based on the mechanical properties of the observed data base, which will be part of the discussion in later in this article, the authors of Reference 52 suggest a possible $\mathrm{Si}$ content as high as $5.0 \%$ could be considered for industrial applications when high resistance and some ductility are requested.

Apart from the aforementioned major alloying elements $\mathrm{C}$ and $\mathrm{Si}$, the contents of trace elements must be limited to prevent segregation and graphite degeneration. This task has become very challenging for the foundries in recent years. Due to today's extraordinarily high variety of modern steels, e.g., in automotive tailored blanks, the available steel scrap is characterized by increased and frequently partly unknown contents of trace elements and an increased variation in chemical composition as well. ${ }^{6}$ This makes process control more complex and rises costs with the foundries.

Trace elements can be assorted into two groups as far as concerning the metallurgical promotion or inhibition of 
chunky graphite. General understanding is that $\mathrm{Ce}, \mathrm{Ca}, \mathrm{Cu}$, $\mathrm{Ni}, \mathrm{Si}, \mathrm{Al}$ and rare earth metals (RE) promote (the so-called chunky group going back to Reference 28 ), whereas $\mathrm{Bi}, \mathrm{Pb}$, $\mathrm{Sb}, \mathrm{Sn}, \mathrm{Cu}$ and $\mathrm{As}$ (the so-called flake group ${ }^{28}$ ) inhibit the formation of chunky graphite. ${ }^{2,6,9,12,13,18,19,25,31,39,56-58}$ Note that $\mathrm{Cu}$ has been mentioned in the literature as both a chunky graphite inhibitor and promoter, e.g. References 6, 9 and 19 .

Recent results on the role of $\mathrm{RE}^{16}$ even showed a positive effect of very low-level Ce addition $(0.004-0.005 \%)$ on decreasing the amount of chunky graphite, while Reference 59 states a critical Ce amount of $0.0029 \%$ above which exploded or chunky graphite could appear. It has been confirmed in Reference 39 that Ce can basically compensate the detrimental effect of $\mathrm{Pb}$ on the graphite morphology. Individual addition of $\mathrm{Pb}$ to the melt led to lamellar graphite and lamellar outgrowths from graphite spheroids. By way of contrast, combined addition of $\mathrm{Ce}$ and $\mathrm{Pb}$ suppressed lamellae formation although excess of $\mathrm{Ce}$ in the melt promoted degenerated spheroids and chunky graphite. The findings of References 16 and 39 are basically in line with earlier studies ${ }^{60,61}$ discussing an optimum RE content for a maximum graphite nodularity which is sensitive to base metal composition, process variables and section size. At present, it seems to be generally accepted that RE (Ce) contents should be kept at low levels not greater than approximately $0.02 \%$ for prevention of chunky graphite. ${ }^{3,19}$

Boron has been reported to both promote ${ }^{6}$ and inhibit chunky graphite. ${ }^{9,37} \mathrm{~A}$ beneficial effect of $\mathrm{Zr}$ and $\mathrm{Sr}$ has been identified in Reference 62 when a fully nodular microstructure without chunky graphite was obtained with cubic blocks of $500 \mathrm{~mm}$ in edge using a combination of rare earth-free $\mathrm{MgFeSi}$ with a $\mathrm{Zr}$ - and Sr-containing inoculant. On the other hand, Bi-containing inoculants gave chunky graphite in Reference 62.

From the metallurgical point of view, oxygen, sulfur and trace elements need to be controlled to achieve a stable $\mathrm{Mg}$ treatment process. Owing to $\mathrm{S}$ and $\mathrm{O}$ being surface active elements, they will boost prism plane growth of the graphite as it is typical for chunky graphite. ${ }^{19}$

An interesting proposal to systematize the potential of trace elements to promote graphite degeneracy in nodular irons is presented in Figure 9. The concept has been discussed in Reference 22 with respect to the correlation between weight, size and electron hull structure of trace element atoms and their ability to adsorb at graphite surfaces. The used compilation of concentration limits has been elaborated by Reference 44 and complemented in Reference 59. Lacaze ${ }^{22}$ concludes the heavier the trace element atoms are, the lower is their critical concentration limit to avoid detrimental influence on graphite shape.

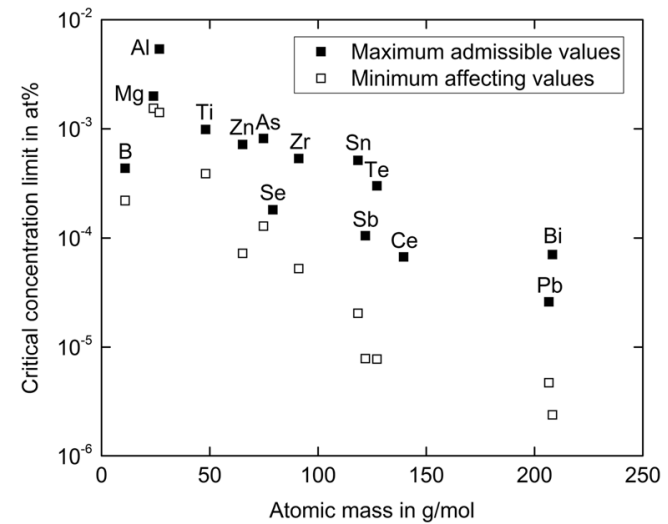

Figure 9. Relation between atomic mass of trace elements and their reported critical concentration limits ${ }^{59}$ for avoiding a detrimental effect, solid symbols-maximum admissible values not to affect graphite shape, open symbols-minimum values seen to affect graphite shape, figure drawn after Reference 22.

\section{Metallurgical Auxiliary Means for Prevention of Chunky Graphite}

It is worth noting that common foundry practice to compensate for detrimental elements by the addition of $\mathrm{Ce}$ and to simultaneously counterbalance a possible Ce excess by $\mathrm{Sb}$ addition cannot be rated process safe as has been emphasized in Reference 2. Although chunky graphite can mostly be avoided, low nodule counts are often obtained as well. A criterion for assessing the complex effect of technically relevant trace elements on the graphite formation $\left(S_{b}\right)$ was reported in Reference 44, Eqn. 3:

$$
\begin{aligned}
S_{b}= & 4.4 w_{\mathrm{Ti}}+2.0 w_{\mathrm{As}}+2.3 w_{\mathrm{Sn}}+5.0 w_{\mathrm{Sb}}+290.0 w_{\mathrm{Pb}} \\
& +370.0 w_{\mathrm{Bi}}+1.6 w_{\mathrm{Al}}
\end{aligned}
$$

Eqn. 3

where $w_{i}$ stands for the content of the element " $i$ " in wt $\%$. The appropriateness of a melt to produce SGI free from degenerated graphite requires $S_{b}$ values of the charge lower than unity; otherwise, the addition of rare earth elements should be made. Nevertheless, since solidification time is not considered by $S_{b}$, it is concluded in Reference 6 that application limits for heavy-sectioned castings focusing avoidance of chunky graphite cannot be obtained using Eqn. 3.

It must generally be pointed out that interactions between single elements and simultaneous effects such as the possible promotion of unwanted pearlite must always be considered as well. An evocative example for this conclusion is reported in Reference 18 using the effect of $\mathrm{Cu}$. While $\mathrm{Cu}$ used to be reported decreasing the risk of chunky graphite appearance, the investigation in Reference 18 established this beneficial effect being dependent on the presence of La. Furthermore, a negative cross-effect, i.e., 
an increase in chunky graphite, was associated when $\mathrm{Sb}$ was present as well. Perhaps, this complex behavior may contribute to $\mathrm{Cu}$ being reported as inhibitor as well as promoter of $\mathrm{CHG}$, see discussion earlier in this article.

Focusing the lack of practical quantitative metallurgical tools for chunky graphite prevention, an empirical relation to consider the influence of $\mathrm{Ce}, \mathrm{Pb}, \mathrm{Sb}$ and $\mathrm{As}$ on the maximum tolerable Si content up to which the absence of chunky graphite can be guaranteed was established in Reference 13. Based on numerous experiments, Figure 10 and Eqn. 4 are obtained to describe a critical Si content, $w_{\mathrm{Si}}$, above which chunky graphite appears.

$w_{\mathrm{Si}}=\frac{2.26-1.5\left(\frac{w_{\mathrm{Ce}}}{w_{\mathrm{Pb}}+w_{\mathrm{Sb}}+w_{\mathrm{As}}}\right)}{1-0.64\left(\frac{w_{\mathrm{Ce}}}{w_{\mathrm{Pb}}+w_{\mathrm{Sb}}+w_{\mathrm{As}}}\right)}$

where $w_{i}$ stands for the content of the element " $i$ " in $\mathrm{wt} \%$. Equation (4) holds for a wall thickness of $200 \mathrm{~mm}$. With smaller wall thicknesses of 5-100 mm, the curve moves to higher tolerable element contents as indicated by the arrow in Figure 10.

The investigations in Reference 6 proved that the criterion of Eqn. 4 exclusively works with melts containing the considered elements only and fails if further elements like $\mathrm{Al}, \mathrm{Ca}, \mathrm{B}$ and $\mathrm{Bi}$ are present. Therefore, the element ratio was established in Reference 6 as a new empirical parameter to indicate the risk of chunky graphite formation accounting for the elements $\mathrm{Ce}, \mathrm{B}, \mathrm{Ca}, \mathrm{Al}, \mathrm{Bi}, \mathrm{Pb}, \mathrm{Sb}$ and As and the thermal modulus (Figure 11). Since it had been elaborated that section size has an influence on acceptable limits of trace elements, four ranges are distinguished in Reference 6 depending on the thermal modulus. Below an element ratio of approximately 45 and a thermal modulus not greater than $4.2 \mathrm{~cm}$, no chunky graphite is formed (range 1). In range 2, between element ratios of approximately 45-60, the risk of chunky graphite formation increases caused by a rising excess of chunky graphite promoting elements. Above the limit of approximately 60,

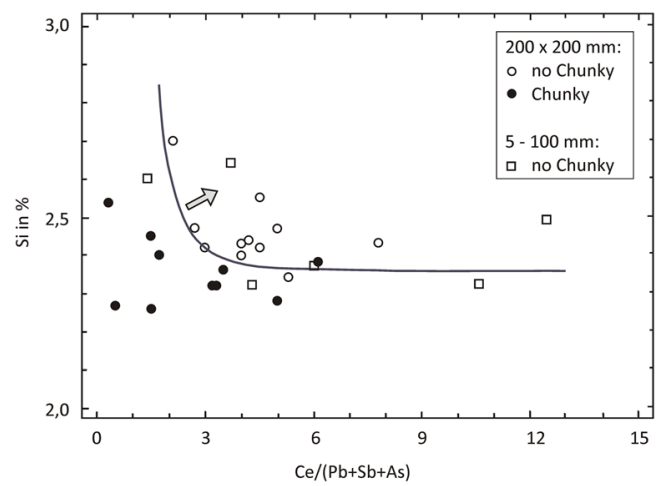

Figure 10. Maximum tolerable Si content up to which the absence of chunky graphite can be guaranteed, Si is given in wt\% and the elements on the abscissa are inserted in ppm, 3.40\% $\leq C \leq 3.77 \%$, after Reference 13. in range 3, chunky graphite will surely be observed with a thermal modulus of $4.2 \mathrm{~cm}$. Due to a higher solidification rate with a thermal modulus of $2.5 \mathrm{~cm}$, a higher score of detrimental elements can be tolerated and chunky graphite formation is postponed to element ratios above approximately 90 (range 4 in Figure 11).

Based on the chemical composition, the authors of Reference 18 presented another quantitative tool to evaluate the risk of chunky graphite in heavy-sectioned SGI. By multivariate statistical analyses of 68 SGI heats casted in cubic blocks of $300 \mathrm{~mm}$ in edge, the influence of $\mathrm{Ce}, \mathrm{Cu}, \mathrm{La}, \mathrm{P}$, $\mathrm{Sb}$ and $\mathrm{Sn}$ on the relative volume affected by chunky graphite, $V_{\mathrm{V}}$, was investigated (Figure 12). Equation (5) is established with $w_{i}$ being the mass fraction of element $i$ as obtained from chemical analysis.

$$
\begin{aligned}
\left(V_{\mathrm{V}}\right)^{0.5}= & -3.1-1214.0\left(1-64.6 w_{\mathrm{Sb}}-0.37 w_{\mathrm{Cu}}\right) w_{\mathrm{Sb}} \\
& -55.2\left(1-4.8 w_{\mathrm{Sn}}-114.8 w_{\mathrm{Sb}}\right) w_{\mathrm{Sn}} \\
& +924.2\left(1-64.4 w_{\mathrm{Ce}}\right) w_{\mathrm{Ce}} \\
& +605.0\left(1-0.59 w_{\mathrm{Cu}}\right) w_{\mathrm{La}}+133.3 w_{\mathrm{P}}
\end{aligned}
$$

Eqn. 5

Nevertheless, in the final analysis an even more extensive study was proposed in Reference 18 to account for supplementary low-level elements known to modify graphite growth.

Recently, the authors of Reference 51 investigated 31 SGI melts with high Si contents (2.29-9.12 wt\%) and proposed the empirical index $\Omega_{\mathrm{Si}}$ to capture the effect of Si combined with the elements $\mathrm{Ce}, \mathrm{Sb}$ and $\mathrm{Mg}$ for predicting the risk of graphite degeneration, Eqn. 6:

$\Omega_{\mathrm{Si}}=w_{\mathrm{Si}}+800\left(w_{\mathrm{Ce}} \frac{55}{140.1}-2 w_{\mathrm{Sb}} \frac{55}{121.8}\right)+50 w_{\mathrm{Mg}} \frac{55}{24.3}$

Eqn. 6

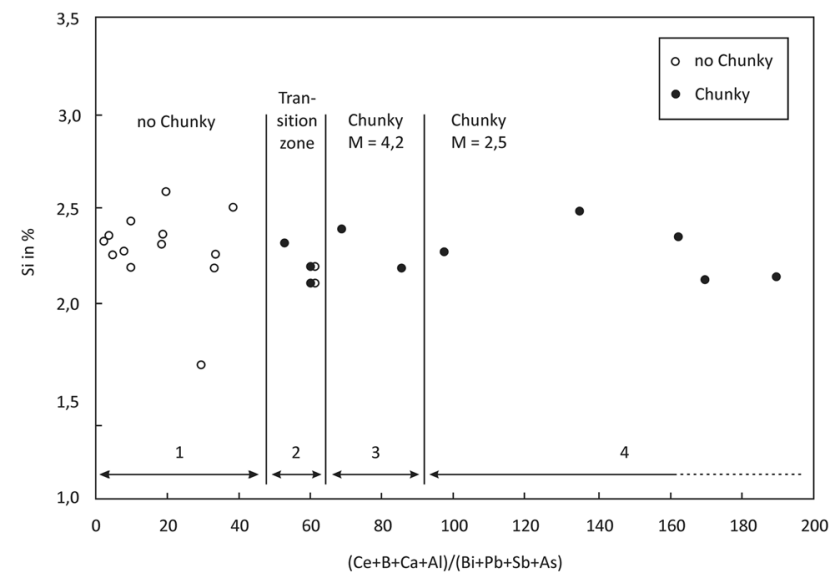

Figure 11. Influence of element ratio parameter on the risk of chunky graphite formation in SGI, M-thermal modulus, $3.47 \% \leq C \leq 3.75 \%$, after Reference 6 . 


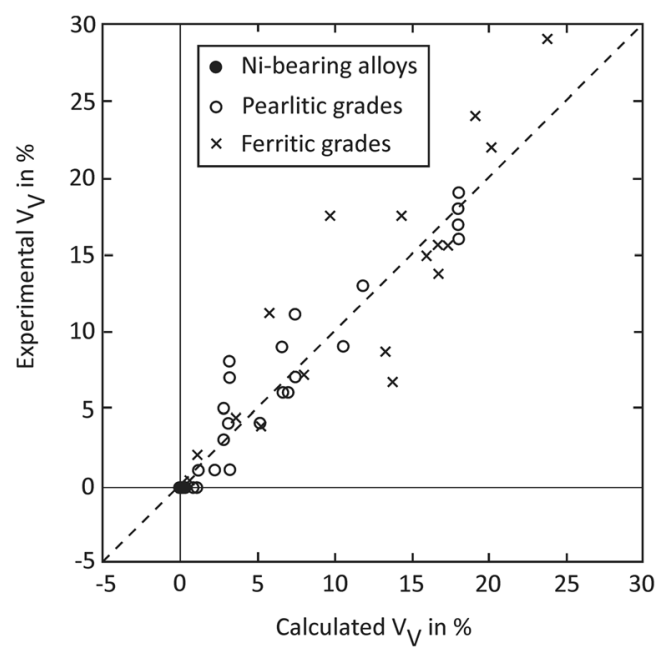

Figure 12. Comparison of experimental and calculated values of the relative volume affected by chunky graphite, $V_{V}$, using Eqn. 5, carbon content not reported, $1.92 \% \leq S i \leq 2.41 \%$, after Reference 18.

where $w_{i}$ is the content in wt\% of element " $i$ " and 55, $140.1,121.8$ and 24.3 are the atomic mass of $\mathrm{Fe}, \mathrm{Ce}, \mathrm{Sb}$ and $\mathrm{Mg}$, respectively. Sb counteracts the effect of Ce by combining with it, while it does not tight $\mathrm{Mg}$ which is also known to lead to similar graphite degeneracy as Ce when added in access. ${ }^{51}$ As can be seen in Figure 13a, there is a steep increase in the area fraction of chunky graphite when $\Omega_{\mathrm{Si}}$ increases above a critical value of about 7. Again, similarly as with the element ratio parameter in Reference 6, the critical value of $\Omega_{\mathrm{Si}}$ decreased (to a value in between 4.0 and 4.5) when the thermal modulus of the casting increased from using Y2 keel-blocks in Reference 51 to cubic blocks with an edge length of $300 \mathrm{~mm}$ References 46 and 63 (Figure 13b).

A basic lesson learned from all analyzed studies is that correlating the chemical composition with the risk of chunky graphite formation is very complex due to the broad variety of influencing parameters. Basically, the particular operating background and process parameters must carefully be considered. Although appearing attractive, the extrapolation of validity ranges should strictly be prohibited. The impact of the chemical composition or single elements is continuously superimposed and may even be governed by further technological factors like the conduct of heat, oxygen contents, inoculation, $\mathrm{Mg}$ treatment, the gating system and the solidification rate. Therefore, foundries usually define critical element limits based on operating data. Due to time and cost reasons, these data may contain inherent uncertainties. Mostly, not all relevant elements will be covered by the available chemical analyses and there are difficulties in determining the low levels of trace elements. ${ }^{59}$ And, typically, only spark source spectroscopy techniques with limited accuracy concerning trace elements are routinely used in foundry operation. ${ }^{6}$ Consequently, the chunky graphite limits do not provide a
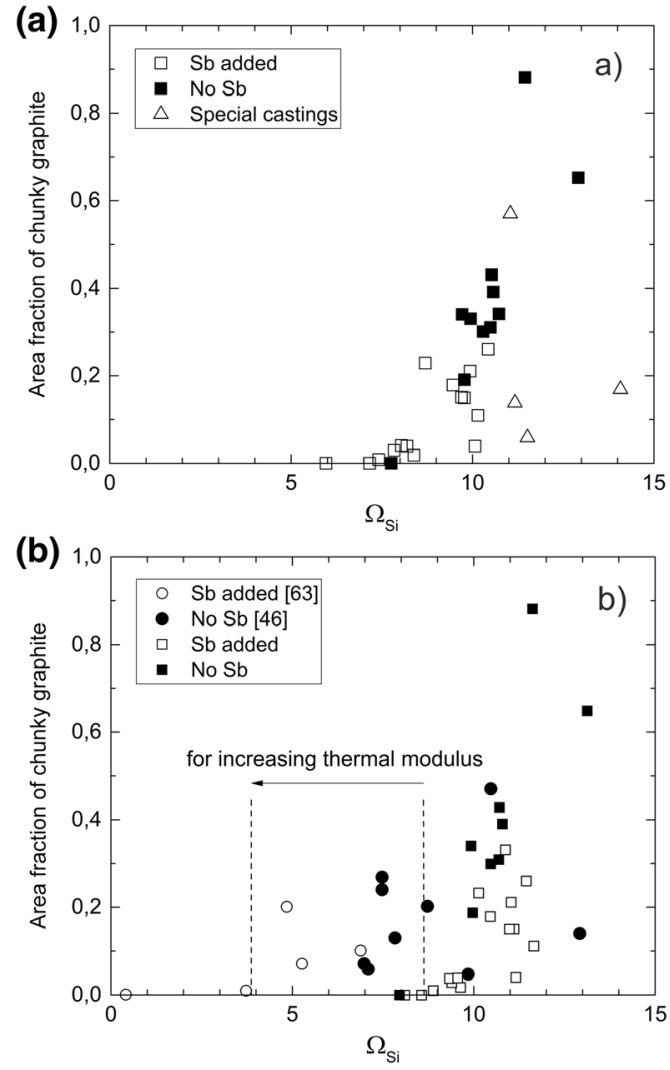

Figure 13. (a) Correlation between the index $\Omega_{S i}$ and the area fraction of chunky graphite, $2.26 \% \leq C \leq 3.16 \%$, $2.29 \% \leq S i \leq 9.12 \%$. Special castings have out of the series composition or treatment, after Reference 51 (b) data of Reference 51 without special casting data but including previous results from References 46 and $633.68 \% \leq C \leq 3.71 \%$, after Reference 51 .

$100 \%$ safety level and/or costly conservativity levels must be applied.

\section{Effect of Solidification Rate, Inoculation and Undercooling}

Since early studies on the subject, ${ }^{28,64}$ it has been qualitatively known and practically observed in the foundries that chunky graphite preferably emerges with low solidification rates as they are typical for heavy-sectioned castings. Scientific investigations using casted blocks and cylinders with different thermal moduli between 2 and $5 \mathrm{~cm}^{6,11,65}$ and stepped casting blocks $^{58}$ demonstrated that the amount of chunky graphite significantly increased with higher modulus and wall thickness, i.e., lower solidification rate. The authors of Reference 25 correlated the solidification rate with the silicon contents and basically confirmed earlier results of Reference 37 (Figure 14). According to Figure 14, the formation of chunky graphite is limited to long solidification times and high $\mathrm{Si}$ contents. The different positions of the limiting curves from References 25 and 37 underline the significant impact of different additionally superimposed metallurgical factors. 
Basically, with respect to avoidance of chunky graphite, any means to reduce hot spots or to increase solidification and cooling rates is beneficial. Where possible, the use of chills has proved to be an adequate and efficient preventive measure. ${ }^{12,25,30,33,42,66}$

As shown before in this article, the formation of chunky graphite in heavy sections of SGI is obviously closely related to the supercooling level and a lack of nuclei for crystallization. Enhanced attention is therefore paid to the technical process of inoculation, especially late and mold inoculation techniques. ${ }^{14,41,42,65-68}$ Basic goals of these techniques are to facilitate crystallization, increase nodule count and finally prevent graphite degenerations. The efficiency of mold inoculation depends on multiple factors such as composition and quantity of inoculant, manner of placing, pouring temperature, choice of the gating system as well as geometry and size of the casting. In general, only some of these interacting factors have been considered simultaneously in published studies on the subject. This might be a major root cause for different findings. In Reference 66 it was observed that the lifetime of nuclei from mold inoculation was shorter than with original melt nuclei so that the former had been ineffective with long-term solidification in heavy sections. Finally, a low nodule count and chunky graphite appeared. This corresponds to investigations on the chemical composition of nuclei in heavy-sectioned graphite particles in Reference 69 showing that the nuclei of nodules from secondary graphite nucleation did not contain any element that could be associated with inoculation treatment. Others indicate that the refinement of graphite particles is pronounced by the addition of antimony and big graphite nodules as well as low nodule count are ascribed to Ostwald ripening of graphite nodules in very slowly solidifying melts. ${ }^{58}$ Although mold inoculation increases the nodule

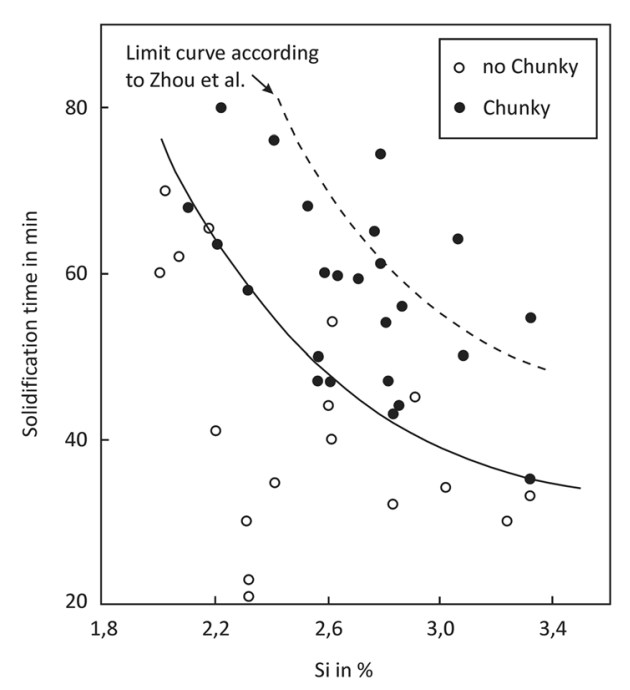

Figure 14. Influence of silicon contents and solidification time on the formation of chunky graphite, $3.40 \% \leq$ $C \leq 3.70 \%$, after Reference 25 , the dashed line recalls results of Zhou et al. ${ }^{37}$ count, the authors of Reference 65 emphasize that simultaneously the risk of chunky graphite formation increases if lengthy eutectic plateaus at nearly constant temperatures prevail as they are typical with the solidification of sandcasted heavy SGI sections. The findings in Reference 14 support earlier results of References 70, 71 and 72 and show that mold inoculation with the addition of $\mathrm{Bi}$ has a positive effect on the suppression of chunky graphite in heavy-sectioned SGI. In Reference 3 attention is drawn to the fact that most of the common inoculants consist of around $70 \%$ of Si. This must be taken into consideration when setting the carbon equivalent and adjusting the inoculation. The latter effect of increasing chunky graphite with stronger inoculation leading to increase in Si and rare earth contents as well as lower undercooling during eutectic transformation has experimentally been observed in References 51 and 52 with SGI melts having high Si contents.

In order to elaborate chunky graphite promoting or preventing conditions, a schematic on the correlation between growth rate and eutectic undercooling has been presented in Reference 29 (Figure 15). The figure was semiquantitatively deduced based on literature data and supported by experimental data gained in Reference 46. According to Figure 15, chunky graphite is favored at low undercooling with respect to spheroidal graphite, unless very efficient nucleation capability (higher nodule count) exists in the melt so that the curve representing spheroidal graphite growth is shifted to lower undercooling. It is concluded that for heavy-sectioned castings, where the cooling rate of the bulk eutectic will be low, every element that could favor chunky graphite such as Ce should be avoided as chunky graphite eutectic cells would otherwise easily overtake spheroidal growth. ${ }^{29}$

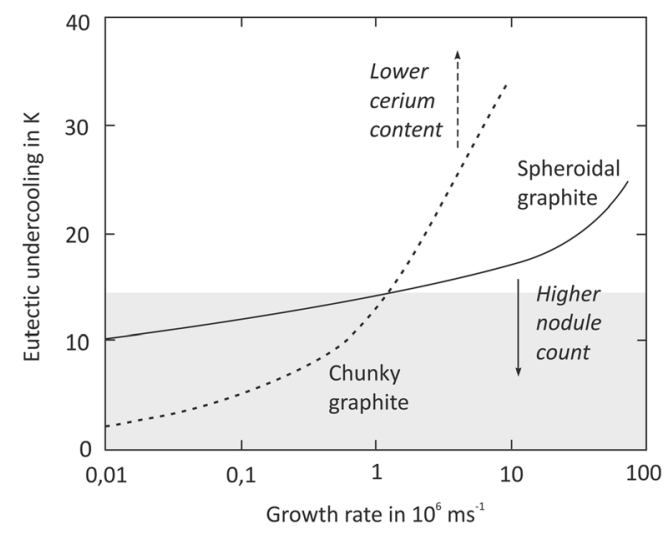

Figure 15. Correlation between growth rate and eutectic undercooling for chunky and spheroidal graphite in a $\mathrm{Fe}-\mathrm{C}-\mathrm{Si}$ alloy treated with $\mathrm{Ce}$. The gray shaded area illustrates the range of undercoolings observed in Reference 46 for the bulk eutectic reaction in heavysectioned blocks with various amounts of chunky graphite, $3.61 \% \leq C \leq 3.73 \%, 2.07 \% \leq S i \leq 2.35 \%$, after Reference 29. 


\section{Preliminary Conclusion on Causes and Prevention of Chunky Graphite}

As demonstrated above, the appearance of chunky graphite in heavy sections of SGI is controlled by numerous, frequently interacting metallurgical influence factors. The development of quantitative rules to prevent chunky graphite has therefore proved to be complex and their practical impact has been limited due to narrow validity windows. Facing partly controversial results and the big scatter of literature data, no specific numbers of element contents, temperatures, etc., can be emphasized in this overview. Nevertheless, considering the present state of knowledge, the following baseline for preventive actions in terms of general metallurgical and process measures can be drawn to avoid chunky graphite in heavy-sectioned SGI castings:

- Increase in cooling and solidification rate, e.g., by the use of chills or mold material with high heat transfer capacity, low thermal module.

- Avoidance of hot spots.

- Improvement in the nucleation state of the original melt.

- Adequate inoculation.

- Reduction in Si content.

- Slightly hypoeutectic carbon equivalent.

- Control of trace elements, strive for balance of chunky graphite promoting and counteracting elements.

- Balancing $\mathrm{Ce}$ and other RE at a low level.

- Addition of Bi and Sb.

\section{Morphology and Characterization of Chunky Graphite}

\section{Appearance, Microstructure and Forms of Chunky Graphite}

On a macroscopic scale, the presence of chunky graphite can be revealed by dark areas at the surface of a component which may become obvious after machining or sectioning (Figure 1). From a microscopical point of view, Figures 16 and 17 show in detail metallographic sections with typical chunky graphite in heavy-sectioned ferritic SGI. ${ }^{73}$ Furthermore, an overview of the microstructure in a component heavily contaminated with chunky graphite is given in Figure $18 .^{74}$

The location of chunky graphite normally, but not exclusively, indicates the location of the thermal center of a casting. ${ }^{3,38,45}$ Chunky graphite usually grows in eutectic cells of graphite and austenite for which cell sizes between approximately $0.5 \mathrm{~mm}$ and $4 \mathrm{~mm}$ have been reported. ${ }^{9,13,14,34,37,65}$ For comparison, the size scale can evocatively be illustrated in terms of criteria for defect sizes in ultrasonic testing. Already less than two and a

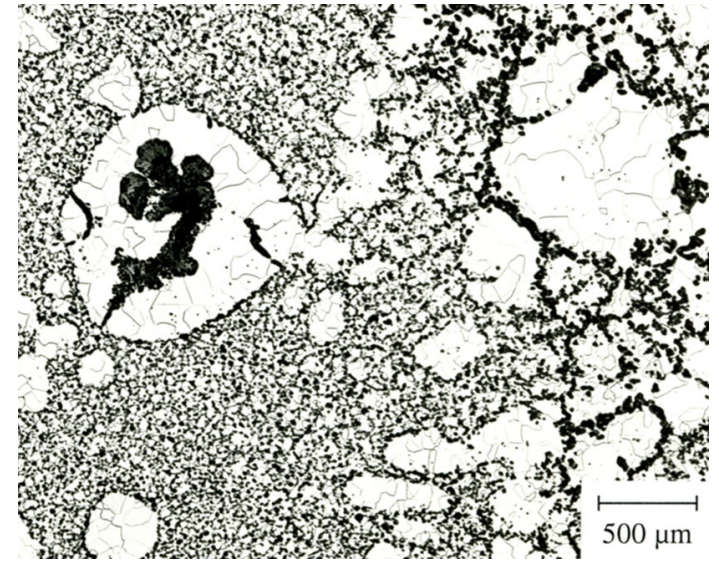

Figure 16. Chunky graphite in heavy-sectioned SGI, metallographic section etched with alcoholic nitric acid $(3 \%) .^{73}$

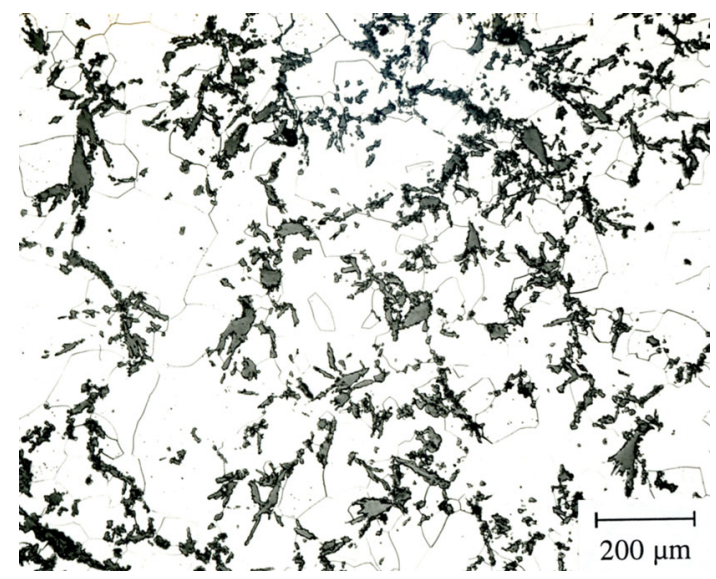

Figure 17. Chunky graphite in heavy-sectioned SGI, metallographic section etched with alcoholic nitric acid $(3 \%) .^{73}$

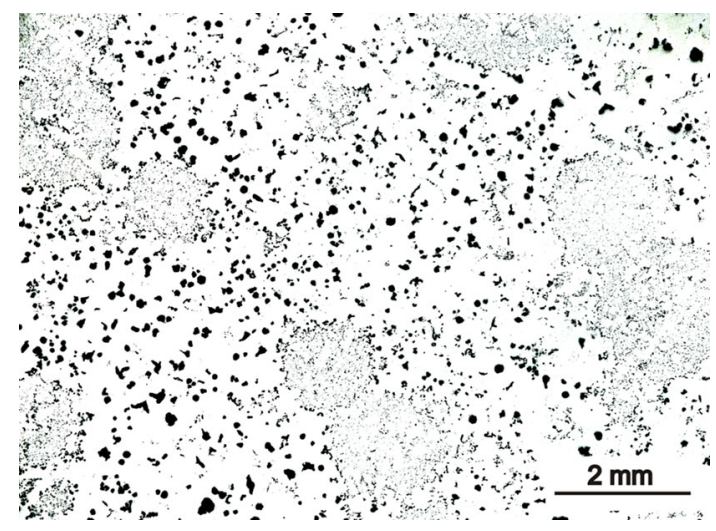

Figure 18. Overview of chunky graphite appearance in heavy-sectioned SGI, non-etched metallographic section, after Reference 74.

half socialized 4-mm cells of $\mathrm{CHG}$ would cause to violate a CDR 6 limit (circular disk-shaped reflector) provided the effect of CHG would be set equal to those of a cavity (CDR 6-equivalent reflector size of a circle with a 
diameter of $6 \mathrm{~mm}$ ). It should be recognized that chunky graphite does not need to grow in perfectly shaped eutectic cells and the visibility of single cells in metallographic sections decreases with increasing chunky graphite share. ${ }^{9}$ Furthermore, the visibility of CHG depends on how the chunky graphite aggregate is randomly hit by machining or a metallographic section. A feature additionally complicating the recognizability of $\mathrm{CHG}$ is that irregular-shaped graphite particles which do not match the usual classification criteria of corresponding material and test standards like References 75-80 are frequently observed in cast irons contaminated with chunky graphite as well. ${ }^{9}$ There can even exist a real continuity between spheroids, exploded graphite, chunky graphite and other graphite aggregates in clusters of graphite precipitates. ${ }^{39}$ The distribution of chunky graphite is not uniform within the affected zone.

A noteworthy review of microstructural features of chunky graphite in SGI was presented in Reference 29. The authors refer to early basic studies ${ }^{30,81}$ which already identified two different forms of chunky graphite, fine and coarse as it was considered in Reference 49 as well. However, the common feature of both forms is a radial structure with growth along the c-axis like known from nodular graphite. It was emphasized in Reference 81, that the difference in size was due to the extent of the affected zones. Coarse chunky graphite (Figure 19) precipitates between dendrites at some late stage of solidification while fine chunky graphite (Figure 18) arises in large areas.

As outlined in Reference 6, chunky graphite appears in two different arrangements; interdendritic and globular in spheric eutectic cells. The same classification has been reported in References 1, 3 and 38, but the latter form was denominated cluster. Thus, as far as concerning the appearance of chunky graphite, it can be concluded that studies (e.g., References 1, 3, 6, 29, 30, 38, 49 and 81) may use different terms, but are substantially in line distinguishing with chunky graphite between interdendritic/coarse on the one hand and fine/globular in spherical eutectic cells/clusters on the other hand.

The morphology of chunky graphite is of a remarkably high complexity. Major feature of CHG is its filigree threedimensional, string-like, multi-branched and interconnected structure throughout each cell, see, e.g., References $1,14,20,21,24,25,29,30,34,38,39,47$ and 66. This type of structure does not really become obvious by twodimensional metallographic sections (Figure 16, Figure 17, Figure 18), where graphite appears as discrete particles. A better flavor of the specific chunky graphite morphology can be revealed by deep etching and SEM observation. The images a) to d) of Figure $20^{74}$ illustrate in detail how the spatial structure of the chunky graphite displayed in Figure 18 had been made visible by incremental deep etching. A second example at larger magnification is given in
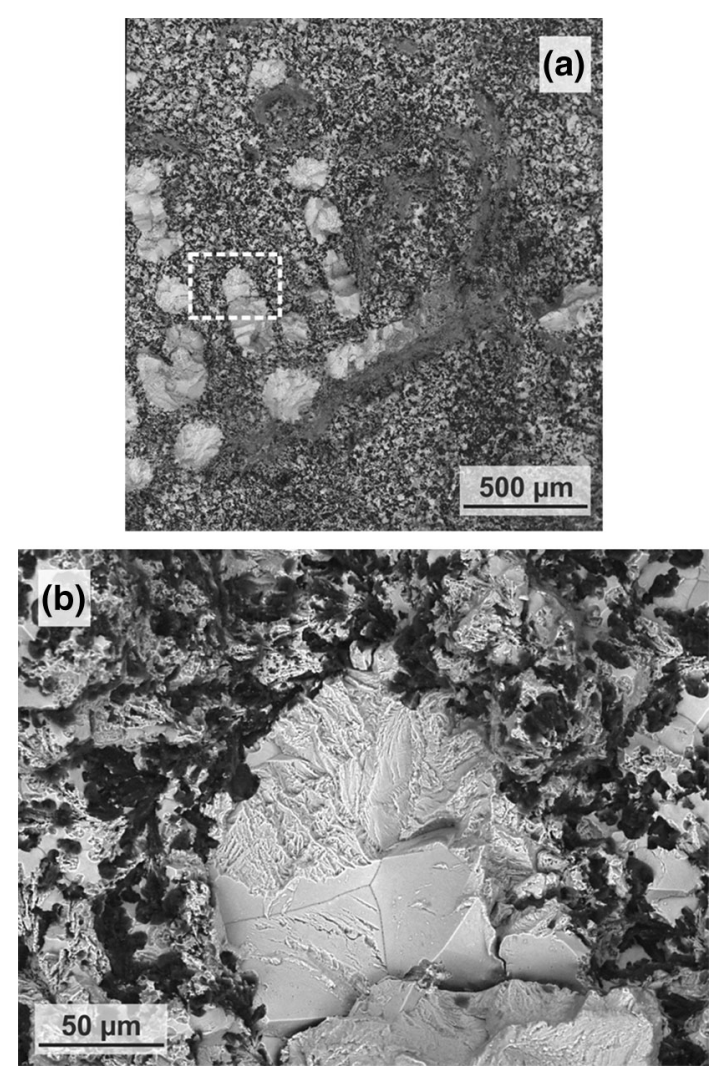

Figure 19. (a) Interdendritic chunky graphite on a fracture surface of ferritic SGI, (b) detail (white frame) of (a), SEM BSE contrast technique.

Figure $21 .^{74}$ If the metallic matrix is completely dissolved by etching, CHG particles of several millimeters in size may be extracted. ${ }^{82}$

\section{Avoiding Microstructural Misinterpretation of Chunky Graphite}

Chunky graphite may be found to resemble type D distribution of flake graphite upon examination under an optical microscope (Figure 22). However, according to Reference 47 chunky graphite lacks the characteristic flake nature of type D-graphite, being more segmented in nature.

The risk of misinterpretation of degenerated graphite in SGI as either chunky or compacted graphite (Figures 23, 24) should not be underestimated. As has been pointed out in Reference 29 , chunky graphite had even been confused with compacted graphite for a while in the early literature, e.g., Reference 28 and 83 and recent literature gives rise to discussion yet again. Taken at face value, the small elongated compacted graphite particles (Figure 25$)^{84}$ (Figure 26), ${ }^{85}$ may in two-dimensional metallographic sections indeed look similar to the appearance of the chunky graphite degeneration.

Using X-ray tomography during solidification, ${ }^{23}$ the microstructural appearance of compacted graphite structures in a small in situ sample (diameter $2.5 \mathrm{~mm}$, height 

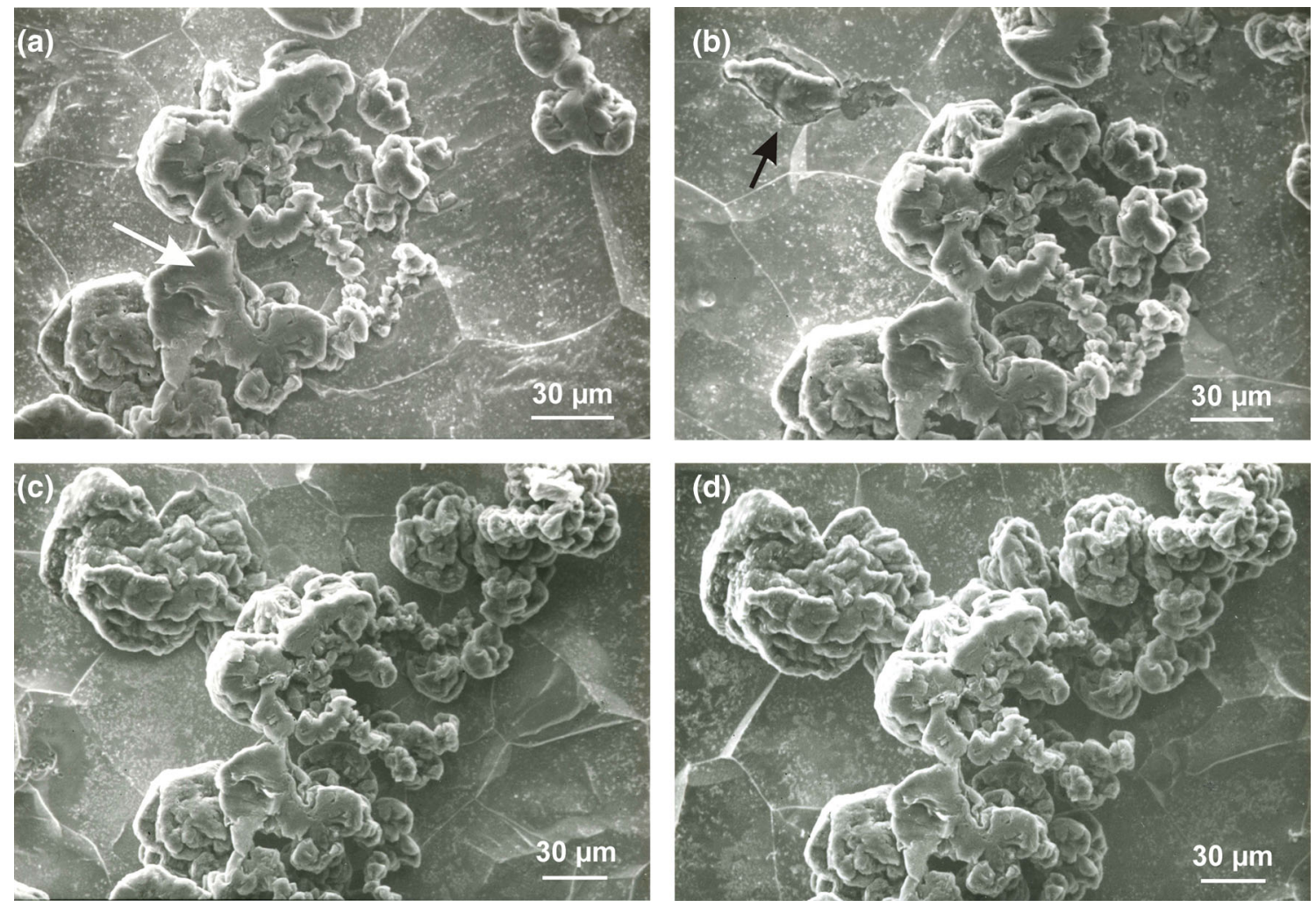

Figure 20. Detail of chunky graphite in heavy-sectioned SGI (Figure 18), deep etching technique: (a) $5 \mathrm{~min}$, (b) $10 \mathrm{~min}$, (c) $20 \mathrm{~min}$, (d) $30 \mathrm{~min}$; white arrow in (a) marks the original plane of polishing; black arrow in (b) marks an example of a sequentially exposed graphite branch. ${ }^{74}$

$8 \mathrm{~mm}$ ) has been attributed as being either of arch type, plate-like or rod-like while combinations prevail (Figure 27). Concerning spatial representation, a branched type of structure has also been ascribed to compacted graphite in References 86 and 87, while coherent structures are rarely observed. Figure 28 illustrates an extraordinarily large rosette-like compacted graphite structure which has been investigated in Reference 23. An example of a comparable structure has been attributed cluster of compacted graphite in Reference 85. Rounded branch ends have been found to be typical with compacted graphite. ${ }^{23,88}$ Concerning geometry, the branch ends are even termed spherical. ${ }^{87}$ This appearance is underlined from the growth mechanism point of view by Reference 31, saying that toward the end of the compacted particle growth a substantial thickening and blunting of the particle ends occurs.

A lower degree of size, complexity, fineness/branching tendency and interconnectivity of compacted graphite may be considered major criteria to distinguish compacted from chunky graphite. Additionally, according to Reference 29, compacted graphite string distribution is randomly oriented like lamellas found in gray irons while chunky graphite particles show some alignment as a consequence of the interconnections in the strings. Stefanescu et al. ${ }^{24}$ advocate that the shape of the stacked graphite platelets which is primarily hexagonal with compacted graphite appears to become irregular with chunky graphite. Furthermore, stacking of platelets along the c-axis is much more pronounced with chunky graphite also producing the typical conical sectors.

According to Reference 53, an apparently similar but not identical form of graphite degeneration compared to chunky graphite was observed with Si solution-strengthened SGI (Figure 29). The observed graphite degeneration is supposed to be subjected to a growth mechanism different from CHG. It consists of concatenated small graphite spheres,${ }^{53}$ while CHG grows by deposition of more or less irregular hexagonally shaped carbon platelets. Nevertheless, it should be noted in that context that recent comprehensive investigations on $\mathrm{Si}$ solution-strengthened $\mathrm{SGI}^{51}$ clearly demonstrated chunky graphite in these materials showing the known microstructural features as they are typical with conventional ferritic SGI.

Corresponding to the widely used SEM SE (secondary electron) contrast technique, BSE (backscattering electron) contrast technique has proved to be a very useful tool within fractographical analyses to recognize graphite in a metallic matrix; especially by observation at low magnifications, a good overview can be gained (Figure 30) and typical chunky graphite patterns may easier be identified with BSE (Figure 31) than with SE technique (Figure 32) 

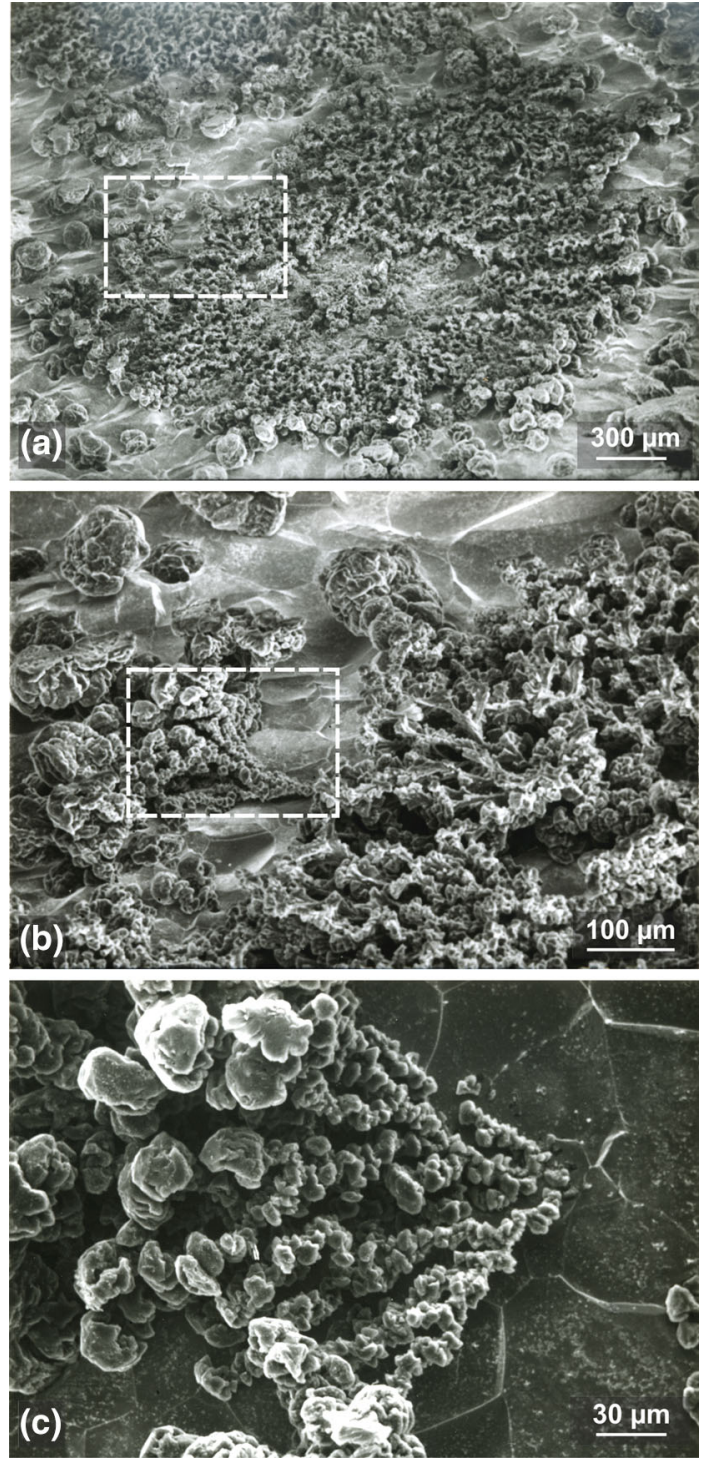

Figure 21. Chunky graphite in heavy-sectioned SGI, sub-volume of Figure 18, deep etching technique: $60 \mathrm{~min}$, images (b) and (c) are magnifications of the white frames in the preceding images. ${ }^{74}$

due to the sharp BSE black (graphite, C) and white (ferrite, Fe) element contrast. While the SE image (Figure 32) does not allow a reliable assignment of graphite forms, the BSE image (Figure 31) reveals typical chunky graphite arrangements. Nevertheless, the reliable recognition of chunky graphite on fracture surfaces can be a challenge and requires experience because of the enhanced local graphite amount on the crack path and possible partly demolition of graphite due to the fracture process.

When microstructural details are primarily focused, SE contrast technique will be first choice. Thus, the specimen topography becomes accessible as it is illustrated in Figure 33. Figure 33(a) and (b) display subsequent magnifications from details in Figure 32 outlining the branched

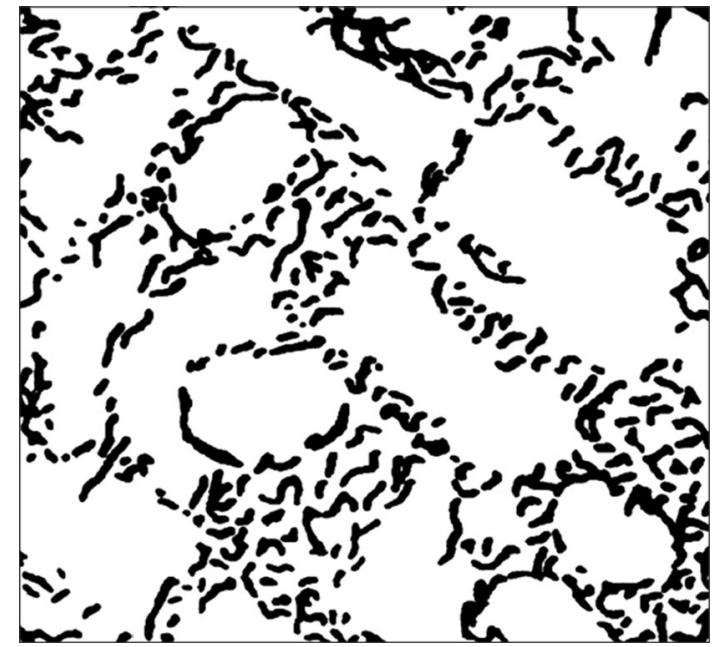

Figure 22. Schematic of type $D$ flake graphite distribution according to ISO 945-1, binary image processed based on Reference 31.

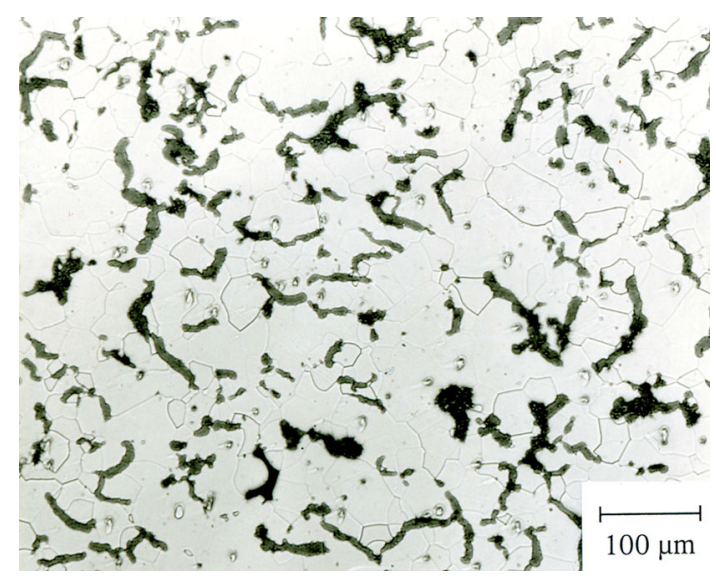

Figure 23. Ferritic ductile cast iron with compacted graphite, etched with alcoholic nitric acid (3\%). ${ }^{73}$

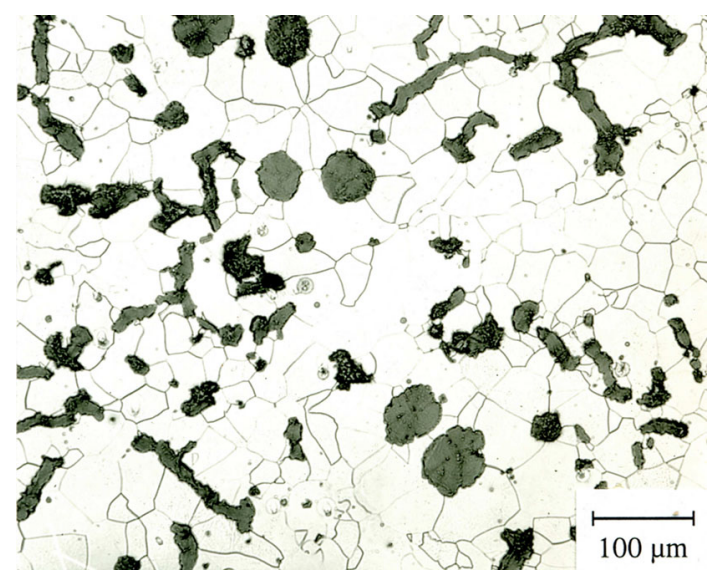

Figure 24. Ferritic ductile cast iron with compacted graphite and enhanced nodule share, etched with alcoholic nitric acid (3\%). ${ }^{73}$ 
and layered or stacked structure of chunky graphite as it appears when being exposed on a fracture surface.

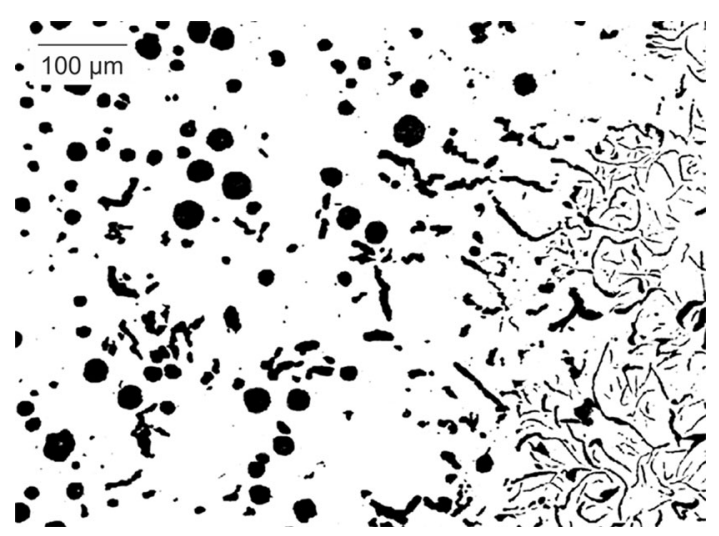

Figure 25. Ductile nodular cast iron with compacted (center and lower left) and flake graphite (right), binary image processed based on Reference 84.

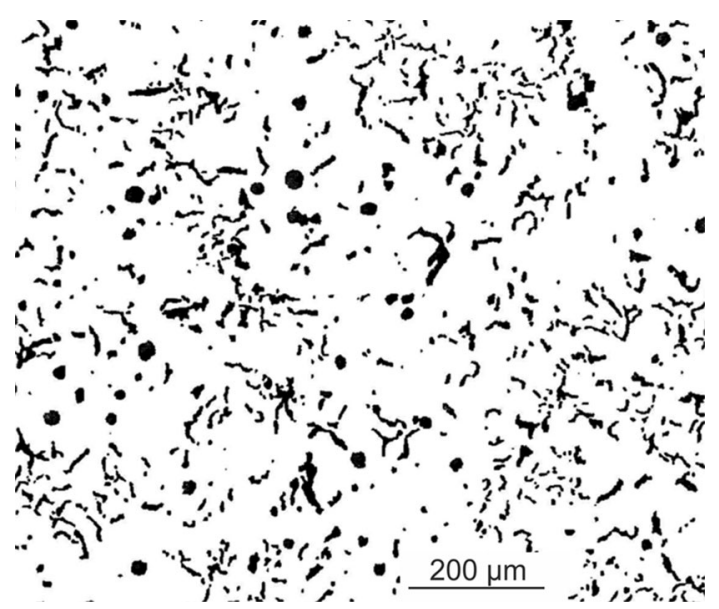

Figure 26. Typical compacted graphite cast iron containing approximately $20 \%$ of nodules, binary image processed based on Reference 85.
Figure 34 demonstrates a practical case where the risk of misinterpreting the real chunky graphite amount in the microstructure is considerably high when being based on two-dimensional surface estimation. There are only traces of chunky graphite visible on the mechanical notch ground and the flanks of the displayed fracture mechanics specimen. By way of contrast, slightly below the former notch tip, a tremendous amount of chunky graphite network is spreading across the ligament of the specimen.

In order to remove or confirm any suspicion of CHG being present in a specimen or component, it can generally be recommended to be a valuable and appropriate strategy to ramp up the investigation effort. Complementary 3d-information should be gained even though most of the actions currently qualifying for this are invasive and destructive. Measures proved to be effective cover replacement of metallographic microsection screening by complete observation of the specimen or area of interest, additional microsections with different orientations, deep etching and SEM observation, SEM observation of available fracture surfaces and application of advanced investigation techniques like X-ray computed tomography.

\section{Advanced Characterization Techniques and Quantification of Chunky Graphite Amount}

Significant further insight into the morphology of chunky graphite could be provided by investigation with synchrotron radiation X-ray computed tomography (CT). Synchrotron CT measurements of an SGI specimen with chunky graphite were performed by the Federal Institute for Materials Research and Testing (BAM) using the beamline BAMline ${ }^{89}$ at the synchrotron source BESSY II in Berlin, Germany. Operating in the hard X-ray regime (45 keV), the experimental setup and analysis procedure enabled to provide results with a spatial resolution substantially beyond the micrometer limit (approximately $0.4 \mu \mathrm{m})$. 2d-sections through a cylindrical specimen (diameter $1 \mathrm{~mm}$, height $6.5 \mathrm{~mm}$ ), but especially precise
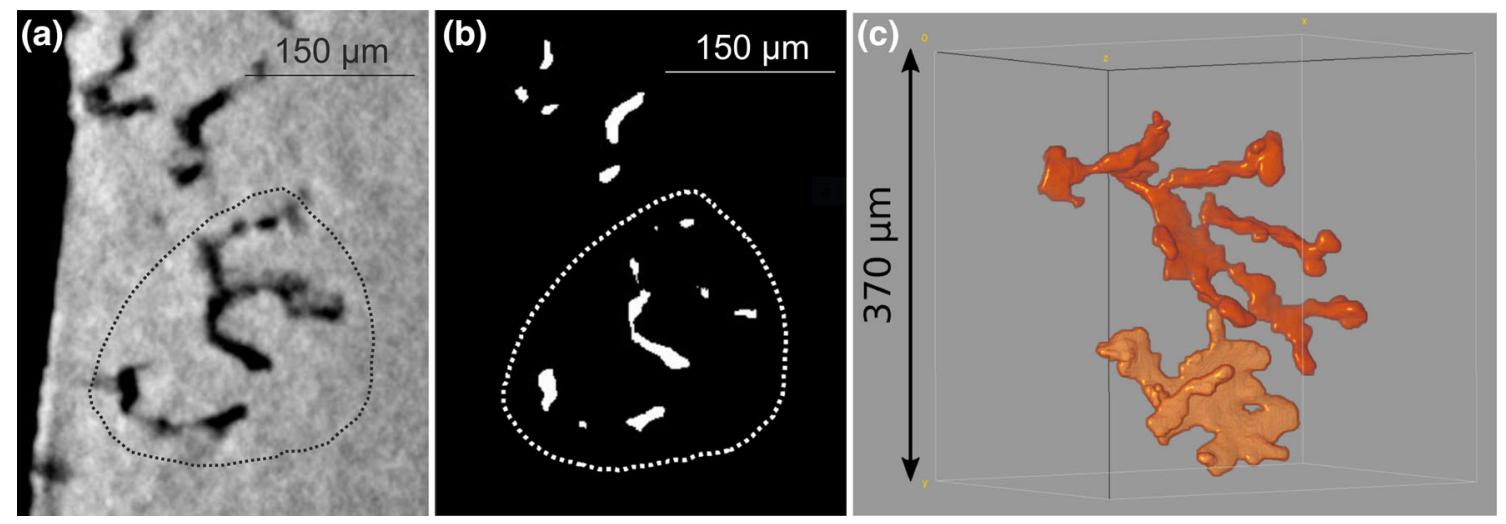

Figure 27. Compacted graphite in SGI analyzed using synchrotron X-ray tomography during solidification: (a) 2d-section from tomogram, (b) binary version of (a) after filtering and segmentation, (c) 3d-rendering of two unconnected particles intersected by the 2d-section in (a), after Reference 23. 


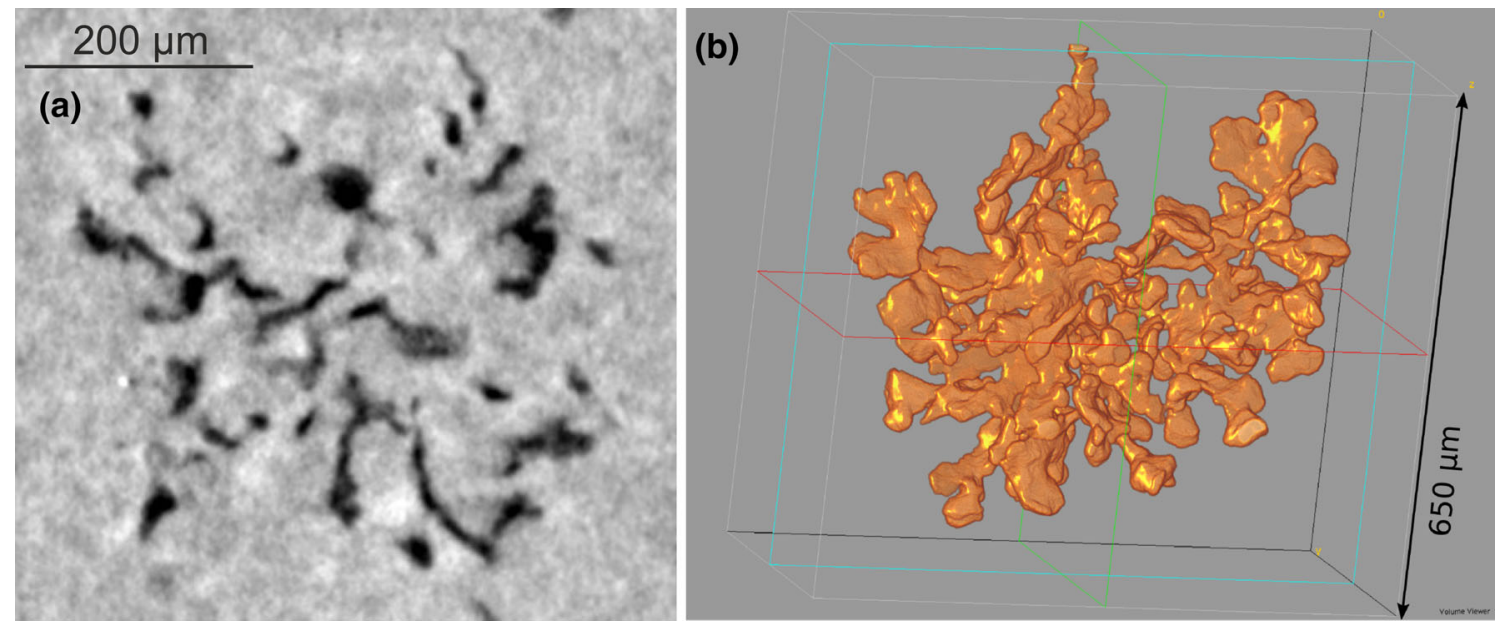

Figure 28. Compacted graphite in SGI analyzed using synchrotron X-ray tomography during solidification: (a) 2d-section from tomogram, (b) 3d-rendering of the volume containing the $2 d$ section in (a), after Reference 23.

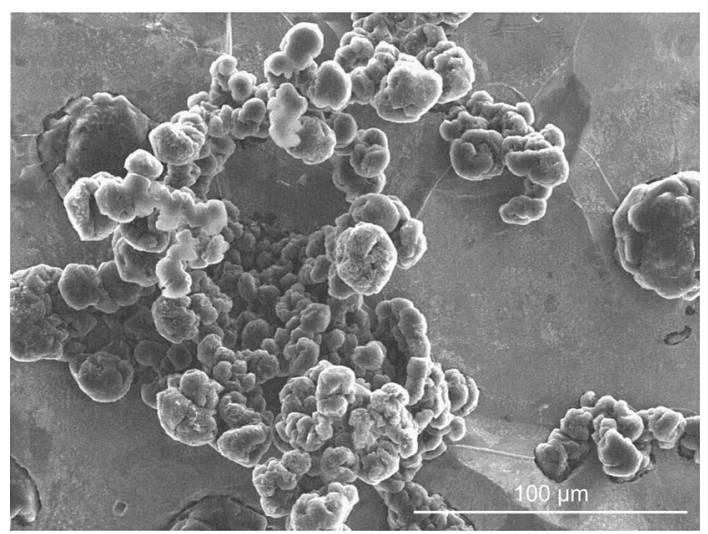

Figure 29. Degenerated graphite assembly in Si solution-strengthened SGI with high Si content, deep etching technique. ${ }^{53}$

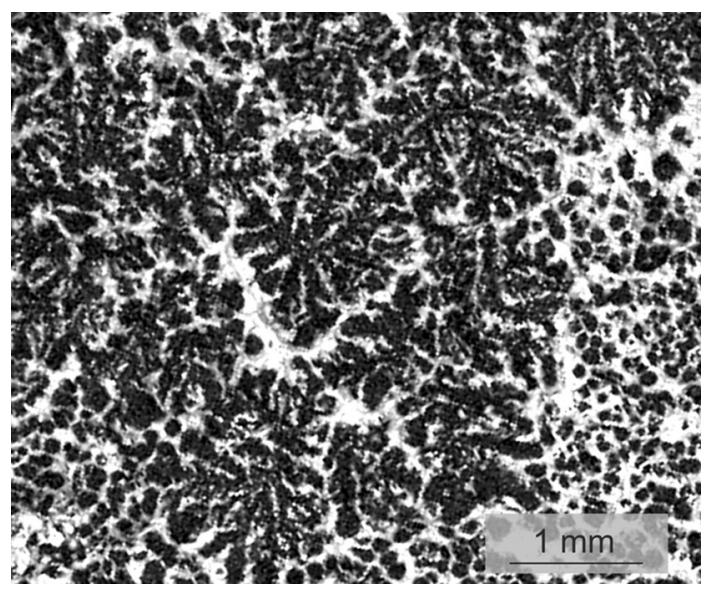

Figure 30. Overview of the fracture surface with typical chunky graphite cells in a specimen quasi-statically tested at room temperature, heavy-sectioned ferritic SGI, SEM BSE contrast technique.

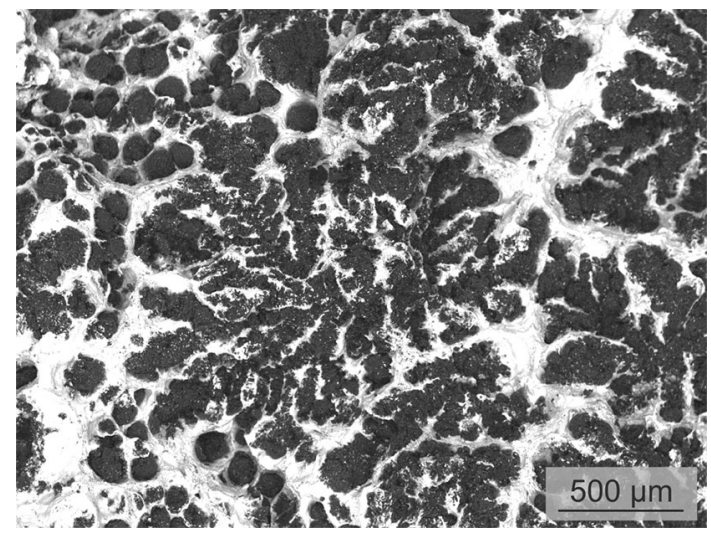

Figure 31. Chunky graphite on the fracture surface of a specimen quasi-statically tested at room temperature, heavy-sectioned ferritic SGI, SEM BSE contrast technique, imaging area is identical to Figure 32.

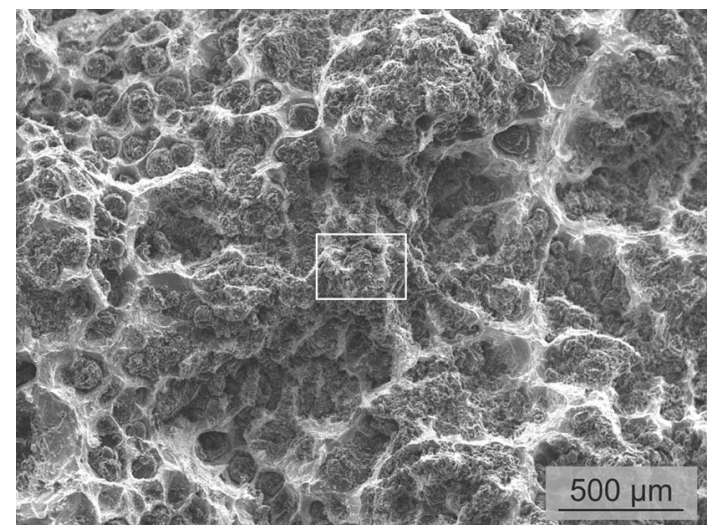

Figure 32. Chunky graphite on the fracture surface of a specimen quasi-statically tested at room temperature, heavy-sectioned ferritic SGI, SEM SE contrast technique, imaging area is identical to Figure 31, for the white frame, see Figure 33. 

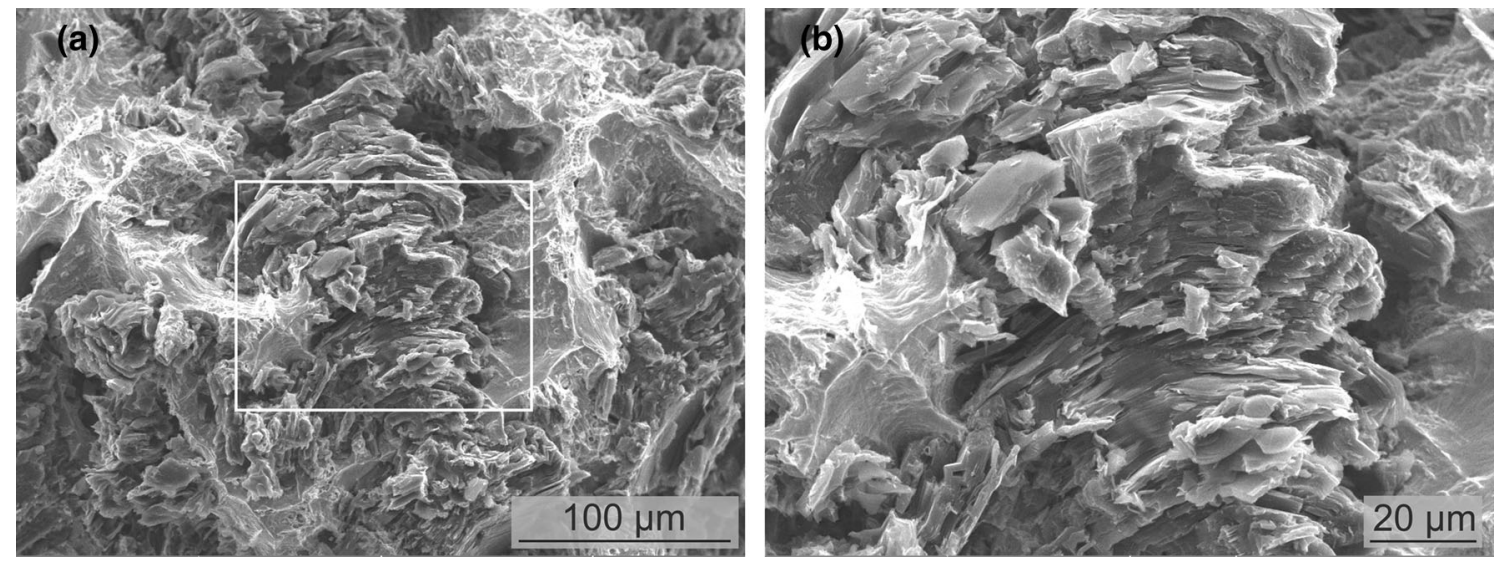

Figure 33. Structural details of chunky graphite on the fracture surface of a specimen quasistatically tested at room temperature, heavy-sectioned SGI, the image (a) is a magnification of the area in the white frame marked in Figure 32, and (b) is a subsequent magnification of the white frame in (a).
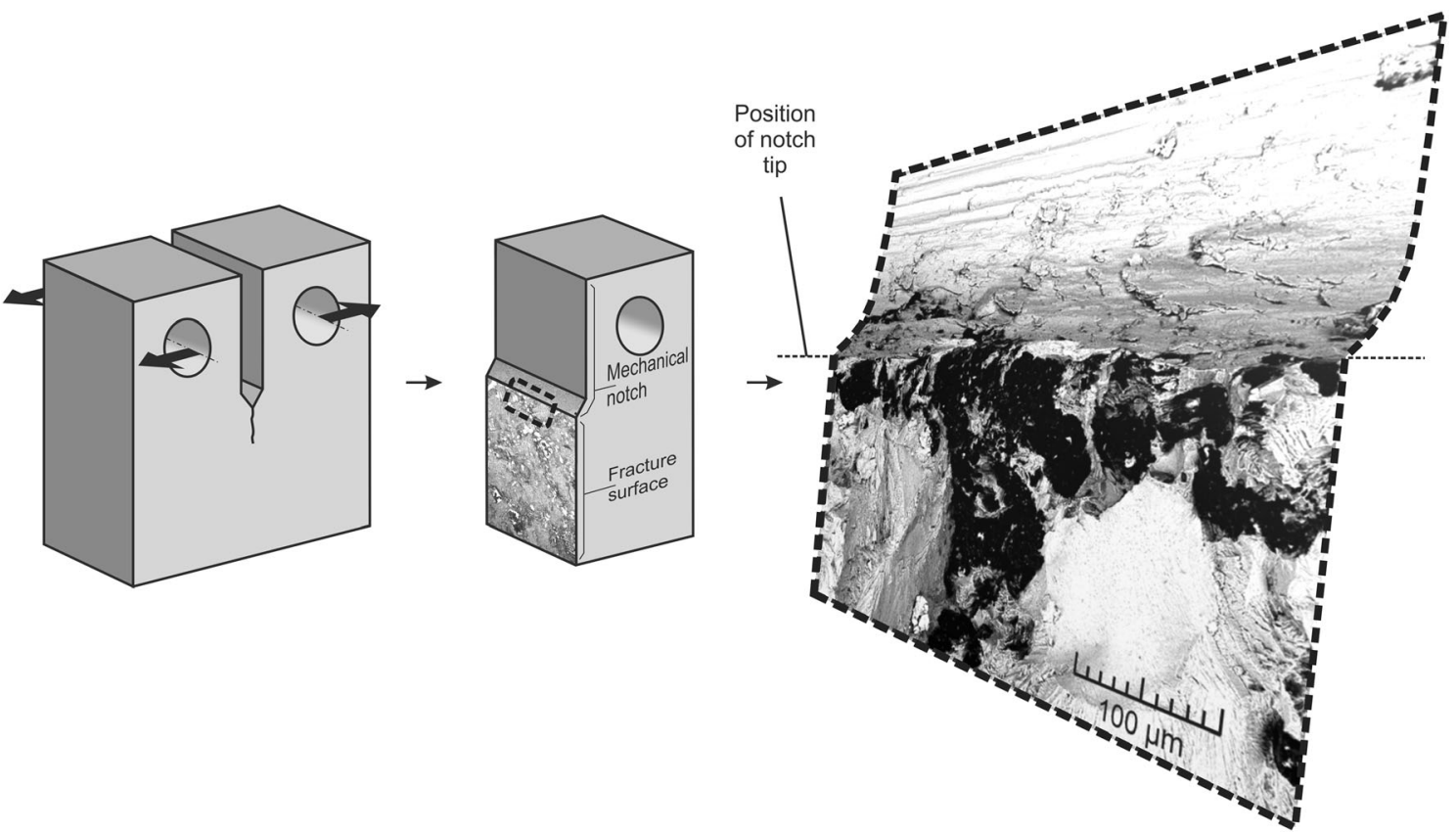

Figure 34. Chunky graphite arrangement in the ligament of a fracture mechanics $C(T)$ specimen of ferritic SGI, investigated after fracture mechanics test by SEM BSE contrast technique.

volume renderings and animations of the reconstructed microstructure, provided outstanding knowledge about the filigree, highly branched long-range spatial nature of the chunky graphite morphology. Figure 35 displays a 2 d-CT section through the cylindrical specimen (left) overlayed by top views of 3d-reconstructions of the graphite at two marked positions (right). The focus of the subsequent analysis was directed to these sub-volumes since the chunky graphite obviously showed different appearances there, filigree (lower left) and coarse (top right). It can be concluded from Figures 36 and 37, representing the subvolumes in Figure 35, that a highly branched interconnected spatial structure exists with chunky graphite independently from local variations in precipitation fineness.

On principle, quality assessment of a materials microstructure and estimation of microstructural impact on service properties of a component require to determine appropriate quantitative, statistically based microstructural parameters. With cast iron, stereological analyses of structures visible in metallographic sections usually provide corresponding graphite morphology parameters. But in contrast to graphite nodules and deviations from the spherical form other than chunky, the morphology and 

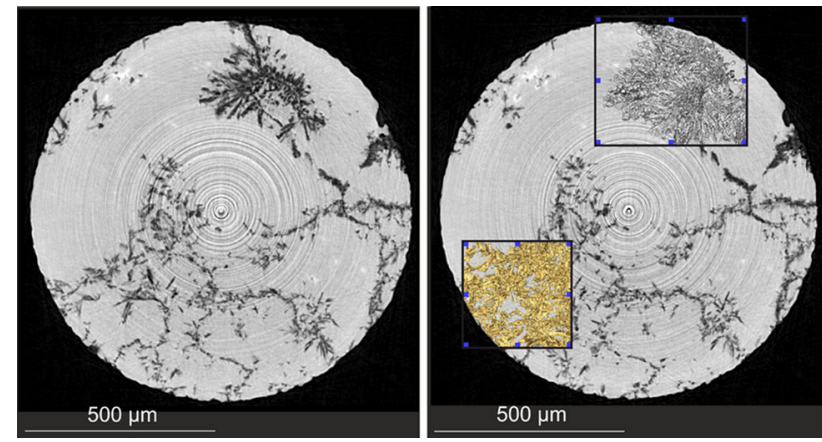

Figure 35. Synchrotron CT investigation of SGI with chunky graphite, 2d-section through a cylindrical specimen (left) overlaid by top views of 3d-reconstructions of the graphite at the marked positions (right).

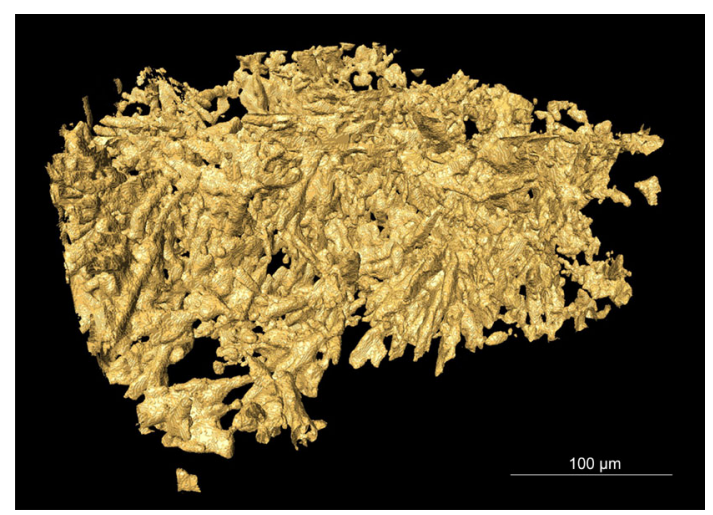

Figure 36. Synchrotron CT investigation of SGI with chunky graphite, 3d-image of the marked lower left position in Figure 35.

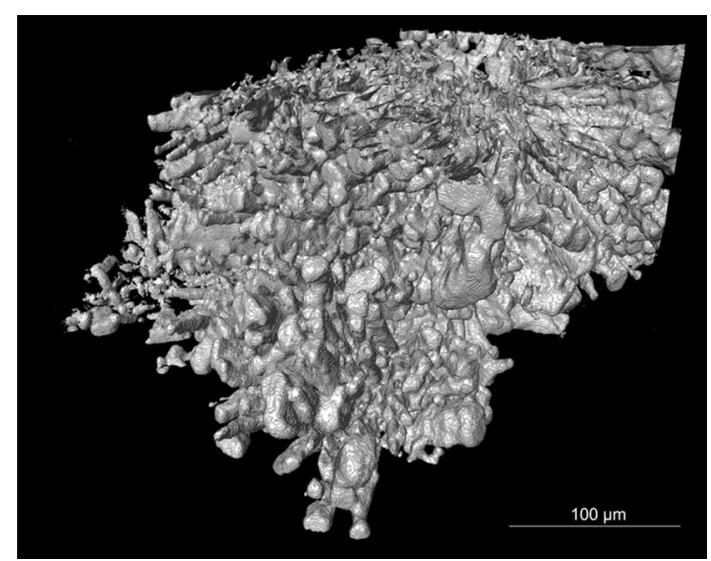

Figure 37. Synchrotron CT investigation of SGI with chunky graphite, 3d-image of the marked top right position in Figure 35.

volumetric amount of chunky graphite cannot be accessed by stereological interpretation of 2d-metallographic section data. This is due to the highly irregular, branched anisotropic spatial structure of chunky graphite which is nonisometric and non-dispersed. De facto, as practised in References 9, 20, 82, 90-93, only areal fraction parameters are determined which rather provide glimpses of the chunky graphite share in the respective microsection and are usually not truly statistically based. The same holds for similarly performed analyses of fracture surfaces. Those areal parameters are typically defined as ratio between the section area affected by chunky graphite and the total section area and are manually determined as reported in References 9, 20, 82, 91-93 (Figure 38(a) and (b)). Furthermore, the ratio between the chunky graphite area and the total graphite area has been reported as well as possible parameter in Reference 90 (Figure 38(a) and (c)).

The average chunky graphite content measured on metallographic sections is always lower than its counterpart measured on the fracture surface. This gives evidence that the chunky graphite phase is the preferential easy path for crack propagation. ${ }^{93}$ In order to quantitatively analyze the fracture surfaces of fracture mechanical specimens, line scans across the specimen in front of the fatigue crack have been used as well to provide the ratio between chunky graphite affected line length and total line length, thus finally providing an area section value. ${ }^{91}$

Summing up, as far as the present state of knowledge is concerned, it can be concluded that it has not yet been possible to establish tools nor technical procedures for a quantitative volumetric determination of the chunky graphite amount in components. Recalling that appropriate reliable nondestructive testing methods for chunky graphite determination in castings have not yet been established as well, the problem of how to reliably assess the impact of chunky graphite on the components service properties must currently be considered unsolved.

A more adequate quantitative characterization of microstructural heterogeneity, morphology and interconnectivity may be obtained in the future. Further development of nondestructive tomographic techniques as they have already been presented above with qualitative imaging may contribute. The current capabilities of laboratory computed X-ray tomography ${ }^{94}$ do not allow to gain sufficient quantitative insight into filigree structures of larger metallic objects such as chunky graphite in cast iron materials. On the other hand, time-resolved and spatial resolution synchrotron tomography methods, for which a recent overview on status and perspectives was presented in Reference 95, offer resolution advantages with bigger metallic objects at the expense of high experimental effort and costs.

Further promising, versatile but destructive methods for 3d-microstructural characterization are serial sectioning light and electron microscopy-based tomographic techniques to elucidate the microstructure of materials. ${ }^{96,97}$ Using FIB (focused ion beam) serial cross-sectioning together with 3d-reconstruction of SEM SE images, ${ }^{88,98}$ the shape of single compacted and temper graphite particles in 

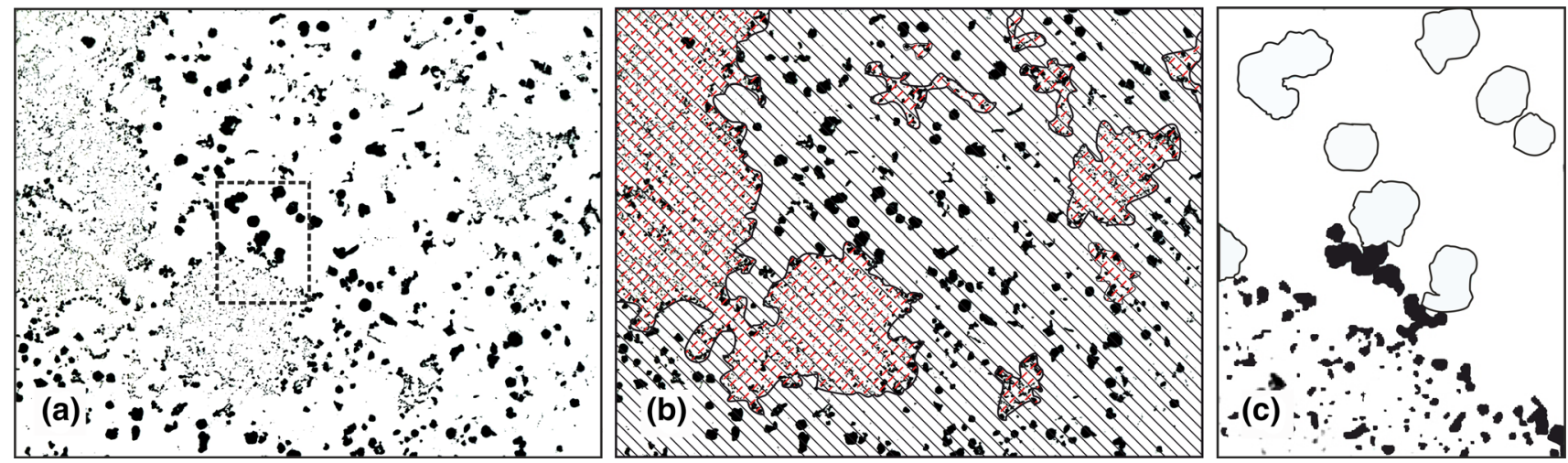

Figure 38. Determination of the parameter area fraction of chunky graphite: (a) example of a microstructure containing chunky graphite; (b) area fraction of chunky graphite in terms of ratio between the section area affected by chunky graphite (dashed hatching) and the total section area of (a) (solid hatching); (c) in terms of ratio between the chunky graphite area (black) and the total graphite area (black + white) illustrated for the dashed black frame in (a).

ductile cast iron has been investigated focusing provision of precise 3d-data for FE simulations. Nevertheless, due to the comparatively small material volumes which typically can be investigated by those techniques, they do not yet seem to be of great practical impact with respect to a quantitative characterization of chunky graphite in castings, and certainly not with heavy sections. In the future, an increasing number of fields of application are expected to open up in the course of an advancing automation of serial sectioning techniques. ${ }^{97}$

Although the chunky graphite degeneration in heavy SGI sections has been a real-life technical problem and a research subject for many decades, it has not yet been addressed nor have acceptance criteria been established in international material and test standards related to SGI such as EN $1563,{ }^{50}$ ISO $1083,{ }^{75}$ ISO $945-1,{ }^{76}$ ISO $945-4,{ }^{77}$ ASTM A247, ${ }^{78}$ ASTM E $2567^{79}$ or JIS G $5504 .^{80}$ The difficulties in quantitative characterization of chunky graphite as well as remaining challenges in its process-safe control may be considered major reasons for this status. Consistently, safety regulations for heavy-sectioned SGI components such as transport and storage casks for radioactive materials explicitly exclude chunky graphite. $^{99,100}$

\section{The Impact of Chunky Graphite on Properties of SGI}

The current situation is characterized by doubts and discussions about the acceptance or rejection of SGI components containing chunky graphite. This is accountable since in contrast to the reasonable qualitative understanding of the effects of chunky graphite on the properties of SGI, the knowledge on its quantitative impact must unfortunately be called rudimentary. As long as an appropriate method to quantify the chunky graphite content in a component on a three-dimensional basis will not be available and technically established, it is most likely that the current situation will endure.

Therefore, the aim of the present chapter is to provide a comprehensive overview on the current published state of the art in this domain. A set of diagrams have been elaborated compiling available original quantitative experimental data on the subject. The corresponding literature can roughly be assorted in three categories. Exclusively data of such studies are considered in the diagrams where either quantitative information on the experimentally determined chunky graphite share had been provided by the authors (category 1), $9,20,73,82,91-93,101$ or the author of this article had been able to deduce qualified estimates based on the information given (category 2). ${ }^{8,14,66}$ Investigations belonging to category $3,{ }^{47,102,103}$ confirm the findings deduced from categories 1 and 2 but are more of a semiquantitative nature with respect to chunky graphite share and therefore not physically included in the diagrams.

\section{Strength and Ductility}

Chunky graphite widely disrupts the three-dimensional matrix continuity, thus reducing the load bearing net section of the material. Simultaneously, the notch effect of graphite is enhanced significantly compared with spheroidal graphite or even the compacted graphite shape.

The studies known to the author report that hardness and yield strength $(Y S)$ of ferritic SGI are hardly affected by chunky graphite degeneration. This finding about $Y S$ may justify the position of some design engineers not paying special attention to the chunky graphite degeneration. ${ }^{20}$ Nevertheless, this must be considered a one-dimensional and potentially dangerous view. By arguing so, the 


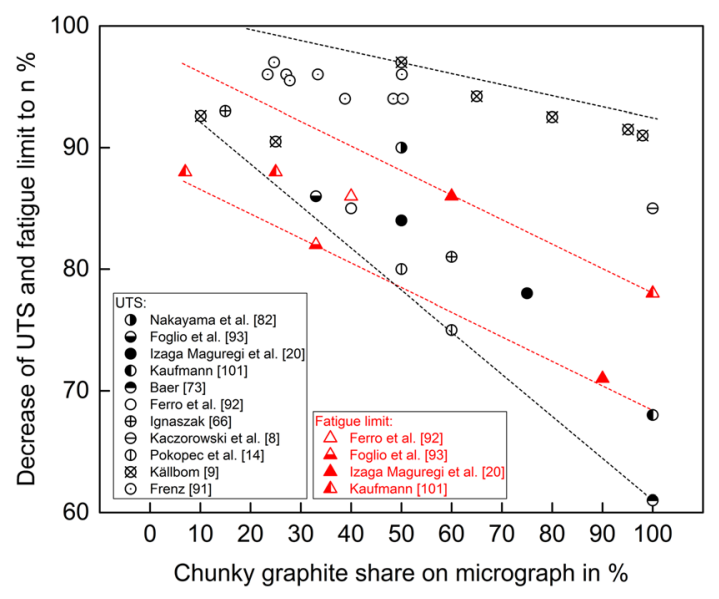

Figure 39. Ferritic SGI, Si contents $<3.5 \%$ : Decrease in ultimate tensile strength (UTS) and fatigue limit in dependence on the chunky graphite share (ratio between chunky graphite area and total graphite area on the micrograph). Note 1: The UTS data from Reference 91 are for the chunky graphite share on tensile fracture specimen surfaces. Note 2: Fatigue testing conditions: axial, ${ }^{20}$ axial, $R=0,9^{92}$ rotating bending, $R=-1,{ }^{93}$ axial, bending, $R=-1, \alpha_{K}=1.0$ and 1.1. ${ }^{101}$

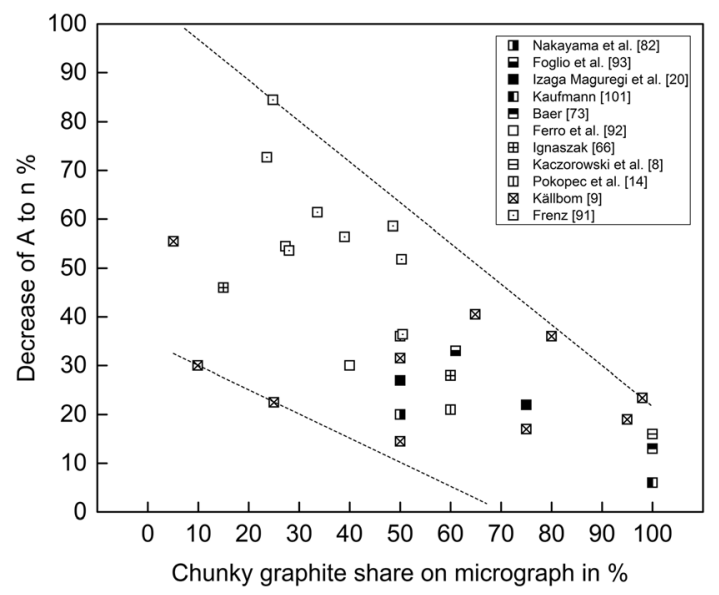

Figure 40. Ferritic SGI, Si contents $<3.5 \%$ : Decrease in elongation after fracture $(A)$ in dependence on the chunky graphite share (ratio between chunky graphite area and total graphite area on the micrograph). Note 1: The unit of the $y$-axis is percent relative to the value of the sound material, not to mix up with the common unit of the strain value $A$. Note 2: The data from Reference 91 are for chunky graphite share on tensile fracture specimen surfaces.

tremendous detrimental impact of chunky graphite on ductility, ultimate tensile strength (UTS), toughness and fatigue limit, which are important structural safety factors, is neglected.
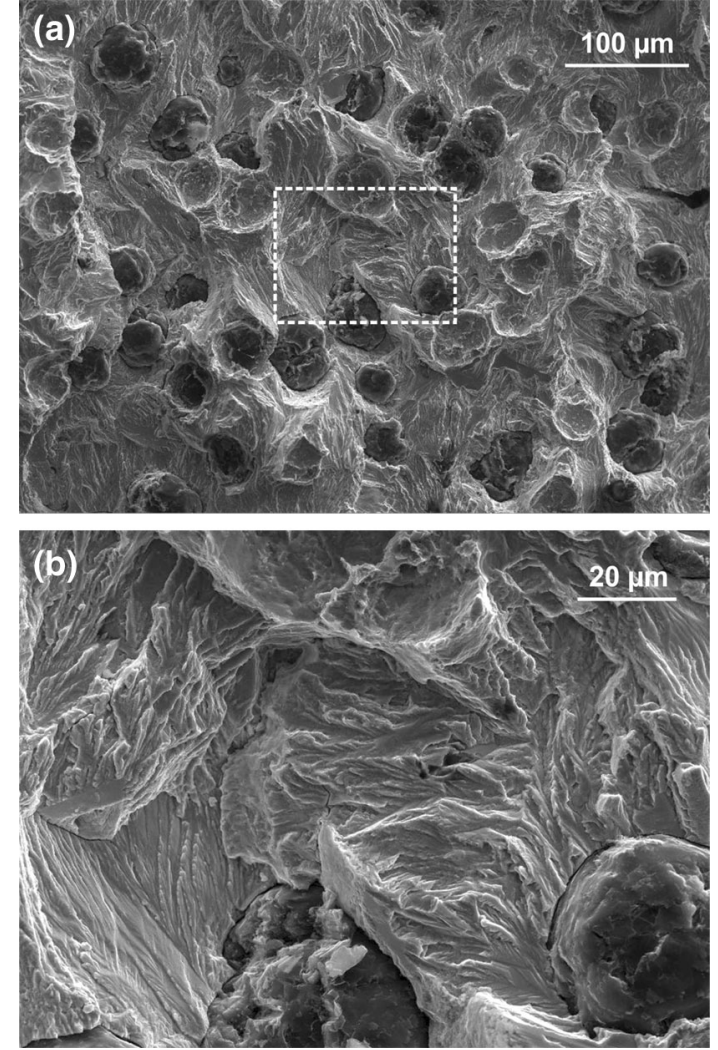

Figure 41. (a) Fatigue crack growth in ferritic SGI, SEM SE image, EN-GJS-400, (b) detail of white frame in (a). ${ }^{74}$

Figures 39 and 40 conflate information on the correlation between the chunky graphite share and mechanical properties of ferritic SGI. All data are for conventional, low Si ferritic EN-GJS-400 materials except of the results in References 9 and 82 where silicon solid solutionstrengthened SGI with $3.2-3.5 \%$ of $\mathrm{Si}$ have been investigated.

As can be seen from Figure 39, UTS continuously decreases to a level of 60 to $90 \%$ of the sound materials value with the chunky graphite share increasing to $100 \%{ }^{8,9,14,20,47,66,73,82,91-93,101}$ While the scatter of the data is large, the trend is clear. Furthermore, it should be kept in mind that the statistical basis of the datum points in Figures 39 and 40 is mostly humble. Likewise, the data of Reference 91 are available only for the chunky graphite share on tensile fracture specimen surfaces which is usually bigger than on micrographs. But even taking the latter feature into account, the data of Reference 91 match very well to the scatter band. The fatigue limit which is displayed in Figure 39 as well is discussed in more detail in the next subchapter.

Ductility in terms of elongation after fracture $(A)$ (Figure 40) is much more susceptible to chunky graphite degeneration than UTS and almost vanishes with $100 \%$ of 

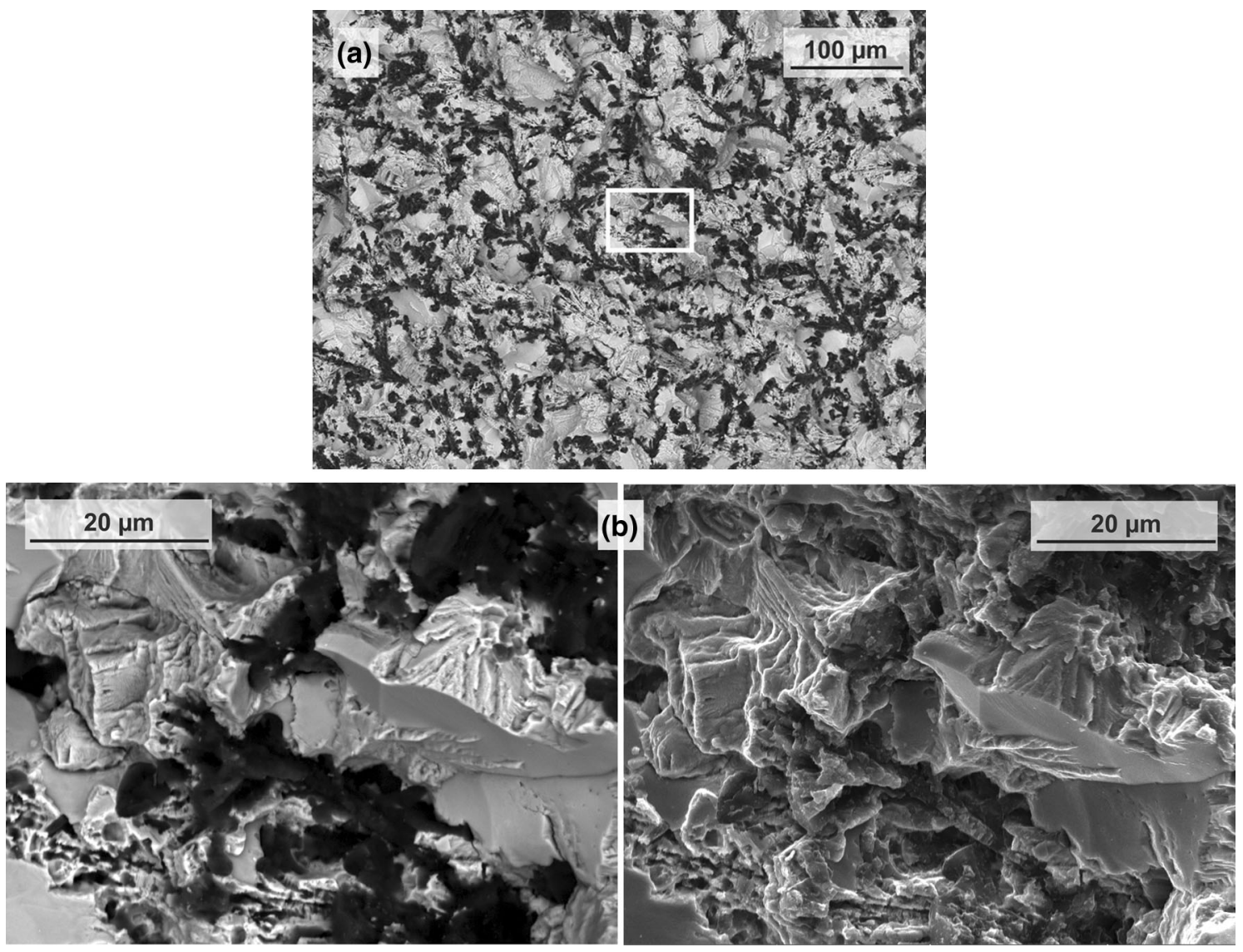

Figure 42. (a) Fatigue crack growth in ferritic SGI containing chunky graphite degeneration, SEM BSE image, (b) detail of white frame in (a) with SEM BSE image left and SE image right.

chunky graphite. $1,3,8,9,14,20,47,49,51,66,73,82,91-93,101-103$ Consequently, premature failure of the whole chunky graphite affected region in a component may arise, ${ }^{1,8,47,82}$ and cleavage fracture in areas otherwise consisting exclusively of ferrite and graphite nodules is promoted. ${ }^{82,91,92,102,103}$

The fundamental correlations between chunky graphite and strength as well as ductility demonstrated for low Si ferritic SGI have been confirmed in Reference 52 for silicon contents up to $4.0 \%$. However, the sensitivity to chunky graphite is much less prevalent at Si contents higher than this value. Chunky graphite apparently does not show a significant effect on UTS and YS in SGI with Si contents higher than $4.0 \%$. However, it has a negative effect on $A$. Ductile rupture in areas containing nodules and partly even those containing chunky graphite has been reported for medium Si levels of about 3.9-4.6\% and corresponding chunky graphite contents of $19 \%$ and $43 \%$, respectively. It is suggested in Reference 52 that this different behavior to SGI materials with low $\mathrm{Si}$ contents is due to the matrix strengthening effect of $\mathrm{Si}$ which overtakes the detrimental effect of chunky graphite at Si contents higher than $4.6 \% .^{52}$

\section{Fatigue Limit and Fatigue Crack Growth Rate}

Basically, the notch sensitivity of ferritic SGI containing chunky graphite is enhanced due to its reduced ductility. Local areas with chunky graphite can act as initiation spots for microcracks. ${ }^{20}$ The interconnected spatial structure of chunky graphite then leads to facilitated crack growth in fatigue tests and subsequently a substantial reduction in the fatigue limit. In addition, areas with spheroidal graphite being socialized with chunky graphite may show a decreased nodularity level, ${ }^{102}$ while there is evidence for a non-influenced nodularity level in those areas as well. ${ }^{92}$ Notwithstanding that, reduced nodularity may give an additional boost to the decrease in fatigue limit, while chunky graphite acts as the major influence. ${ }^{102}$

The low strength associated with graphite particles makes them mechanically equivalent to defects or holes, ${ }^{104}$ and the fatigue crack growth mechanism in cast iron changes due to the presence of chunky graphite. With spheroidal graphite morphology, cracks usually grow through the matrix trans-granularly passing around the graphite nodules and following the graphite-matrix interface ${ }^{84,105-109}$ (Figure 41$){ }^{74}$ In contrast, cracks penetrate into agglomerates of interconnected chunky graphite, thus tracking weak areas 

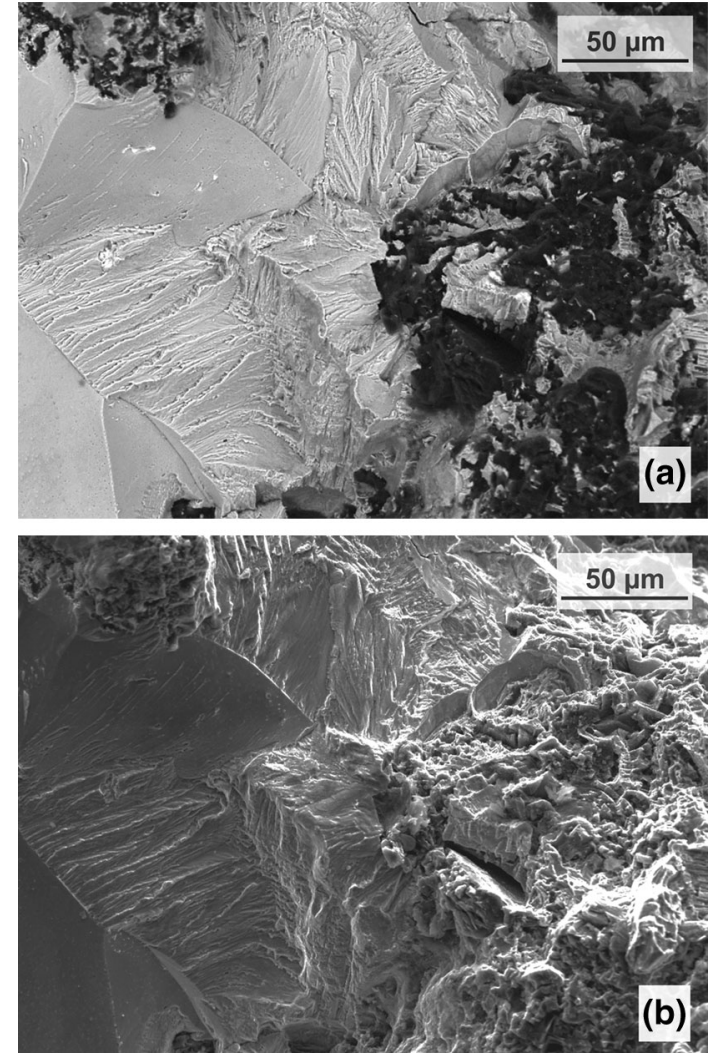

Figure 43. Fatigue striations on the fracture surface of a ferritic SGI specimen containing chunky graphite degeneration, (a) SEM BSE image, (b) SEM SE image.

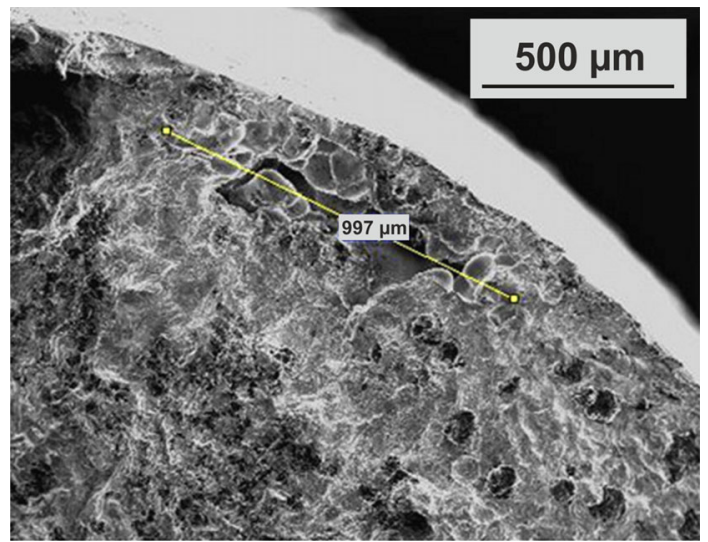

Figure 44. Near surface microporosity that initiated the fatigue crack in a SGI test specimen containing chunky graphite degeneration. The graphite in the area around the microporosity is nodular. Chunky graphite can be seen down left in the SEM SE image (area in darker gray). Reprinted by permission from Elsevier. ${ }^{93}$

with high graphite concentration ${ }^{92,93,102}$ (Figure 42). In chunky graphite-free ferrite grains, typical fatigue striation patterns can be observed (Figure 43).

Hampering of crack growth due to blunting of the crack tip by graphite nodules acting like big voids on the path has not been observed with chunky graphite. The main effect of chunky graphite on the fatigue life is to be a preferential path for crack propagation in comparison with the areas containing spheroidal graphite. ${ }^{93}$

Attention should be paid to microporosity (also called micro-shrinkage) which may dominate and hide the impact of chunky graphite. ${ }^{92}$ Actually, micro-shrinkage cavities were found to be the exclusive ${ }^{93}$ or dominant ${ }^{110-112}$ initial defects for fatigue cracks. This was observed independently from the presence and amount of chunky graphite and independently of whether the cavities had been surrounded by spheroidal or by chunky graphite (Figure 44).

It is consensus that the fatigue limit of SGI components is basically controlled by casting defects when the graphite morphology itself is spheroidal as designed. ${ }^{4,113-118}$ More precise, it is outlined in Reference 119 that the size of the microporosities must be at least as big as the size of the graphite nodules to take over and dominate crack initiation. Otherwise, large graphite particles, especially when they are placed at or near the surface and when deviating from the spheroidal shape, act as crack initiation spots. Experimental evidence on bigger cavities (shrinkage) heavily influencing the fatigue strength has been provided in Reference 101 as well as Reference 120. It is worth noting that Reference 101 is a comprehensive, systematic study on the influences of microstructural casting imperfections like dross, microporosity and chunky graphite on the fatigue strength of ferritic SGI. For size classification purposes of the cavities, the system according to ASTM E $802^{121}$ and ASTM E $186^{122}$ had been adopted in Reference 101. The bigger the cavity and the closer it is placed to the specimen surface, the lower is the fatigue limit. A fatigue limit decrease of approximately $50 \%$ has been observed for the biggest surface-sectioned cavity class CC 5 compared to the sound material (bending, $R=-1, \alpha_{K}=1.1$ ).

Thus, when the total fatigue life including the crack initiation and crack propagation stages is considered, a synergistic effect of both features, microporosity and chunky graphite, resulting in a reduced fatigue limit can be assumed. Both detrimental effects are worth to be considered holistically. This is due to the experience that unfavorable casting and solidification conditions can easily induce enhanced microporosity simultaneously accompanied by chunky graphite degeneration.

A more quantitative approach to the fatigue life of SGI components can be followed when it is acknowledged that the fatigue behavior is not primarily governed by the type of defect but by its geometry and position. ${ }^{123}$ Early studies focusing on the graphite morphology effect on the fatigue behavior of SGI proposed straightforward prediction models considering fatigue strength in dependence on the Vickers hardness and the mean diameter of the graphite nodules. ${ }^{124-126}$ Focusing the effects of small defects and 
nonmetallic inclusions on the fatigue strength, a widely used model was proposed in Reference 127. It is based on experiments and considers the effects of the square root of the maximum projected defect area $(\sqrt{\text { area }})$ onto the principle stress plane and the Vickers hardness on the fatigue limit. Based on References 124-127, a novel quantitative correlation between size, distance as well as the relative position of graphite particles and the fatigue limit has been developed in Reference 128. Likewise References 112, 128 and 129, considered the square root area model from Reference 127 and adapted it to SGI.

Several investigations ${ }^{20,92,93,101,102}$ indicate that the relative decrease in the fatigue limit due to chunky graphite seems to be approximately equivalent to the UTS reduction (Figure 39). This was observed independently from the type of fatigue loading. Furthermore, the comparison of References 20, 92, 93 and 101 with Reference 102 exhibits that the detrimental influence of chunky graphite is enhanced the higher the strength and the lower the ductility of the metallic matrix get due to the matrix changing from ferrite to pearlite. Therefore, from the practical fatigue design point of view, the proposal was made for heavysectioned ductile irons to account for the presence of chunky graphite by simply considering the decrease in fatigue limit equivalent to the UTS reduction. ${ }^{93}$ Nevertheless, since the chunky graphite distribution is extremely uneven inside a casting and the experimental database of Figure 39 is fairly limited, the trends in Figure 39 must be rated vague from a quantitative point of view at the present stage. Additional investigations should provide deeper insight here before any application within component assessment could be considered.

Based on data of Reference 101, Figures 45 and 46 outline the influences of chunky graphite, notch acuity and mean stress on the fatigue limit of ferritic SGI also incorporating

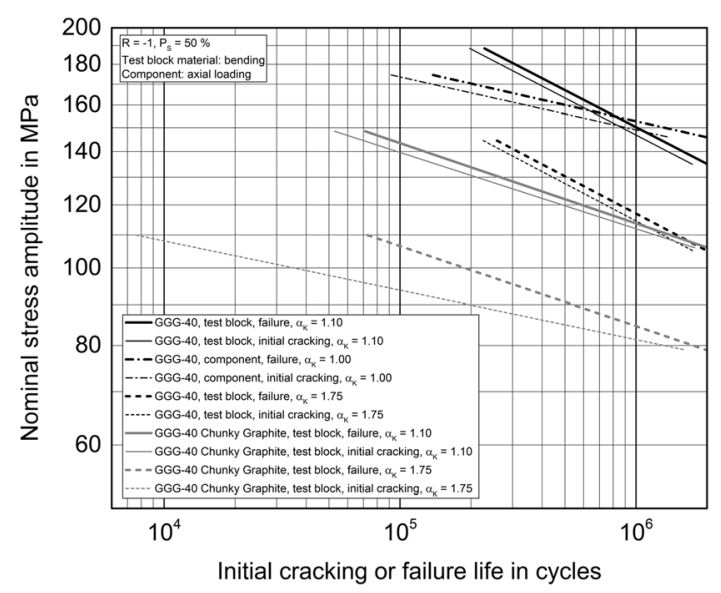

Figure 45. S-N curves for ferritic SGI GGG-40 and GGG40 containing $100 \%$ chunky graphite, bend and axial loading, $R=-1, P_{S}$-probability of survival, data from Reference 101. the curves for initial cracking (crack initiation). As far as concerning the effect of external notches, it has been observed in Reference 101 that an increase in notch factor from $\alpha_{K}=1.1-1.75$ induced a drop of the fatigue limit of approximately $25 \%$. This counts additionally to the drop by chunky graphite degeneration which had been $22 \%$ (Figure 39).

Another challenging and currently unsolved problem regarding a reliable experimental property characterization of components containing chunky graphite reveal the investigations in Reference 101. A summary of corresponding fatigue data is given in Figure 47. The fatigue strength data achieved in Reference 101 with specimens directly extracted from the investigated casting containing $7-25 \%$ chunky graphite exhibited extraordinarily high scatter. The root cause is to be seen in distinct local microstructure variations. It is emphasized in Reference

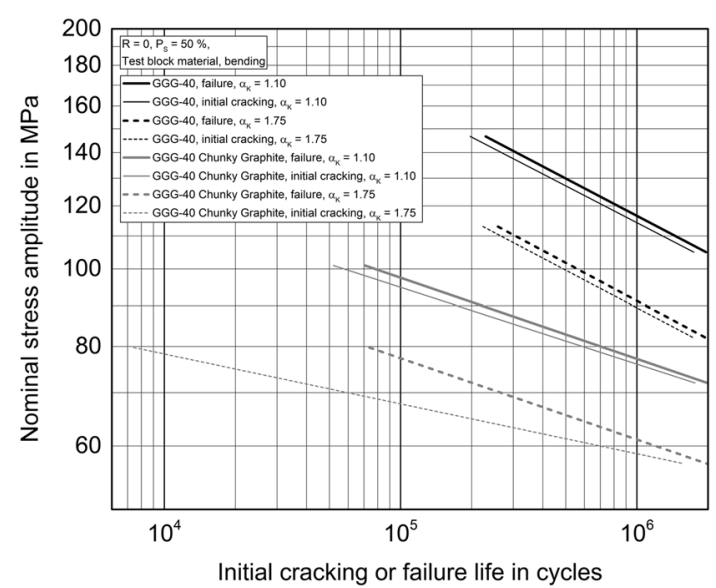

Figure 46. S-N curves for ferritic SGI GGG-40 and GGG40 containing $100 \%$ chunky graphite, bending, $R=0$, $P_{S}$-probability of survival, data from Reference 101.

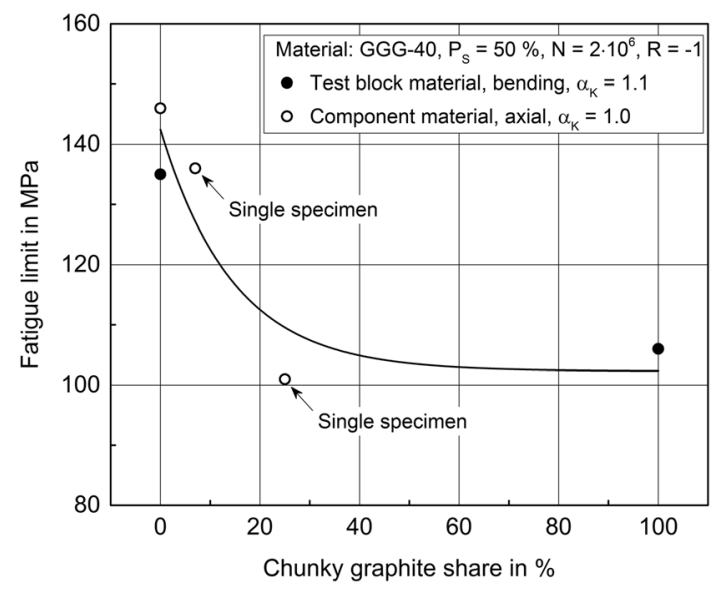

Figure 47. Influence of chunky graphite on the fatigue limit of ferritic nodular cast iron GGG-40, $P_{s}$-probability of survival, $N$-number of load cycles, $\alpha_{K}$-notch factor, after Reference 101. 
101 that those scattering and statistically irrelevant type of data should not be used for fatigue design purposes. Instead, data from $100 \%$ chunky graphite microstructure might perform conservatively.

In terms of fracture mechanics, the resistance of SGI to stable crack extension under cyclic loading can be expressed as fatigue crack growth rate depending on the crack tip stress intensity factor range, $\mathrm{d} a / \mathrm{d} N$ versus $\Delta K$. Details of the experimental method can be looked up in relevant test standards, e.g., ASTM E 647. ${ }^{130}$ Two published studies have been identified dealing with the influence of chunky graphite on the fatigue crack growth rate in SGI. ${ }^{101,131}$ Both investigations can be traced back to the same casted 600-mm-thick SGI block containing 100\% of chunky graphite in its central region. Figures 16 and 17 show examples of the corresponding microstructure. Compared to sound ferritic SGI qualities, References 101, 131 consistently show a significant increase in crack growth rate due to chunky graphite of up to nearly a decade at higher stress intensity values (Figure 48). At the same time, the fracture toughness in terms of $\Delta K_{\mathrm{fc}}$, respectively, $K_{c}$ is decreased distinctly.

The comparison of the results from References 101 and 131 reaffirms a basic problem with the investigation of SGI containing chunky graphite which had already been pronounced earlier in this article. Although nominally identical material with $100 \%$ chunky graphite originating from the same block has been investigated, the results in terms of $\mathrm{d} a / \mathrm{d} N-\Delta K$ curves differ significantly (Figure 48 ). The main root cause is again likely to be seen in the notable heterogeneous structure of chunky graphite itself, high local scatter of microstructure and a comparatively poor experimental statistical basis. Local microstructural

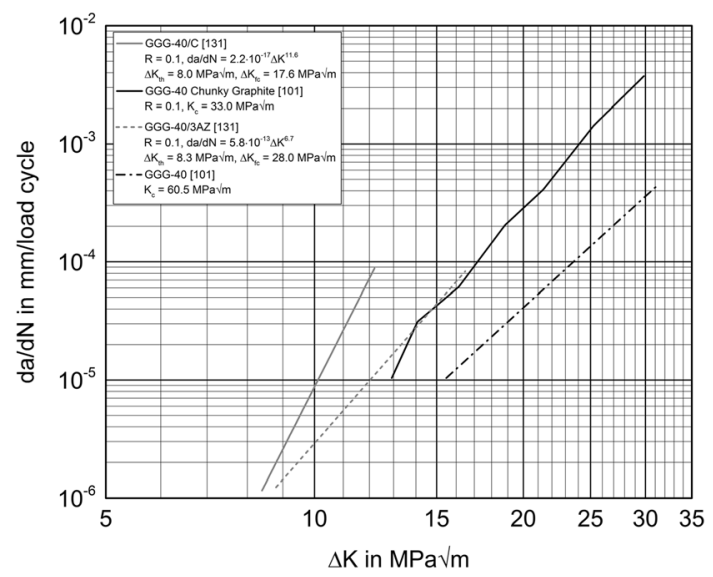

Figure 48. Fatigue crack growth rate as a function of crack tip stress intensity factor range, da/dN versus $\Delta K$, for ferritic SGI materials containing chunky graphite compared with sound SGI materials GGG-40/3AZ and GGG-40: GGG-40/C, 100\% chunky graphite, $S E(B) 10$ specimens, $R=0.1 ;{ }^{131}$ GGG-40 Chunky Graphite, $100 \%$ chunky graphite, $C(T) 24$ specimens, $R=0.1^{101}$ heterogeneities may even cause discontinuous $\mathrm{d} a / \mathrm{d} N-$ $\Delta K$ curves as reported in Reference 101 (Figure 48).

Thus, it becomes evident again that a qualitative or semiquantitative description of the microstructure locally revealed by polished sections cannot be adequate for a systematic understanding nor consideration of the impact of chunky graphite on the material properties.

\section{Fracture Toughness}

While there is qualitative consensus about chunky graphite detrimentally affecting the toughness of SGI, published studies $^{73,91,103,131}$ containing quantitative fracture mechanical data considering chunky graphite degeneration are rare.

From the viewpoint of fracture mechanism, chunky graphite promotes a change in fracture mode from ductile to brittle fracture. Consequently, brittle fracture can appear even under moderate loading conditions (room temperature, quasi-static fracture mechanics test) ${ }^{73,103}$ (Figure 49). Chunky graphite weakens the ferritic matrix and suppresses
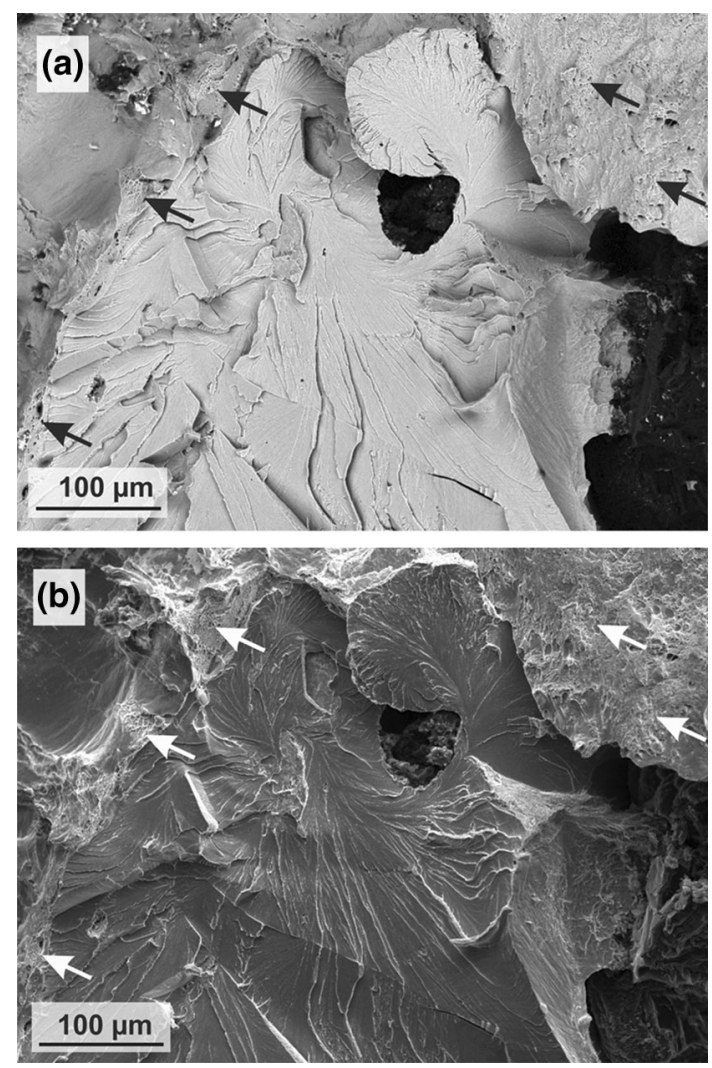

Figure 49. Brittle fracture within the area of stable crack growth on the fracture surface of a $S E(B) 10$ fracture mechanics specimen, ferritic SGI (Si content $2.33 \%$ ) containing chunky graphite (black color in figure a)), quasi-static loading, room temperature, (a) SEM BSE and (b) SEM SE contrast technique, black/white arrows mark dimple areas representing ductile fracture. 
or at least hinders plasticity-induced, energy-consuming ductile damage processes which normally occur during ductile cracking in the sound material. Ductile damage typically covers debonding of graphite nodules from the matrix, void growth, void coalescence and formation of microcracks by shear of ferrite matrix bridges. A corresponding behavior applies to uniaxial tensile testing which has been discussed earlier in this article.

Fracture mechanics testing of SGI containing defects and/ or graphite degenerations is experimentally challenging. The specific fracture behavior of the affected cast material may cause features like non-uniform crack growth and local brittle events-so-called pop-ins-which frequently

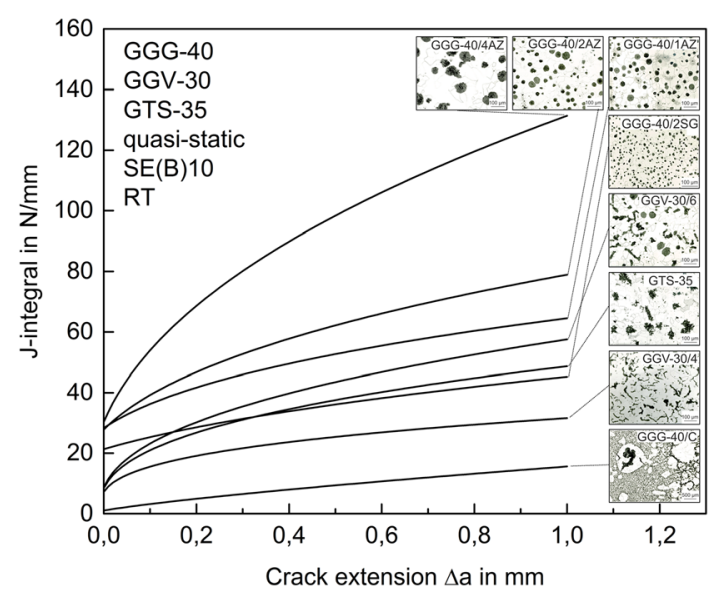

Figure 50. Crack resistance curves of ferritic nodular cast iron materials with varying graphite morphology (GGG-40) including malleable (GTS) and compacted (GGV) graphite cast iron, quasi-static loading, $S E(B) 10$, $20 \%$ side grooving, room temperature, data from Reference 73.

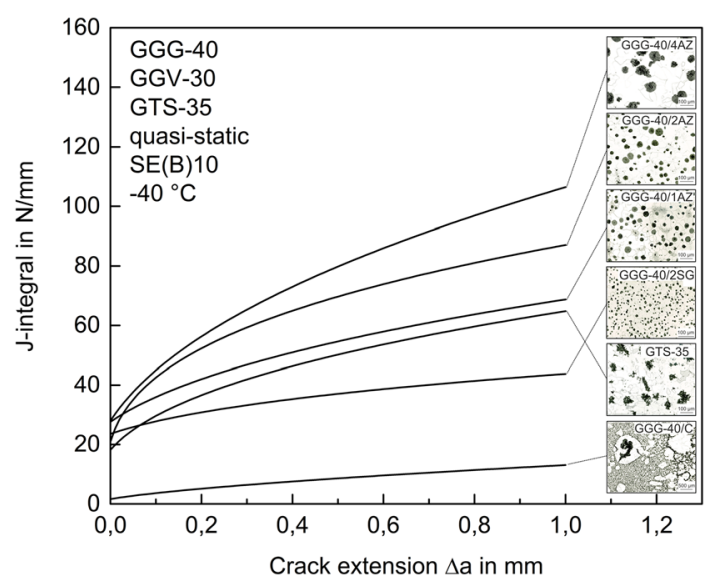

Figure 51. Crack resistance curves of ferritic nodular cast iron materials with varying graphite morphology (GGG-40) including malleable (GTS) cast iron, quasistatic loading, $S E(B) 10,20 \%$ side grooving, $-40^{\circ} \mathrm{C}$, data from Reference 73. result in nonconformance with regulations of the testing standards. Thus, the worst-case scenario that valid fracture mechanical material characteristics cannot be determined at all may easily become real. The problem comes to a head since normally only a rather limited portfolio of specimens is available.

The influence of approximately $100 \%$ chunky graphite on the crack resistance behavior of ferritic SGI is considered in Figures 50 and $51 .^{73}$ For comparison, several cast iron materials with varying graphite morphology including malleable and compacted graphite are included. As can be seen, the crack resistance of SGI in terms of crack initiation toughness and crack growth resistance is significantly influenced by the graphite morphology. While the toughness of compacted graphite iron is already shifted to a significantly reduced level compared to spheroidal graphite, the material containing chunky graphite is characterized by a further deterioration ending up at a rudimentary low degree of toughness. It is worth noting that the material GGG-40/C in Figures 50 and 51 origins from the same block as the chunky graphite material of Reference 101 which has already been discussed above considering fatigue properties.

In order to characterize the influence of the graphite morphology on the toughness of cast iron quantitatively, graphite morphology data have been correlated with the crack initiation toughness. Figure 52 displays the crack initiation toughness parameter $J_{i E P}$ as function of the product of the mean distance of graphite particles $\lambda$ and their shape factor $f .^{73,132}$ Figure 52 takes the influence of the ductile matrix (the larger the particle distance, the more the energy consumption by matrix plasticity is possible) and the notch effect of graphite (the more the $f$ deviates from unity, the

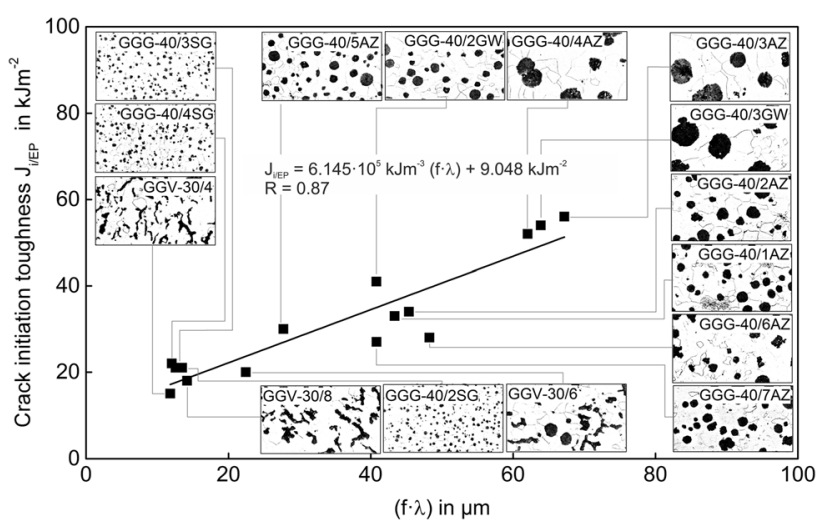

Figure 52. Crack initiation toughness $J_{i / E P}$ as function of the product of the mean distance of graphite particles, $\lambda$, and the particle shape factor, $f$, $(0<f<1$, for a sphere holds $f=1$ ), ferritic cast iron materials, room temperature, quasi-static loading, $S E(B) 10$ specimen, $20 \%$ side grooving $\left(J_{i / E P}\right.$ is determined using the direct current electric potential drop technique, DCPD. $J_{i / E P}$ is close to the physical crack initiation.). ${ }^{73}$ 


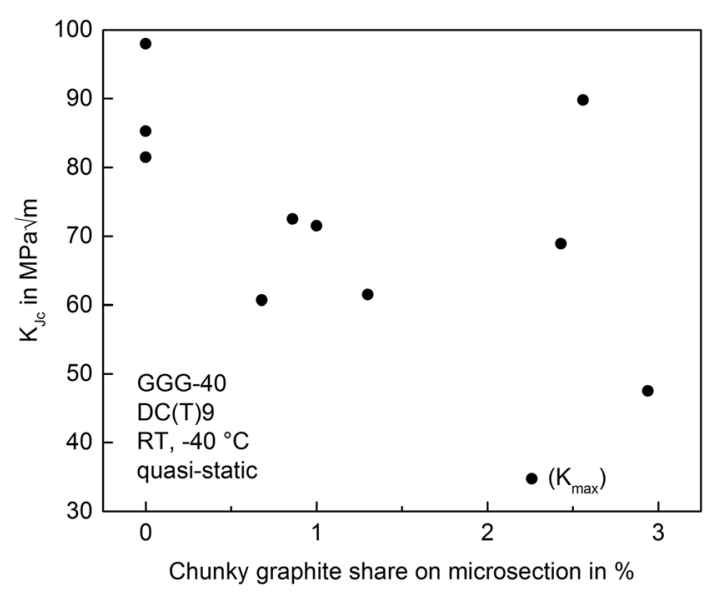

Figure 53. Fracture toughness $K_{J c}$ of nodular cast iron containing chunky graphite as function of the chunky graphite share on microsections behind the fracture surface of disk-shaped compact specimens $D C(T) 9$, $K_{J C}$-fracture toughness converted from J-integral at crack initiation, $K_{\max }-s t r e s s$ intensity at onset of instable fracture, quasi-static loading, room temperature and - $40{ }^{\circ} \mathrm{C}$, data from Reference 91.

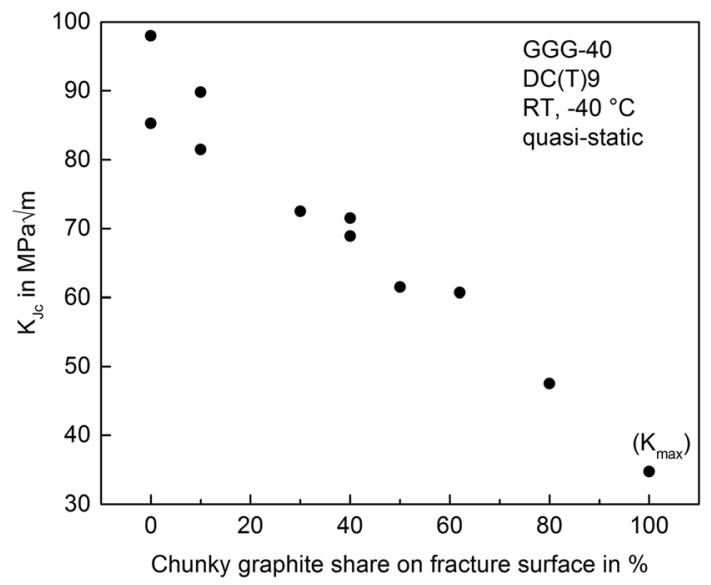

Figure 54. Fracture toughness of nodular cast iron containing chunky graphite as function of the chunky graphite share on the fracture surface of disk-shaped compact specimens $D C(T) 9$ (measured as line share of a line across the specimen thickness right in front the fatigue pre-crack), $K_{J C}$-fracture toughness converted from J-integral at crack initiation, $K_{\max }$-stress intensity at onset of instable fracture, quasi-static loading, room temperature and $-40^{\circ} \mathrm{C}$, data from Reference 91.

more pronounced is the notch effect) simultaneously into account. Originally, this approach goes back to Ritchie's void growth model. ${ }^{133}$ Further models ${ }^{134-136}$ are basically in line with Figure 52 but incorporate mechanical properties such as yield strength and elongation after fracture. When Figures 50 and 51 are recalled, ferritic SGI containing CHG should be expected in Figure 52 somewhere next to the origin of the chart. But since the morphology of CHG cannot be accessed by simple microstructural parameters as has been demonstrated earlier in this article,

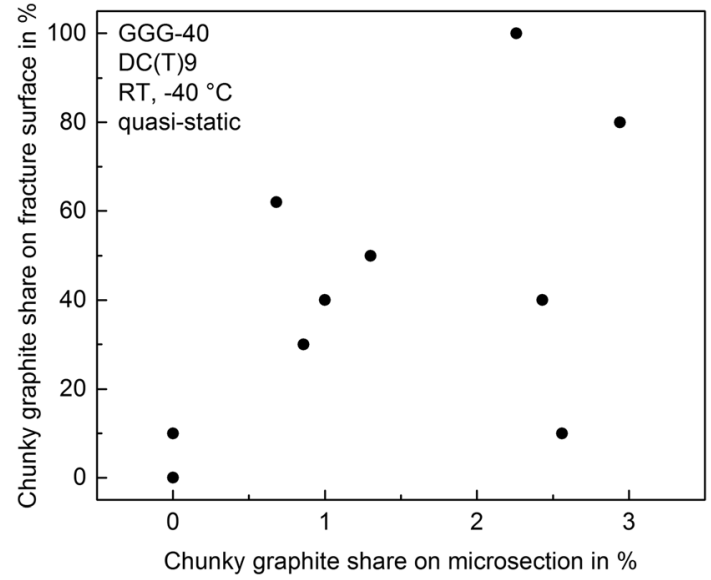

Figure 55. Chunky graphite share determined on the fracture surface versus chunky graphite share determined on microsections of a fracture mechanics specimen, disk-shaped compact specimen $D C(T) 9$, quasistatic loading, room temperature and $-40^{\circ} \mathrm{C}$, data from Reference 91.

attempts to upgrade the correlation in Figure 52 by covering CHG too must fail.

Results from Reference 91 highlight the detrimental effect of chunky graphite on the fracture toughness as well (Figures 53 and 54). Although the investigated material nominally contained a chunky graphite share with a maximum of only $3 \%$ of the total microstructure, sudden failure by brittle fracture was observed when approximately $100 \%$ of chunky graphite was exposed by the crack path on the fracture surface. Thus, the quasi-static fracture toughness decreased from close to $100 \mathrm{MPa} \sqrt{\mathrm{m}}$ to the remarkably low value of $36 \mathrm{MPa} \sqrt{\mathrm{m}}$ at room temperature.

It became especially obvious in Reference 91 that the fracture toughness of SGI containing chunky graphite does not correlate with the chunky graphite share determined on microsections behind the fracture surface of fracture mechanics specimens (Figure 53) but with the chunky graphite share determined on the fracture surface (Figure 54). The latter is only accessible postmortem and was measured along a line across the specimen thickness in front of the fatigue pre-crack, the former as share of the total observed microsection area.

A correlation between the chunky graphite shares on microsections and fracture surfaces, respectively, could not be established (Figure 55). As far as concerning practical issues of component assessment, this is quite important a result. It means that fracture toughness and crack resistance of SGI containing chunky graphite cannot be predicted by analyzing chunky graphite shares on microsections.

On the other hand, this is not very much surprising when the heterogeneous three-dimensional microstructure of chunky graphite-as outlined in chapter 4-is recalled. 
The achievable fracture toughness is essentially governed by the chunky graphite configuration which is randomly locally present in the ligament of the specimen or the position of interest in the component, e.g., Figure 34. While fracture mechanics specimens feature a mechanical pre-notch and mostly side grooves, tensile specimens are characterized by a smooth and quite large, elongated test section subjected to a uniform stress state. Therefore, with respect to the maximally stressed material volume, the fracture mechanics specimen is much more locally focused than a tensile specimen and thus producing bigger scatter of test results.

\section{Summary}

The following overall picture of chunky graphite in ferritic SGI emerges when the current published state of knowledge is briefly summarized.

Although several theories on the formation and growth of chunky graphite in SGI have been proposed, a universal, generally accepted explanation has not yet been established. Considering the present state of knowledge, a condensed baseline concerning formation and growth of chunky graphite in heavy-sectioned SGI castings was drawn.

The appearance of chunky graphite in SGI is controlled by numerous, frequently interacting metallurgical factors. The chemical composition, solidification rate and nucleation have been identified as major influence factors. Developing quantitative rules to prevent chunky graphite has proved to be complex, and their practical impact has been limited due to narrow validity windows. It is established that the avoidance of chunky graphite in heavy sections cannot yet be rated a hundred percent process safe. Facing partly controversial results and the big scatter of literature data, no specific numbers of recommended chemical element contents, temperatures, etc., can be emphasized in this overview. Nevertheless, a reference line for preventive actions in terms of general metallurgical and process measures could be drawn to avoid chunky graphite in heavy-sectioned ferritic SGI castings. Among others, the most relevant measures reported to be effective against chunky graphite formation are increase in cooling rate, reduction in silicon content, control of trace elements and addition of specific alloying elements.

As far as concerning the morphology of chunky graphite, a comprehensive qualitative knowledge has especially been obtained by fractographic studies, deep etching and modern tomographic techniques. Thus, the characteristic filigree three-dimensional string-like, multi-branched chunky graphite structure has been revealed. A lesson learned is that within the analysis of 2d-metallographic sections, the risk of mix-up with graphite degenerations other than chunky or other regular graphite forms should be considered. The published literature leads to the conclusion that it has not yet been possible to establish tools nor technical procedures for quantitatively determining the volumetric share of chunky graphite in castings on a daily use basis. Recalling that appropriate reliable nondestructive testing methods for chunky graphite detection in castings have not yet been established either, the problem of how to reliably assess the impact of chunky graphite on the components service properties must currently be considered unsolved.

The present situation is congruously characterized by doubts and discussions about the acceptance or rejection of SGI components containing chunky graphite. Driven by this, the state of knowledge about the impact of chunky graphite on properties of SGI has been analyzed and systematized based on published original experimental data.

Hardness and yield strength of ferritic SGI with Si contents lower than approximately $3.5 \%$ are hardly affected by chunky graphite degeneration. On the contrary, UTS continuously decreases with increasing $\mathrm{CHG}$ amount and ductility in terms of elongation after fracture is extremely susceptible to chunky graphite. As reported with alloys containing $\mathrm{Si}$ contents above approximately $4.0 \%$, the sensitivity to chunky graphite is much less prevalent due to the Si solution strengthening effect.

When it comes to cyclic loading, chunky graphite causes a substantial reduction in fatigue limit and a significant increase in crack growth rate.

Probably the most detrimental effect of chunky graphite can be attributed to its reduction in the materials toughness. Even with quasi-static loading at room temperature, chunky graphite promotes a change in fracture mode from ductile to brittle fracture. A very important lesson learned is that the fracture toughness of SGI containing chunky graphite does not correlate with the chunky graphite share determined on $2 \mathrm{~d}$-microsections but with the chunky graphite share finally, postmortem revealed on the fracture surface. The achievable fracture toughness is essentially governed by the chunky graphite configuration which is randomly locally present in the ligament of the specimen or at a loading hotspot in a component. Thus, due to the nonisometric, non-dispersed structure of chunky graphite, the fracture toughness and crack resistance of SGI containing chunky graphite cannot be predicted by analyzing chunky graphite shares on microsections. At the most, an assumed share of $100 \%$ of chunky graphite could be used for a conservative assessment when any indication of chunky graphite is present. Nevertheless, not even the latter scenario is presently realistic since statistically safeguarded correlations between the chunky graphite share and material properties are not available. 
At this stage, due to the high safety and quality requirements established in many cases as well as the economic impact of complex heavy SGI castings, neither customers nor certification bodies would be able to bear the inherent risk being related to chunky graphite. Current international SGI material standards do not provide solutions either since they have not yet been dealing with chunky graphite at all. Therefore, the only current safe operational strategy appears to be aware of the origins of chunky graphite, metallurgically optimize the production and avoid chunky graphite completely otherwise strictly not tolerating it.

As long as nondestructive detection and characterization methods for chunky graphite will not be established and available in regular production, the only way in quality control to estimate if a casting is affected by chunky graphite seems to be to cut samples out of it at critical positions located by thorough casting simulations and to examine them.

\section{Acknowledgements}

The author gratefully acknowledges the outstanding contributions of the following BAM colleagues: Dr. Fabien Léonard who performed and analyzed the synchrotron X-ray tomography measurements as well as Katrin Ohm and Michaela Buchheim who carried out metallographic and fractographic SEM investigations. Special thanks to Peter Wossidlo for fracture mechanics testing.

Open Access This article is distributed under the terms of the Creative Commons Attribution 4.0 International License (http://crea tivecommons.org/licenses/by/4.0/), which permits unrestricted use, distribution, and reproduction in any medium, provided you give appropriate credit to the original author(s) and the source, provide a link to the Creative Commons license, and indicate if changes were made.

\section{REFERENCES}

1. M. Gagné, C. Labrecque, Microstructural defects in heavy section ductile iron castings: formation and effect on properties. AFS Trans. 2009, paper 09-101, pp. 561-571

2. H. Löblich, Einfluss der Keimbildungsbedingungen auf die Entstehung von Chunky-Graphit in dickwandigem Gusseisen mit Kugelgraphit EN-GJS. Giesserei 93(6), 28-41 (2006)

3. C. Hartung, O. Knustad, K. Wardenaer, Chunky graphite in ductile iron castings - theories and examples, in 8th International Foundrymen Conference, Opatija, Croatia, June 5-7 (2008)

4. M. Shirani, G. Härkegard, Fatigue life distribution and size effect in ductile cast iron for wind turbine components. Eng. Fail. Anal. 18, 12-24 (2011)
5. H. Roedter, M. Gagné, Ductile iron for heavy section wind mill castings: a European experience, in Proceedings of the Keith D. Millis World Symposium on Ductile Iron, Crown Plaza Resort, Hilton Head, South Carolina, October 20-23, (2003), 8 pages

6. U. Petzschmann, Vermeidung von Chunky-Graphit in dickwandigen Gussstücken aus Gusseisen mit Kugelgraphit, Final report AiF-Vorhaben 16801 N, Institut für Gießereitechnik, Düsseldorf (2013)

7. J. Lacaze, I. Asenjo, S. Mendéz, J. Sertucha, P. Larranaga, R. Suárez, Experimental evidence for metallurgical modification associated to Chunky graphite in heavy section ductile iron castings. Int. J. Metalcasting/Winter, pp. 35-41 (2012)

8. J. Kaczorowski, K. Jozwiak, M. Innocenti, Cast iron casing cracking due to chunky graphite formation. J. Fail. Anal. Prev. 13, 445-450 (2013)

9. R. Källbom, Chunky Graphite in heavy section ductile iron castings. Thesis for the degree of Licentiate of Engineering, Chalmers University of Technology, Göteborg, Sweden (2006)

10. M. Gagné, C. Labreque, A. Javaid, Effect of wall thickness on the graphite morphology and properties of D5-S austenitic ductile iron. Trans. Am. Foundry Soc. 115, 1-11 (2007)

11. Y. Kawada, H. Kato, Y. Nagai, R. Morimoto, Change in ultrasonic characteristics with chunky graphite existing in spheroidal graphite cast iron. J. JFS 76(2), 93-97 (2004)

12. W. Maschke, Chunkygrafit - sein Auftreten und seine Vermeidung. Giesserei 12, 36-41 (2015)

13. H. Löblich, Einfluss der Keimbildungsbedingungen auf die Entstehung von Chunky-Graphit in dickwandigem sowie legiertem Gusseisen mit Kugelgraphit GJS, Final report AiF-Forschungsvorhaben Nr. 13696 N/1, Bericht E-317, Institut für Gießereitechnik, Düsseldorf (2005)

14. I.M. Pokopec, P. Mrvar, B. Bauer, Effect of inoculation on the formation of chunky graphite in ductile iron castings. Mater. Technol. 51(2), 275-281 (2017)

15. R. Källbom, K. Hamberg, L.E. Björkegren, Chunky graphite in ductile iron castings, World Foundry Congress, Harrogate, United Kingdom, 4-7 June 2006, pp. 184/1-184/8

16. U. De la Torre, J. Lacaze, J. Sertucha, Chunky graphite formation in ductile cast irons: effect of silicon, carbon and rare earth. Int. J. Mater. Res. 107(11), 1041-1050 (2016)

17. B. Pustal, A. Bührig-Polaczek, Physico-chemical causes of the formation of chunky graphite in austenitic ductile iron. Acta Mater. 124, 137-142 (2017)

18. J. Sertucha, J. Lacaze, S. Armendariz, P. Larranaga, Statistical analysis of the influence of some trace elements on chunky graphite formation in heavy section nodular iron castings. Metall. Mater. Trans. A 44, 1159-1162 (2013)

19. H. Borgström, V. Fourlakidis, A review of side-lined Chunky graphite phenomena, in Proceedings of 10th 
International Symposium on the Science and Processing of Cast Iron-SPCI10, 10-13 Nov 2014; Mar del Plata, Argentina, 7 pages

20. J. Izaga Maguregi, R. Suarez Creo, J.A. Goni Güemes, Failures on components in service, fatigue loads and presence of chunky graphite, in Proceedings of 66th World Foundry Congress, Casting technology -5000 years and beyond, vol. 2, Istanbul, Sep. 6-9 (2004), pp. 953-962

21. D.M. Stefanescu, G. Alonso, P. Larranaga, E. De la Fuente, R. Suarez, Reexamination of crystal growth theory of graphite in iron-carbon alloys. Acta Mater. 139, 109-121 (2017)

22. J. Lacaze, Trace elements and graphite shape degeneracy in nodular graphite cast irons. Int. J. Metalcasting 11(1), 44-51 (2017)

23. M.K. Bjerre, In-situ observations of graphite formation during solidification of cast irons, $\mathrm{PhD}$ Thesis, Technical University of Denmark (DTU) (2017)

24. D.M. Stefanescu, R. Huff, G. Alonso, G. Larranaga, E. de la Fuente, R. Suarez, On the crystallization of compacted and chunky graphite from liquid multicomponent iron-carbon-silicon-based melts. Metall. Mater. Trans. A 47A, 4012-4023 (2016)

25. B. Prinz, K.J. Reifferscheid, T. Schulze, R. Döpp, E. Schürmann, Untersuchung von Ursachen von Graphitentartungen bei Gußeisen mit Kugelgraphit in Form von Chunky-Graphit. Gießereiforschung 43(3), 107-115 (1991)

26. R. Källbom, K. Hamberg, L.-E. Björkegren, Chunky Graphite-Formation and Influence on Mechanical Properties in Ductile Cast Iron, VTT Symposium 237, Espoo, Finland, June 2005, 25 pages

27. J. Sertucha, J. Lacaze, R. Gonzalez-Martinez, Chunky graphite in spheroidal graphite iron: review of recent results and definition of a predicting index, in IOP Conference Series: Materials Science and Engineering, vol 529, paper 012017 (2019)

28. S.I. Karsay, E. Campomanes, Control of graphite structure in heavy ductile iron castings. Trans. AFS 78, 85-92 (1970)

29. J. Lacaze, L. Magnusson Åberg, J. Sertucha, Review of microstructural features of chunky graphite in ductile cast irons, in Proceedings of Keith Millis Symposium on Ductile Cast Iron, Nashville, TN, USA (2013)

30. P.C. Liu, C.L. Li, D.H. Wu, C.R. Loper Jr., SEM study of chunky graphite in heavy section ductile iron. Trans. AFS 91, 119-126 (1983)

31. Giesserei-Lexikon, 18. Auflage (Fachverlag Schiele \& Schön GmbH, Berlin, 2001)

32. G. Peschel, Carbon-Carbon Bonds: Hybridization (Institute of Physics, FU Berlin, Germany, 05. May 2011). https://www.physik.fu-berlin.de/einrichtun gen/ag/ag-reich/lehre/Archiv/ss2011/docs/Gina_ Peschel-Handout.pdf. Accessed 25 July 2019
33. H. Itofuji, A. Masutani, Nucleation and growth behaviour of chunky graphite. Int. J. Cast Met. Res. 13(1), 1-14 (2001)

34. H. Itofuji, H. Uchikawa, Formation mechanism of chunky graphite in heavy-section ductile cast irons. Trans. AFS 98, 429-448 (1990)

35. R. Schlüsselberger, J. Daubmeier, V. Grossmann, Long term holding of magnesium treated iron melts. Giesserei-Praxis 21, 320-324 (1983)

36. S. Yamamoto, B. Chang, Y. Kawano, R. Ozaki, Y. Murakami, Mechanism of nodularization of graphite on cast irons treated with magnesium. Met. Sci. 12, 239-246 (1978)

37. J. Zhou, W. Schmitz, S. Engler, Untersuchung der Gefügebildung von Gusseisen mit Kugelgraphit bei langsamer Erstarrung. Gießereiforschung 39(2), 55-70 (1987)

38. M. Gagné, D. Argo, Heavy section ductile iron castings part II: formation of chunk graphite, in Proceedings of the International Conference on Advanced Casting Technology, Kalamazoo, Michigan, USA, 12-14 November 1986, pp. 245-256

39. B. Tonn, J. Lacaze, S. Duwe, Degenerated graphite growth in ductile iron. Mater. Sci. Forum 925, 62-69 (2018)

40. S. Mendez, D. Lopez, I. Asenjo, P. Larranaga, J. Lacaze, Improved analytical method for chemical analysis of cast irons-application to castings with chunky graphite. ISIJ Int. 51(2), 242-249 (2011)

41. S. Hasse, Guß- und Gefügefehler, Erkennung, Deutung und Vermeidung von Guß- und Gefügefehlern bei der Erzeugung von gegossenen Komponenten, 2nd edn. (Fachverlag Schiele \& Schön GmbH, Berlin, 2003)

42. J. Zhou, W. Schmitz, S. Engler, Zum Stand der Kenntnisse über die Gefügebildung von Gußeisen mit Kugelgraphit bei langsamer Erstarrung. Gießereiforschung 39(2), 49-54 (1987)

43. D.M. Stefanescu, Solidification and modeling of cast iron-a short history of the defining moments. Mater. Sci. Eng. A 413-414, 322-333 (2005)

44. T. Thielemann, Zur Wirkung von Spurenelementen im Gusseisen mit Kugelgraphit. Gießereitechnik 16, 16-24 (1970)

45. H.W. Hoover Jr., A literature survey on degenerated graphite in heavy section ductile iron. AFS Trans. 94, 86-102 (1986)

46. J. Sertucha, R. Suárez, I. Asenjo, P. Larranaga, J. Lacaze, I. Ferrer, S. Armendariz, Thermal analysis of the formation of chunky graphite during solidification of heavy-section spheroidal graphite iron parts. ISIJ Int. 49(2), 220-228 (2009)

47. M. Gagné, D. Argo, Heavy section ductile iron castings part I: structure and properties, in Proceedings of the International Conference on Advanced Casting Technology, Kalamazoo, Michigan, USA, 12-14 November 1986, pp. 231-244

48. The Sorelmetal Book of Ductile Iron (Rio Tinto Iron \& Titanium Inc., Montreal, 2004) 
49. B. Bauer, I.M. Pokopec, M. Petric, P. Mrvar, Effect of $\mathrm{Si}$ and $\mathrm{Ni}$ addition on graphite morphology in heavy-section spheroidal graphite iron parts. Mater. Sci. Forum 925, 70-77 (2018)

50. EN 1563, Founding-Spheroidal Graphite Cast Irons (2011)

51. R. González-Martinez, U. de la Torre, J. Lacaze, J. Sertucha, Effects of high silicon contents on graphite morphology and room temperature mechanical properties of as-cast ferritic ductile cast irons. Part I-microstructure. Mater. Sci. Eng. A 712, 794-802 (2018)

52. R. González-Martinez, U. de la Torre, A. Ebel, J. Lacaze, J. Sertucha, Effects of high silicon contents on graphite morphology and room temperature mechanical properties of as-cast ferritic ductile cast irons. Part II-mechanical properties. Mater. Sci. Eng. A 712, 803-811 (2018)

53. H. Löblich, Werkstoff- und fertigungstechnische Grundlagen der Herstellung und Anwendung von hoch siliziumhaltigen Gusseisen mit Kugelgraphit, Final report AiF-Vorhaben $41 \mathrm{EN}$ (Institut für Gießereitechnik, Düsseldorf, 2012)

54. W. Stets, H. Löblich, G. Gassner, P. Schumacher, Solution strengthened ferritic ductile cast iron, properties, production and application. Int. J. Met. Cast. 8(2), 35-40 (2014)

55. L.E. Björkegren, K. Hamberg, Silicon alloyed ductile iron with excellent ductility and machinability, in Proceedings of Keith Millis Symposium on Ductile Cast Iron, Hilton Head (2003)

56. S. Hasse, Die Wirkung von Spurenelementen in Gusseisen mit Kugelgraphit. Gießerei-Praxis 15(16), 271-278 (1995)

57. L. Dekker, B. Tonn, Keimbildende Wirkung von Antimon in dickwandigem GJS zur Vermeidung von Chunky-Graphit. Giesserei-Rundschau 57, 218-221 (2010)

58. X.G. Diao, Z.L. Ning, F.Y. Cao, S.Z. Ren, J.F. Sun, Effects of antimony addition and section size on formation of chunky graphite in ductile iron. Mater. Sci. Technol. 27(4), 834-838 (2011)

59. L. Magnusson Åberg, C. Hartung, J. Lacaze, Trace elements and the control limits in ductile iron, in Proceedings of the 10th International Symposium Science and Processing of Cast Irons SPCI10, Mar del Plata, Argentina, 10-13th Nov 2014. http://rinfi. fi.mdp.edu.ar/xmlui/handle/123456789/28, Accessed 24 July 2019

60. C.V. White, R.A. Flinn, P.K. Trojan, AFS Trans. 91, 549 (1983)

61. T. Skaland, Nucleation mechanisms in ductile iron, in Proceedings of the AFS Cast Iron Inoculation Conference, 29-30 Sept 2005, Schaumburg, Illinois

62. L. Magnusson Åberg, Graphite morphology in heavy section ductile iron. Trans. Indian Inst. Met. 68(6), 1007-1011 (2015)

63. P. Larranaga, I. Asenjo, J. Sertucha, R. Suarez, I. Ferrer, J. Lacaze, Effect of antimony and cerium on the formation of chunky graphite during solidification of heavy-section castings of near-eutectic spheroidal graphite irons. Metall. Mater. Trans. A 40A, 654-661 (2009)

64. I. Karsay, R.D. Schelleng, Nickel alloyed austenitic ductile iron graphite structures. Trans. Am. Foundrym. Soc. 69, 725-730 (1961)

65. I. Asenjo, P. Larranaga, J. Sertucha, R. Suárez, J.-M. Gómez, I. Ferrer, J. Lacaze, Effect of mould inoculation on formation of chunky graphite in heavy section spheroidal graphite cast iron parts. Int. J. Cast Met. Res. 20(6), 319-324 (2007)

66. Z. Ignaszak, Nodular graphite degeneration in the post-inoculated ductile iron. Int. J. Cast Met. Res. 16(1-3), 93-97 (2003)

67. A. Javaid, C.R. Loper, Production of heavy-section ductile cast iron. AFS Trans. 103, 135-150 (1995)

68. I. Riposan, M. Chisamera, V. Uta, S. Stan, The importance of rare earth contribution from nodulizing alloys and their subsequent effect on the inoculation of ductile iron. Int. J. Met. Cast. 8(2), 65-78 (2014)

69. M.M. Celis, B. Domengès, E. Hug, J. Lacaze, Analysis of nuclei in a heavy-section nodular iron casting. Mater. Sci. Forum 925, 173-180 (2018)

70. P. Ferro, A. Fabrizi, R. Cervo, C. Carollo, Effect of inoculant containing rare earth metals and bismuth on microstructure and mechanical properties of heavy-section near-eutectic ductile iron castings. J. Mater. Process. Technol. 213, 1601-1608 (2013)

71. E.N. Pan, C.Y. Chen, Effects of $\mathrm{Bi}$ and $\mathrm{Sb}$ on graphite structure of heavy-section ductile cast iron. AFS Trans. 104, 845-858 (1996)

72. J. Riposan, M. Chisamera, S. Stan, Performance of heavy ductile iron castings for windmills. China Foundry 7(2), 163-170 (2010)

73. W. Baer, Bruchmechanische Bewertung ferritischer Gusseisenwerkstoffe sowie artgleicher

Schweißverbindungen bei statischer Beanspruchung, Dr.-Ing. Dissertation (TU Bergakademie Freiberg, Germany, 1996)

74. Metallography and Fractography Data Base of BAM Division 5.1, Materialography, Fractography and Ageing of Engineered Materials (Federal Institute for Materials Research and Testing (BAM), Berlin, Germany, 2019)

75. ISO 1083, Spheroidal Graphite Cast Irons-Classification (2018)

76. ISO 945-1, Microstructure of Cast Irons-Part 1: Graphite Classification by Visual Analysis (2017)

77. ISO 945-4, Microstructure of Cast Irons-Part 4: Test Method for Evaluating Nodularity in Spheroidal Graphite Cast Irons (2019)

78. ASTM A247, Standard Test Method for Evaluating the Microstructure of Graphite in Iron Castings (ASTM International, West Conshohocken, 2010)

79. ASTM E2567, Standard Test Method for Determining Nodularity and Nodule Count in Ductile Iron Using Image Analysis (ASTM International, West Conshohocken, 2013) 
80. JIS G 5504, Heavy-Walled Ferritic Spheroidal Graphite Iron Castings for Low Temperature Service (2005)

81. P. Strizik, F. Jeglitsch, Contribution to the mechanism of formation of chunky graphite. AFS Int. Cast Met. J. 1(3), 23-30 (1976)

82. H. Nakayama, B.-R. Zhao, N. Furusato, S. Yamada, T. Nishi, H. Ohta, Effect of amount of chunky graphite on mechanical properties of spheroidal graphite cast iron. Mater. Trans. 59(3), 412-419 (2018)

83. B. Dhindaw, J.D. Verhoeven, Nodular graphite formation in vacuum melted high purity $\mathrm{Fe}-\mathrm{C}-\mathrm{Si}$ alloys. Metall. Trans. A 11A, 1049-1057 (1980)

84. F. Iacoviello, V. di Cocco, Influence of the graphite elements morphology on the fatigue crack propagation mechanisms in a ferritic ductile cast iron. Eng. Fract. Mech. 167, 248-258 (2016)

85. ISO 16112, Compacted (Vermicular) Graphite Cast Irons-Classification (2017)

86. M. Lampic, M. Walz, Gusseisen mit Vermiculargrafit, Teil 1: Definition, Geschichte, Herstellung, GJV als ,grüner“Werkstoff. Giesserei 101(01), 214-227 (2014)

87. M. Lampic, M. Walz, Gusseisen mit Vermiculargrafit, Teil 2: Gefüge. Giesserei 101(02), 86-95 (2014)

88. A. Velichko, C. Holzapfel, F. Mücklich, 3D characterization of graphite morphologies in cast iron. Adv. Eng. Mater. 9(1-2), 39-45 (2007)

89. A. Rack, H. Riesemeier, S. Zabler, T. Weitkamp, B.R. Müller, G. Weidemann, P. Modregger, J. Banhart, L. Helfen, A.N. Danilewsky, H.G. Gräber, R. Heldele, B. Mayzel, J. Goebbels, T. Baumbach, The high-resolution synchrotron-based imaging stations at the BAMline (BESSY) and TopoTomo (ANKA), in Proceedings of SPIE, vol. 7078 (2008), pp. 70780X-1-70780X-9

90. K. Breitkreutz, H. Frenz, P.D. Portella, Zur quantitativen Bestimmung des Chunky-Graphits in Gußeisen. Prakt. Metallogr. 28, 532-541 (1991)

91. H. Frenz, Eigenschaften von ferritischem und ferritisch-perlitischem Gußeisen mit Kugelgraphit unter besonderer Beachtung des Bruchverhaltens, Dr.-Ing. Dissertation, TU Berlin (1991)

92. P. Ferro, P. Lazzarin, F. Berto, Fatigue properties of ductile cast iron containing chunky graphite. Mater. Sci. Eng. A 554, 122-128 (2012)

93. E. Foglio, D. Lusardi, A. Pola, La Vecchia, M. Gelfi, Fatigue design of heavy section ductile irons: Influence of chunky graphite. Mater. Des. 111, 353-361 (2016)

94. E. Zschech, M. Löffler, P. Krüger, J. Gluch, K. Kutukova, I. Zglobicka, J. Silomon, R. Rosenkranz, Y. Standke, E. Topal, Laboratory computed X-ray tomography - a nondestructive technique for 3D microstructure analysis of materials. Pract. Metallogr. 55(8), 539-555 (2018)

95. K. Bugelnig, P. Barriobero-Vila, G. Requena, Synchrotron computer tomography as a characterization method for engineering materials. Pract. Metallogr. 55(8), 556-568 (2018)

96. M.D. Uchic, Serial sectioning methods for generating 3D characterization data of grain- and precipitatescale microstructures, in Computational Methods for Microstructure-Property Relationships, ed. by S. Ghosh, D. Dimiduk (Springer, Berlin, 2011), pp. 31-52

97. F. Mücklich, M. Engstler, D. Britz, J. Gola, Serial sectioning techniques - a versatile method for threedimensional microstructural imaging. Pract. Metallogr. 55(8), 569-578 (2018)

98. A. Velichko, K. Schladitz, C. Holzapfel, F. Mücklich, 3D-Charakterisierung der Graphitmorphologie mit Hilfe der FIB-Nanotomographie. Prakt. Met. Sonderband 38, 169-176 (2006)

99. K.E. Wieser, B. Droste, R. Helms, J. Ziebs, J. Hemptenmacher, Gußeisen mit Kugelgraphit als Werkstoff für Transport- und Lagerbehälter bestrahlter Brennelemente. Amts- und Mitteilungsblatt der Bundesanstalt für Materialprüfung (BAM) 15(1), 4-18 (1985)

100. D. Aurich, R. Helms, K. Wieser, Das sicherheitstechnische Konzept der BAM für Sphärogussbehälter. Amts- und Mitteilungsblatt der Bundesanstalt für Materialforschung und -prüfung (BAM) 17(4), 657-663 (1987)

101. H. Kaufmann, Zur schwingfesten Bemessung dickwandiger Bauteile aus GGG-40 unter Berücksichtigung gießtechnisch bedingter Gefügeungänzen English title: The dimensioning of cyclically-loaded thick-walled components of cast ductile iron GGG40 considering microstructural degenerations from casting, LBF report FB-214. Fraunhofer Institute LBF, Darmstadt (1998)

102. A. Mourujärvi, K. Widell, T. Saukkonen, H. Hänninen, Influence of chunky graphite on mechanical and fatigue properties of heavy-section cast iron. Fatigue Fract. Eng. Mater. Struct. 32, 379-390 (2009)

103. E. Guo, L. Song, L.-P. Wang, D.-R. Liu, Effects of forced cooling on mechanical properties and fracture behavior of heavy section ductile iron. China Foundry 12(6), 398-405 (2016)

104. H. Nisitani, Y. Murakami, Role of nodules on bending and torsional fatigue of nodular cast iron. J. Sci. Mach. 25(4), 543-546 (1973)

105. B. Komber, Bruchmechanische Bewertung des Rissausbreitungsverhaltens ferritischer Gusseisenwerkstoffe bei zyklischer Beanspruchung, Dr.-Ing. Dissertation, TU Bergakademie Freiberg, Germany (1995)

106. P. Hübner, H. Schlosser, G. Pusch, H. Biermann, Load history effects in ductile cast iron for wind turbine components. Int. J. Fatigue 29, 1788-1796 (2007)

107. L. Zybell, H. Chaves, M. Kuna, T. Mottitschka, G. Pusch, H. Biermann, Optical in situ investigations of 
overload effects during fatigue crack growth in nodualr cast iron. Eng. Fract. Mech. 95, 45-56 (2012)

108. G. Hütter, L. Zybell, M. Kuna, Micromechanisms of fracture in nodular cast iron: from experimental findings towards modeling strategies-a review. Eng. Fract. Mech. 144, 118-141 (2015)

109. M. Cavallini, O. Di Bartolomeo, F. Iacoviello, Fatigue crack propagation damaging micromechanisms in ductile cast irons. Eng. Fract. Mech. 75, 694-704 (2008)

110. M. Shirani, G. Härkegard, Casting defects and fatigue behavior of ductile cast iron for wind turbine components: a comprehensive study. Materialwissenschaft \& Werkstofftechnik 42(12), 1059-1074 (2011)

111. P. Kainzinger, C. Guster, M. Severing, A. Wolf, Influence of micro-shrinkage on the fatigue behavior of ductile iron, in 13th ICF International Conference on Fracture, Proceedings on USB Drive, June 16-21, 2013, Beijing, China, 9 pages

112. J. Bergström, C. Burman, J. Svensson, A. Jansson, Very high cycle fatigue of two ductile iron grades. Steel Res. Int. 87(5), 614-622 (2016)

113. B. Pyttel, I. Brunner, D. Schwerdt, C. Berger, Influence of defects on fatigue strength and failure mechanisms in the VHCF-region for quenched and tempered steel and nodular cast iron. Int. J. Fatigue 41, 107-118 (2012)

114. N. Costa, N. Machado, F.S. Silva, A new method for prediction of nodular cast iron fatigue limit. Int. J. Fatigue 32(7), 988-995 (2010)

115. L. Collini, A. Pirondi, R. Bianchi, M. Cova, P.P. Milella, Influence of casting defects on fatigue crack initiation and fatigue limit of ductile cast iron. Procedia Eng. 10, 2898-2903 (2011)

116. C. Bleicher, R. Wagener, H. Kaufmann, T. Melz, Fatigue strength of nodular cast iron with regard to heavy-wall applications. MP Mater. Test. 57(9), 723-732 (2015)

117. J. Luo, R.A. Harding, P. Bowen, Evaluation of the fatigue behaviour of ductile irons with various matrix microstructures. Metall. Mater. Trans. A 33A, 3719-3730 (2002)

118. W. Bauer, Bending Fatigue Behaviour of Ductile Iron with As-Cast Surfaces, Keith Millis Symposium (2003), pp. 143-150

119. A. Henrietz, J. Eufinger, D. Jung, J. Linn, A. EgnerWalter, Hepp, E., Sobota, A., Löblich, H., Stets, W., Richter, J., Leo, G.-S., Fritsche, E., Zenker, N., Pollicino, F., Dobi, D., Stankovic, L. and M. Ali: Maßgeschneiderte Bauteileigenschaften durch Integration von Fertigungs- und Funktionssimulation, Final report of Bundesministerium für Bildung und Forschung (BMBF) project MABIFF, contract no. 01RI0713, Fraunhofer Institut LBF, Darmstadt, Germany, 2011
120. Y. Tanaka, Z. Yang, K. Miyamoto, Evaluation of fatigue limit of spheroidal graphite cast iron. Mater. Trans. JIM 36(6), 749-756 (1995)

121. ASTM E 802, Standard Reference Radiographs for Gray Iron Castings Upto 41/2 in. Thickness (ASTM International, Philadelphia, 1982)

122. ASTM E 186, Standard Reference Radiographs for Heavy-Walled (2 to 41/2 in.) Steel Castings (ASTM International, Philadelphia, 1993)

123. F. Müller, Bewertung des Einflusses von Fehlern auf die Schwingfestigkeit von gegossenen und geschweißten Eisenwerkstoffen, LBF report FB-205 (Fraunhofer Institute LBF, Darmstadt, 1994)

124. M. Sofue, Influence of graphite shape on fatigue strength of spheroidal graphite cast iron. IMONO J. Cast. Inst. Jpn. 51(5), 281-286 (1979)

125. M. Sofue, Evaluation of the role of graphite nodules in fatigue strength of spheroidal graphite cast iron. IMONO J. Cast. Inst. Jpn. 51(3), 159-163 (1979)

126. I. Niimi, M. Ohashi, Y. Komatsu, Y. Hibino, Influence of graphite nodules on the fatigue strength of spheroidal graphite cast iron. IMONO J. Cast. Inst. Jpn. 43(2), 101-107 (1971)

127. Y. Murakami, Metal Fatigue: Effects of Small Defects and Nonmetallic Inclusions (Elsevier, Amsterdam, 2002)

128. N. Costa, N. Machado, F.S. Silva, Influence of graphite nodules geometrical features on fatigue life of high-strength nodular cast iron. JMEPEG 17, 352-362 (2008)

129. M. Endo, K. Yanase, Effects of small defects, matrix structures and loading conditions on the fatigue strength of ductile cast irons. Theoret. Appl. Fract. Mech. 69, 34-43 (2014)

130. ASTM E 647, Standard Test Method for Measurement of Fatigue Crack Growth Rates (ASTM International, West Conshohocken, 2015)

131. W. Baer, G. Pusch, T. Brecht, Einfluss der ChunkyGraphitentartung auf das Risswiderstandsverhalten von ferritischem GGG-40 bei statischer und zyklischer Beanspruchung. Gießerei 83(22), 19-22 (1996)

132. W. Baer, Advanced fracture mechanics testing of DCI - a key to valuable toughness data. Int. J. Metalcasting IJMC 8(2), 25-34 (2014)

133. R.O. Ritchie, W.L. Server, R.A. Wullaert, Critical fracture stress and fracture strain models for the prediction of lower and upper shelf toughness in nuclear pressure vessel steels. Metall. Trans. 10, 1557-1570 (1979)

134. H. Stroppe, G. Pusch, A. Ludwig, Bestimmung der Bruchzähigkeit von ferritischem Gusseisen mit Kugelgraphit aus Kennwerten des Zugversuchs und der Gefügeausbildung. Gießereiforschung 54(4), 115-120 (2002)

135. R.K. Nanstad, F.J. Worzala, C.R. Looper, Static and dynamic toughness of ductile cast iron. Trans. Am. Foundrymen's Soc. 83, 245-256 (1975) 
136. S. Wolfensberger, P. Uggowitzer, M.O. Speidel, Die Bruchzähigkeit von Gusseisen, Teil 2: Gusseisen mit Kugelgraphit. Gießereiforschung 39(2), 71-80 (1987)
Publisher's Note Springer Nature remains neutral with regard to jurisdictional claims in published maps and institutional affiliations. 